Ronaldo Mitsuo Sato

\title{
O meandramento ciclônico da Corrente do Brasil ao largo do Cabo de Santa Marta $\left(\sim 28,5^{\circ} \mathrm{S}\right)$
}

\begin{abstract}
Dissertação apresentada ao Instituto Oceanográfico da Universidade de São Paulo, como parte dos requisitos para obtenção do título de Mestre em Ciências, Programa de Oceanografia, área de Oceanografia Física.
\end{abstract}

Orientador:

Prof. Dr. Ilson Carlos Almeida da Silveira 


\title{
UNIVERSIDADE DE SÃO PAULO INSTITUTO OCEANOGRÁFICO
}

\section{O meandramento ciclônico da Corrente do Brasil ao largo do Cabo de Santa Marta $\left(\sim 28,5^{\circ} \mathrm{S}\right)$}

\author{
Ronaldo Mitsuo Sato
}

Dissertação apresentada ao Instituto Oceanográfico da Universidade de São Paulo, como parte dos requisitos para obtenção do título de Mestre em Ciências, Programa de Oceanografia, área de Oceanografia Física.

Julgada em por

$\operatorname{Prof}(\mathrm{a}) . \operatorname{Dr}(\mathrm{a})$

Conceito

$\operatorname{Prof}(a) \cdot \operatorname{Dr}(a)$

Conceito

$\operatorname{Prof}(a) \cdot \operatorname{Dr}(a)$

Conceito 
“'Faça o que tem que fazer e deixe os outros discutirem se é certo ou não."'

Calvin

“ 'Nunca diga qualquer coisa a não ser que tenha certeza que todo mundo pensa o mesmo.', 


\section{Sumário}

Página

Lista de Figuras iii

Lista de Tabelas viii

Agradecimentos ................................ xii

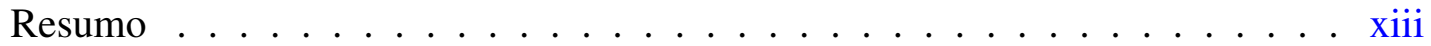

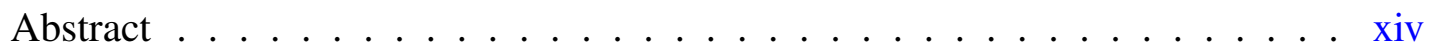

1 Introdução 1

1.1 Padrão de Circulação do Atlântico Sul . . . . . . . . . . . . . . . . . . . 1

1.2 Meandramento na Margem Leste . . . . . . . . . . . . . . . . . 5

1.3 Meandramento na Margem Sudeste . . . . . . . . . . . . . . 7

1.4 Meandramento na Confluência Brasil-Malvinas . . . . . . . . . . . . . . 11

1.5 Meandramento na Margem Sul: Lacunas de Conhecimento . . . . . . . . 13

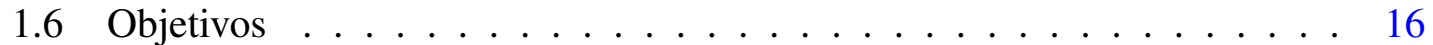

2 Análise de Imagens Satelitárias 17

2.1 Conjunto de dados MUR SST . . . . . . . . . . . . . . . 17

2.2 Aspectos Metodológicos e Resultados . . . . . . . . . . . . . . . . . . . 19

2.3 Resultados e Discussão . . . . . . . . . . . . . . . . . . . . . 25

3 Análise de Observações Quase-Sinóticas 27

3.1 Conjunto de Dados . . . . . . . . . . . . . . . . . . 27

3.1 .1 Conjunto MIRAI . . . . . . . . . . . . . . . . . . 27

3.1 .2 Conjunto CARBOM . . . . . . . . . . . . . . . . 29

3.1 .3 Conjunto EAOS . . . . . . . . . . . . . 30 
3.2 Aspectos Metodológicos . . . . . . . . . . . . . . 30

3.2.1 Processamento de Dados de CTD . . . . . . . . . . . 30

3.2.2 Processamento de Dados de ADCP . . . . . . . . . . . . . 32

3.2.3 Processamento de Dados de L-ADCP . . . . . . . . . . . . . 32

3.2.4 Método Dinâmico: Cálculo da Velocidade Geostrófica . . . . . . 33

3.3 Resultados e Discussão . . . . . . . . . . . . . . . . . . . 36

3.3.1 Resultados do Conjunto MIRAI . . . . . . . . . . . . . . 36

3.3.2 Resultados do Conjunto CARBOM . . . . . . . . . . . 38

3.3.3 Resultados do Conjunto EAOS . . . . . . . . . . . . . . . . 42

4 Análise de Séries Temporais Correntográficas 49

4.1 Conjunto de dados WOCE . . . . . . . . . . . . . . . . . . . 49

4.2 Aspectos Metodológicos . . . . . . . . . . . . . 51

4.3 Resultados e Discussão . . . . . . . . . . . . . . . . . . . . 55

5 Modelo Dinâmico $\quad 64$

5.1 Formulação do Modelo Quase-Geostrófico de 2-camadas . . . . . . . . . 64

5.1.1 Modelo Linear . . . . . . . . . . . . . . . . . . 70

5.1 .2 Modelo Não-linear . . . . . . . . . . . . . . . . . 72

5.2 Resultados e Discussão . . . . . . . . . . . . . . . . . . . . . . 73

5.2.1 Modelo Linear - Propriedades de Estabilidade . . . . . . . . . . 73

5.2.2 Modelo Não-linear . . . . . . . . . . . . . . . . . 75

6 Considerações Finais $\quad 78$

6.1 Síntese da Análise de Imagens Satelitárias . . . . . . . . . . . . . . . . 79

6.2 Síntese da Análise de Observações Quase-sinóticas . . . . . . . . . . . . 80

6.3 Síntese da Análise EOF da Radial do Fundeios WOCE . . . . . . . . . . 81

6.4 Síntese da Simulação com o Modelo Dinâmico . . . . . . . . . . . . . . 81

6.5 Sugestões para Trabalhos Futuros . . . . . . . . . . . . . . 82

Referências Bibliográficas $\quad 84$ 


\section{Lista de Figuras}

1.1 Representação esquemática do padrão de circulação de larga escala em superfície do Oceano Atlântico Sudoeste, segundo os padrões de Stramma \& England (1999). Painel superior esquerdo: circulação no nível de $100 \mathrm{~m}$ de profundidade. Painel superior direito: circulação entre 100 e $500 \mathrm{~m}$ de profundidade. Painel inferior esquerdo: circulação entre 500 e 1200 m. Painel inferior direito: circulação no nível de 2000 m. Adaptado de Silveira et al. (2000a). . . . . . . . . . . . . . . . . . . . . . . 2

1.2 Meandros ciclônicos recorrentes da Corrente do Brasil ao largo do Cabo de São Tomé (CST), de Cabo Frio (CF) e do Cabo de Santa Marta (CSM). A área demarcada corresponde ao local de origem e desenvolvimento do meandro do CSM. . . . . . . . . . .

1.3 Exemplo do meandramento da Corrente do Brasil na Margem Leste. Nesta imagem estão representados o Vórtice de Ilhéus (centrado $\sim 15^{\circ} \mathrm{S}$ ), o Vórtice de Royal-Charlotte $\left(\sim 17^{\circ} \mathrm{S}\right)$ e o Vórtice de Abrolhos $\left(\sim 19^{\circ} \mathrm{S}\right)$. Retirado de Soutelino et al. (2011). . . . . .

1.4 Evidência do meandro ciclônico da Corrente do Brasil ao largo do Cabo de Santa Marta (CSM). Trata-se de uma feição recorrente ao largo do CSM, a qual cresce em amplitude podendo se fechar em vórtice (Vórtice de Santa Marta). Imagem de Temperatura da Superfície do Mar correspondente ao dia 06 de junho de 2007 . . . . . . . . . . . . 15

2.1 Mapa horizontal de Temperatura da Superfície do Mar com a presença do Vórtice de Santa Marta (VSM). O VSM se origina a partir do crescimento em amplitude do meandro ciclônico ao largo do Cabo de Santa Marta (CSM). Imagem referente ao dia 26 de

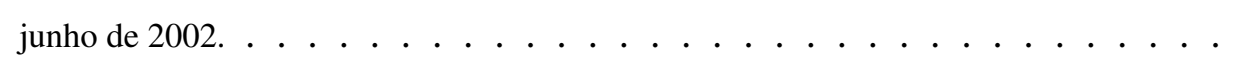


2.2 Mapa horizontal da magnitude do gradiente de Temperatura da Superfície do Mar. A frente térmica da Corrente do Brasil é demarcada pela contabilização dessa grandeza e está associada a borda interna da corrente. Nota-se o meandramento da corrente ao largo do Cabo de Santa Marta (CSM). Imagem referente ao dia 26 de junho de 2002 (correspondente à Figura 2.1) . . . . . . . . . . . . . . . . . . . . . 21

2.3 Paineis superiores: Mapas horizontais de Temperatura da Superfície do Mar (TSM) dos dias 04, 07 e 10 de setembro de 2009. Paineis inferiores: Respectivos mapas da magnitude do gradiente de TSM. . . . . . . . . . . . . . . . . . . . .

2.4 Painel superior: Resultados da digitalização da Frente Térmica associada ao meandro do Cabo de Santa Marta (CSM), referente ao evento ocorrido entre 04 e 10 de setembro de 2010. Nota-se nessas imagens, a propagação do meandro para sul/sudoeste. Painel inferior: Taxa de crescimento $\sigma$ estimada através de ajuste exponencial recursivo a partir da digitalização das frentes (amplitude do meandro). . . . . . . . . . . . .

3.1 Localização das 12 estações hidrográficas coletadas pelo R/V MIRAI (JAMSTEC) no âmbito do Projeto WOCE durante travessia do Oceano Atlântico Sul. Neste trabalho utilizamos os dados de CTD e L-ADCP desse conjunto de dados, que foram coletados na campanha MR03-K04 entre 06 de novembro de 2003 e 05 de dezembro de 2003 . . 28

3.2 Localização das estações hidrográficas coletadas pelo N/Oc. Alpha Crucis (IOUSP) no âmbito do Projeto CARBOM. Neste trabalho utilizamos dados de CTD, L-ADCP e ADCP de casco das três radiais mais ao sul (na direção Sul-Norte, designadas como Radial 7, 6 e 5). Esse conjunto de dados foi coletado entre outubro de 2013 e novembro de 2013. . . . . . . . . . . . . . . . . . . . . . . .

3.3 Localização das estações hidrográficas das campanhas HBS1 coletada em novembro de 1995 no âmbito do Projeto EAOS. Neste trabalho, utilizamos somente os dados de CTD.

3.4 Seção de velocidade observada por L-ADCP do conjunto de dados MIRAI. Escala de cores e contornos com traço mais fino denotando velocidades e contornos com traço mais grosso denotando as interfaces de Massas de Água estimadas por Mémery et al. (2000). . . . . . . . . . . . . . . . . . . . .

3.5 Esquema proposto para interpretação das seções de velocidades observadas do conjunto CARBOM. Presença de meandro ciclônico ao largo do Cabo de Santa Marta. As Radiais 5 e 6 capturam as partes traseira e frontal do cavado da onda. A Radial 7 captura região sem meandramento observável. . . . . . . . . . . . . . . . . . . . 
3.6 Imagem de Temperatura da Superfície do Mar (TSM) do dia 18 de novembro de 2013 com as estações hidrográficas (círculos em cinza) das Radias 5, 6 e 7 do conjunto CARBOM sobrepostas. A Radial 5 foi realizada nos dias 18 e 19 de novembro de 2013, a Radial 6, nos dias 20 e 21, e a Radial 7, nos dias 22 e 23. Nesse intervalo a imagem do dia 18 é a que não apresenta cobertura por nuvens. . . . . . . . . . . . . . 39

3.7 Seção de velocidade observada por L-ADCP da Radial 5 do conjunto CARBOM. Notase que a CB apresenta uma estrutura mais barotrópica. . . . . . . . . . . . . . 40

3.8 Seção de velocidade observada por L-ADCP da Radial 6 do conjunto CARBOM. Evidência de meandro ciclônico frontal. . . . . . . . . . . . . . . . . 41

3.9 Seção de velocidade observada por L-ADCP da Radial 7 do conjunto CARBOM. Confinamento da $\mathrm{CB}$ associado à presença do Cone do Rio Grande. . . . . . . . . . . .

3.10 Mapa horizontal da função de corrente geostrófica $(\psi)$ em 150 m de profundidade da campanha HBS1 do conjunto de dados EAOS. Valores negativos representam circulação ciclônica e positivos, anticiclônica. Isóbata de 150 m utilizada como condição de contorno de Dirichlet. Círculos na cor cinza representam a posição das estações hidrográficas, distribuídas em 5 radiais numeradas em sequência crescente na direção Sul-Norte. 44

3.11 Seção vertical de densidade in-situ $\left[\mathrm{kg} \mathrm{m}^{-3}\right]$ da Radial 4, em escala de cores. Contornos de densidade potencial $\left(\sigma_{0}\left[\mathrm{~kg} \mathrm{~m}^{-3}\right]\right)$ sobrepostos à densidade in-situ. Triângulos invertidos na superfície indicam a posição das estações hidrográficas. . . . . . . . . . 44

3.12 Mapa horizontal de temperatura conservativa em $150 \mathrm{~m}$ de profundidade da campanha HBS1 do conjunto de dados EAOS. Núcleo frio centrado em torno de $26,5^{\circ} \mathrm{S}$ devido à presença de vórtice ciclônico associado ao meandramento da CB. . . . . . . . . . 46

3.13 Mapa horizontal de salinidade absoluta em $150 \mathrm{~m}$ de profundidade da campanha HBS1 do conjunto de dados EAOS. Núcleo de baixa salinidade centrado em torno de $26,7^{\circ} \mathrm{S}$ devido à presença de vórtice ciclônico associado ao meandramento da CB. . . . . . . . 46

3.14 Perfil vertical médio da frequência de Brunt-Väisälä ao quadrado (frequência de estratificação ao quadrado) utilizando as estações hidrográficas da radial 4 compreendidas pelo ciclone. Área hachurada delimita a camada compreendida pela estrutura ciclônica, na qual foi calculado o valor característico dessa frequência. . . . . . . . . . . . . 48 
4.1 Localização da Radial de fundeios do Projeto WOCE. Esse conjunto de dados é composto pelos conjuntos ACM12 (círculos verdes) e ACM3 (círculos amarelos) coletados, respectivamentem pelo WHOI e pelo IFM-Kiel entre janeiro de 1991 e dezembro de 1992. Neste trabalho foram utilizados os 4 fundeios mais próximos à costa.Na direção da região mais rasa para o interior da bacia oceânica, esses fundeios são denominados, respectivamente: ACM12/333, ACM12/334, ACM12/335 e ACM3/906. . . . . . . . 50

4.2 Série original (linha cinza) e filtrada (linha preta) do instrumento em $230 \mathrm{~m}$ do fundeio ACM12/333. Filtragem utilizando-se filtro do tipo Lanczos de 40 h. . . . . . . . . . 53

4.3 Séries temporais "originais" (retirada de dados espúrios) de velocidades observadas dos respectivos correntômetros do fundeio $\mathrm{ACM} 12 / 333$ (instrumento mais próximo à costa entre os utilizados) do Projeto WOCE. . . . . . . . . . . . . . . . 56

4.4 Séries temporais filtradas (filtro tipo Lanczos de $40 \mathrm{~h}$ ) de velocidades observadas dos respectivos correntômetros do fundeio $\mathrm{ACM} 12 / 333$ (instrumento mais próximo à costa entre os utilizados) do Projeto WOCE. . . . . . . . . . . . . . . . . . . . 57

4.5 Seção vertical de velocidade média normal à Radial de fundeios, utilizando as séries temporais de aproximadamente 18 meses dos 4 primeiros fundeios do Projeto WOCE, obtida após a filtragem dos dados com filtro tipo Lanczos de 40 h. . . . . . . . . . 58

4.6 Resultado da análise de EOFs bidimensionais dos fundeios do Projeto WOCE e determinação dos modos estatisticamente significativos através das simulações de Monte Carlo. Nota-se que o primeiro e segundo modos explicam respectivamente $\sim 54,3 \%$ e $\sim 29,8 \%$ da variabilidade, e conjuntamente explicam $\sim 84 \% \ldots \ldots \ldots$

4.7 Estrutura vertical do primeiro modo. Nota-se um padrão espacial confinado na porção mais próxima à quebra da plataforma continental e com cisalhamento vertical até $\sim 1500 \mathrm{~m}$ de profundidade. . . . . . . . . . . . . .

4.8 Espectro de potência que conserva a variância para a primeira EOF. Através da análise espectral da série de amplitude correspondente ao primeiro modo, foi obtido um comprimento de onda com período característico de $\sim 25$ dias. . . . . . . . . . . . 61

4.9 Estrutura vertical do segundo modo. Nota-se um padrão espacial alongado e mais raso (cisalhamento vertical até $\sim 600 \mathrm{~m}$ ) que o primeiro modo. . . . . . . . . . . . 62

4.10 Espectro de potência que conserva a variância para a segunda EOF. Através da análise espectral da série de amplitude correspondente ao segundo modo, foi obtido um comprimento de onda com período característico de $\sim 102$ dias. . . . . . . . . . . . . 63 
5.1 Painel superior: Perfis de velocidades das camadas superior e inferior, delimitadas pela isopicnal de 26,9 $\mathrm{kg} \mathrm{m}^{-3}$ (interface ACAS-AIA) segundo Mémery et al. (2000), obtidos a partir da seção de velocidade de L-ADCP da Radial 7 do conjunto CARBOM. Painel inferior: Perfil de Vorticidade Potencial (VP) obtido respectivamente para a camada superior. . . . . . . . . . . . . . . . . . . 74

5.2 Propriedades de estabilidade linear obtidas a partir do modelo linear. As ondas mais instáveis possuem possuem taxa de crescimento $\sigma \approx 0,034 \mathrm{dia}^{-1}$, comprimento de onda $\lambda \approx 250 \mathrm{~km}$ e se propagam para sul/sudeste com velocidade de fase $c_{p} \approx 0,05 \mathrm{~m}$ $\mathrm{s}^{-1}$. Esses resultados são menores que os observados por meio das imagens satelitárias.

5.3 Resultados do modelo não-linear para os tempos $t=0,15$ e 30, o qual foi inicializado com uma perturbação de pequena amplitude à montante do domínio. Nota-se a formação e crescimento em amplitude do meandro ciclônico, assim como sua propagação à jusante da corrente básica. . . . . . . . . . . . . . . . . 76 


\section{Lista de Tabelas}

2.1 Resultados quantitativos das propriedades dinâmicas, acerca do meandramento da Corrente do Brasil ao largo do Cabo de Santa Marta, estimados a partir da análise de imagens satelitárias (MUR SST) . . . . . . . . . . . . 22

3.1 Valores isopicnais das interfaces (anomalia da densidade potencial, $\sigma_{0}$ ), entre Massas de Água no Oceano Atlântico Sudoeste, estimados por Mémery et al.

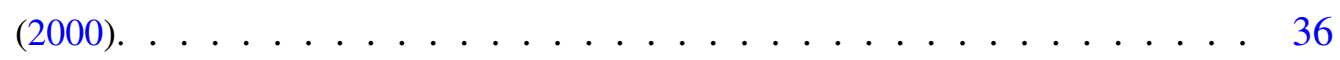

4.1 Descrição da Radial de fundeios do Projeto WOCE, composta pelo conjunto de dados ACM12 e ACM3, e seus respectivos instrumentos. . . . . . . . . . . . 52

5.1 Escalas de Não-dimensionalização. . . . . . . . . . . . . . . . . . . 66 


\section{Lista de Acrônimos}

ACAS Água Central do Atlântico Sul

ACM12 Atlantic Current Meter Array 12

ACM3 Atlantic Current Meter Array 3

ACS Água Circumpolar Superior

ADCP $\quad$ Acoustic Doppler Current Profiler

AIA Água Intermediária Antártica

APAN Água Profunda do Atlântico Norte

AT Água Tropical

AVHRR The Advanced Very High Resolution Radiometer

BiCSE Bifurcação da CSE

BiSan Bifurcação de Santos

CARBOM Caracterização Ambiental e Avaliação dos Recursos Biogênicos Oceânios e da Margem Continental Brasileira e Zona Oceânica Adjacente

CAS Corrente do Atlântico Sul

CB Corrente do Brasil

CBe Corrente de Benguela

CCl Corrente de Contorno Intermediária

cco Corrente de Contorno Oeste

CCP Corrente de Contorno Profunda

CF Cabo Frio

CSE Corrente Sul Equatorial 
CSM Cabo de Santa Marta

CST Cabo de São Tomé

CTD Condutivity-Temperatura-Depth Profiler

DBE Deep Basin Experiment

DC Dinâmica de Contornos

EAOS Estudos Ambientais em Áreas Oceânicas e Costeiras na Região Sul do País

EOF Empirical Orthogonal Function

FT Frente térmica

FURG Universidade Federal do Rio Grande

GHRST Group for High Resolution Sea Surface Temperature

GSAS Giro subtropical do Atlântico Sul

IFM-Kiel Institute for Marine Science

IOUSP Instituto Oceanográfico da Universidade de São Paulo

JAMSTEC Japan Agency for Marine-Earth Science and Technology

L-ADCP $\quad$ Lowered-Acoustic Doppler Current Profiler

MUR SST Multi-scale Ultra-high Resolution Sea Surface Temperature

NOAA National Oceanic and Atmospheric Administration

RCM Rotor-type Current Meters

TSM Temperatura da Superfície do Mar

VACM Vector Averaging Current Meter

VP Vorticidade Potencial

WCRP World Climate Research Programme

WHOI Woods Hole Oceanographic Institute 
WOCE World Ocean Circulation Experiment

XBT Expendable Bathythermograph 


\section{Agradecimentos}

Primeiramente, agradeço ao meu orientador, Prof. Dr. Ilson Carlos Almeida da Silveira, por todas as oportunidades e ensinamentos ao longo desses 5 anos que estive no LaDO. Obrigado por todo o apoio e ajuda!

Obrigado a todo o pessoal do laboratório por toda ajuda e convívio. Obrigado ao Márcio, Ana Paula, Biló, Mestre, Pinguim, Gil, Filipe(s), Ágata, Pedrox. Muito obrigado à Prof. Dra. Sueli Susana de Godoi pelas dicas e conversas.

Agradeço à minha família pelo suporte para todas as dificuldades enfrentadas até hoje. Um obrigado muito especial aos meus pais que sempre tentaram proporcionar o melhor para os filhos. Obrigado ao meu cunhado Vitor, por toda ajuda de computação para resolver alguns problemas de forma mais rápida!

Muito obrigado a minha namorada Bárbara e a Maria José por toda a ajuda e auxílio. Foi tanta ajuda que se eu tentar listar vou me esquecer. Obrigado pela abrigo, alimentação e tudo mais, principalmente depois que minha bolsa acabou! Tive um momento financeiro bem difícil e foi fundamental a ajuda de alguns. Agradeço de coração!

Agradeço a todos os amigos, os amigos de São José, de São Paulo, do futebol e do IO, pela parceria. Sei que no final deste trabalho me ausentei um pouco, mas espero que as coisas voltem ao normal. Obrigado ao pessoal do time de futebol de campo da Física que nestes últimos meses foram o príncipal convívio de amizade e descontração. Em especial agradeço aos amigos que quando souberam do término da minha bolsa ofereceram suas repúblicas como abrigo temporário. Obrigado ao Boituva, Pitu, Tico, Prado por terem oferecido suas casas!

Obrigado a todos! 


\section{Resumo}

O meandramento da Corrente do Brasil (CB) ao sul da Bifurcação de Santos é investigada por meio de imagens satelitárias, dados quase-sinóticos, análise de funções ortogonais empíricas (EOF) de correntômetros de fundeios e um modelo analítico semi-teórico. A análise das imagens satelitárias revelam que em média 1,2 meandros ciclônicos de grande amplitude são formados anualmente nas vizinhanças do Cabo de Santa Marta $\left(\sim 28,5^{\circ} \mathrm{S}\right)$. Os meandros parecem ser geostroficamente instáveis e a taxa de crescimento típica estimada é de $0,05 \mathrm{~m} \mathrm{~s}^{-1}$. Eles ainda se propagam para sul com velocidade de fase de $0,07 \mathrm{~m} \mathrm{~s}^{-1}$. A seção de velocidade, como a inferida por perfis de L-ADCP obtidos durante cruzeiros hidrográficos, revelam que os meandros do Cabo de Santa Marta possuem estrutura de velocidade distinta daquelas observadas em Cabo Frio $\left(23^{\circ} \mathrm{S}\right)$ e Cabo de São Tomé $\left(22^{\circ} \mathrm{S}\right)$. Os meandros alcançam profundidades maiores que $1400 \mathrm{~m}$ e recirculam Água Tropical, Água Central do Attântico Sul, Água Intermediária Antártica e Água Circumpolar Superior. Ocasionalmente, a estrutura do vórtice se funde com a camada subjacente da Corrente de Contorno Oeste Profunda. O padrão geostrófico horizontal dos meandros foram mapeados usando dados de temperatura e salinidade de cruzeiros históricos e foi obtido que a estrutura ciclônica do meandro possui número de Rossby $(\sim 0,07)$ e número de Burger $(\sim 0,06)$ pequenos. Portanto, vorticidade de estiramento parece ter papel importante na dinâmica de meandramento e, consequentemente, instabilidade baroclínica é o fenômeno primariamente responsável pelo crescimento do ciclone. O número de Burger pequeno também sugere que a dinâmica do meandro é influênciada pela topografia. A análise de EOFs bidimensionais conduzida no transecto WOCE $28^{\circ} \mathrm{S}$ de fundeios históricos dos anos 90 mostram que o primeiro modo seccional explica cerca de 54\% da variância das séries e está relacionado ao meandramento da CB. A amplitude do meandro ciclônico é aproximadamente $200 \mathrm{~km}$ uma vez que cruza o transecto e a onda de vorticidade baroclínica associada tem tipicamente 26 dias. Finalmente, um modelo de Dinâmica de Contornos idealizado de 2 camadas é construído para isolar o mecanismo de instabilidade baroclínica e para investigar as razões do crescimento e velocidade de fase para sul. A estrutura do fluxo básico do modelo é construído baseado no ajuste por mínimos quadrados das funções teóricas à média das observações nas espessuras das camadas. A simulação mostrou que o meandro evolui e se desenvolve devido ao fechamento de fase da camada inferior mais lenta relativo à camada superior mais rápida. Além disso, a propagação de fase para sul ocorre como uma consequência direta da componente barotrópica robusta, adquirida pela CB devido o ramo sul da Bifurcação de Santos.

Palavras-chave: Corrente do Brasil, Cabo de Santa Marta, Instabilidade Baroclínica, Atividade de Mesoescala, Meandros Ciclônicos, Modelo de Dinâmica de Contornos. 


\section{Abstract}

The Brazil Current (BC) meandering south of the so-called Antarctic Intemediate Water's Santos Bifurcation is investigated by means of satellite imagery, quasi-synoptic data, empirical orthogonal function (EOF) analysis of currentmeter moorings and a semi-theoretical dynamical model. The analysis of the infrared imagery revealed that on average 1.2 large amplitude cyclonic meanders are formed annualy in the vicinities of Cape Santa Marta $\left(\sim 28.5^{\circ} \mathrm{S}\right)$. The meanders seem to be geophysically unstable and the estimated typical growth rate is of 0.05 days $^{-1}$. They also propagate southward with phase speed of $0.07 \mathrm{~m} \mathrm{~s}^{-1}$. The sectional velocity distributions, as inferred from L-ADCP profiles obtained during hydrographic cruises, revealed that the Cape Santa Marta meanders have a very distinct vertical structure from those observed off Cape Frio $\left(23^{\circ} \mathrm{S}\right)$ and Cape São Tomé $\left(22^{\circ} \mathrm{S}\right)$. The meanders reach much depths of $1400 \mathrm{~m}$ and recirculated Tropical Water, South Atlantic Central Water, Antarctic Intemediate Water and Upper Circumpolar Waters. Occasionally, the eddy structure melds with the underlying Deep Western Boundary Current. Geostrophic horizontal patterns of the meanders were mapped using T-S information from historical cruises and it is obtained that the meander is a low-Rossby number $(\sim 0.07)$ and low-Burger $(\sim 0.06)$ number cyclone feature. Therefore, stretching vorticity seems to play a major role on the meandering dynamics and, consequently, baroclinic instability is the phenomenon primairily responsible for the cyclone growth. The low-Burger number also suggests that the meander dynamics is influenced by the topography. The two-dimensional EOF analysis conducted on the historical $28^{\circ} \mathrm{S}$ WOCE mooring transect from the 90s shows that the first sectional mode explains about $54 \%$ of the series variance and is related to the BC meandering. The amplitude of the cyclonic meander is roughly $200 \mathrm{~km}$ as it crosses the transect and the associated baroclinic vorticity wave period is typically 26 days. Finally, an idealized 2-layer Contour Dynamics model is constructed to isolate the baroclinic instability mechanism and to investigate the reasons for the growth and the southward phase speeds. The model's basic flow structure is built based on least-square fits of the observations averaged within the two layer's vertical extensions. The simulation showed that the meander evolve and grow due to the phase-locking of the slower lower layer relative to the faster upper layer. Also, the southward phase speed occurs as a direct consequence of the robust barotropic component acquired by the BC due to the southern branch of the Santos Bifurcation of the Antarctic Intemediate Water.

Keywords: Brazil Current, Cape of Santa Marta, Baroclinic Instability, Mesoscale Activity, Cyclonic Meanders, Contour Dynamics Model. 


\section{Capítulo 1}

\section{Introdução}

\subsection{Padrão de Circulação do Atlântico Sul}

O giro subtropical faz parte da circulação oceânica de grande escala e é uma feição permanente forçada pelo vento que está presente no oceano superior de cada hemisfério. Além disso, essa feição é assimétrica apresentando uma intensificação das correntes no lado oeste dos giros (efeito da esfericidade terrestre), na forma de um jato estreito e intenso que flui em direção aos polos, para compensar o transporte de Sverdrup, o qual ocorre em direção ao equador em grande parte do domínio. Essas correntes confinadas em jatos estreitos e intensos são denominadas por Corrente de Contorno Oeste (CCO) e são importantes no transporte de calor e sal entre as regiões tropical e polares.

No oceano Atlântio Sul, esse padrão de circulação forçado pelo vento é denominado por Giro subtropical do Atlântico Sul (GSAS) e está centrado em $\sim 30^{\circ}$ S. Segundo Stramma \& England (1999), o GSAS é limitado em sua porção austral pela Corrente do Atlântico Sul (CAS), à leste pela Corrente de Benguela (CBe), ao norte pela Corrente Sul Equatorial (CSE) e para fechar o giro em sua porção oeste, pela Corrente do Brasil (CB). Quanto à forma tridimensional do GSAS, há uma variação em sua porção norte em relação à profundidade da coluna de água em que a influência do vento ocorre, de forma que, a sua extensão em direção ao norte diminui com o aumento da profundidade (Stramma \& England, 1999).

Essa variação ocorre devido ao padrão estratificado da Bifurcação da CSE (BiCSE). Essa corrente, que flui de leste para oeste, bifurca-se (em um ramo para sul e outro para 

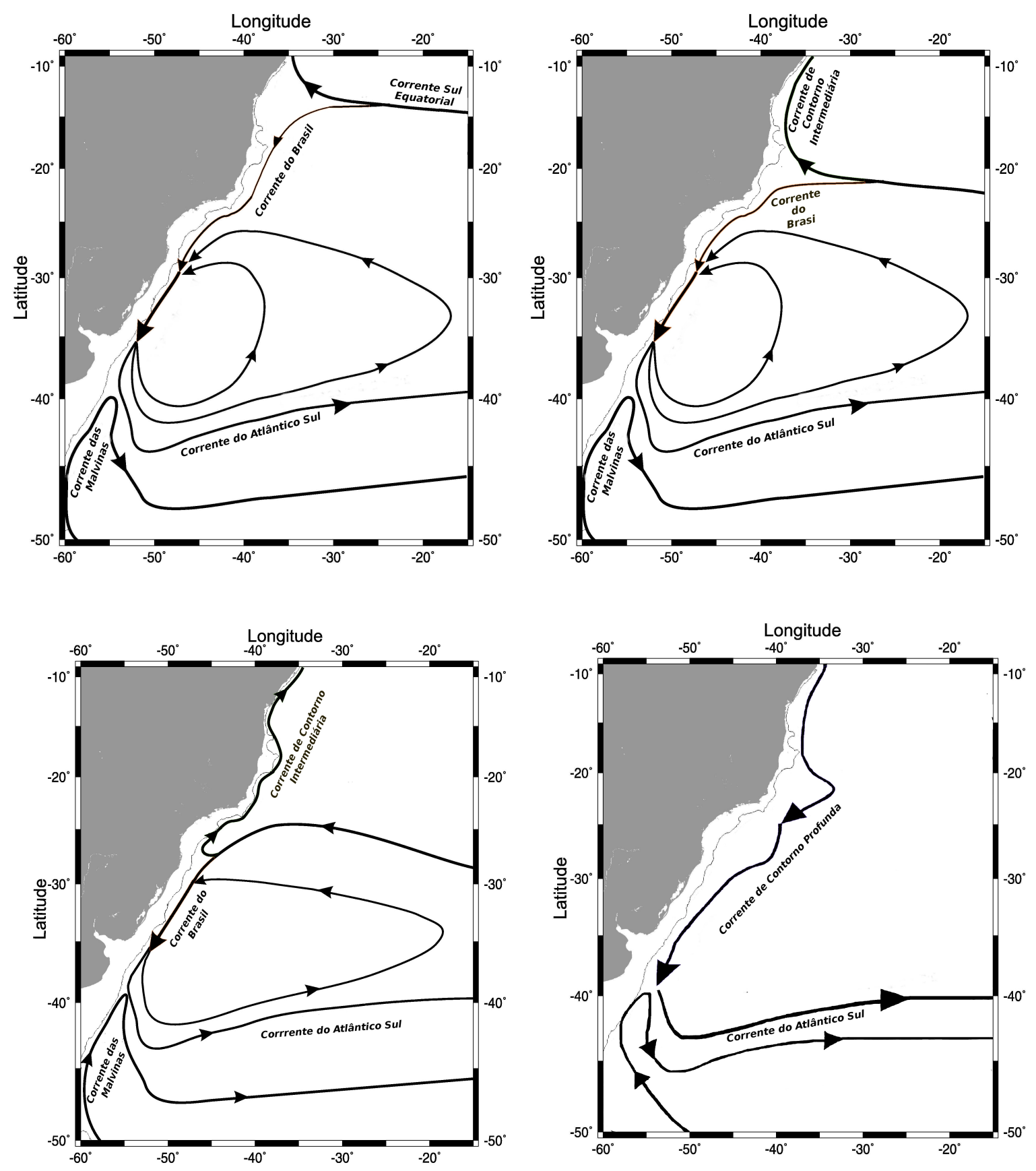

Figura 1.1: Representação esquemática do padrão de circulação de larga escala em superfície do Oceano Atlântico Sudoeste, segundo os padrões de Stramma \& England (1999). Painel superior esquerdo: circulação no nível de $100 \mathrm{~m}$ de profundidade. Painel superior direito: circulação entre 100 e $500 \mathrm{~m}$ de profundidade. Painel inferior esquerdo: circulação entre 500 e $1200 \mathrm{~m}$. Painel inferior direito: circulação no nível de 2000 m. Adaptado de Silveira et al. (2000a). 
norte) ao atingir a margem continental brasileira em latitudes distintas dependendo da profundidade observada (Figura 1.1). A partir da BiCSE ocorre a formação das CCOs presentes no oceano Atlântico Sudoeste e esse padrão pode ser dividido em três camadas principais no oceano superior (Stramma \& England, 1999). Segundo Silveira et al. (2000a), essas camadas coincidem com o domínio vertical das três massas de água principais que compõem a coluna de água no Atlântico Sul, sendo elas: Água Tropical (AT), Água Central do Atlântico Sul (ACAS) e Água Intermediária Antártica (AIA). Subjacente a essas camadas, reside a Água Profunda do Atlântico Norte (APAN), porém essa camada profunda (abaixo dos 1200 m) não faz parte da circulação do GSAS (Figura 1.1, painel inferior direito). A APAN é originada no norte do Oceano Atlântico e faz parte da circulação termohalina, estando associada à circulação da Corrente de Contorno Profunda (CCP) (Schmitz, 1995; Mémery et al., 2000).

Conforme os padrões de circulação de grande escala estabelecidos por Stramma \& England (1999), a origem da CB ocorre a partir do ramo sul da BiCSE em torno de $16^{\circ} \mathrm{S}$, ocupa os primeiros $100 \mathrm{~m}$ da coluna de água e flui para sul transportando apenas AT (Figura 1.1, painel superior esquerdo); o ramo norte da BiCSE fornece aporte em subsuperfície para a Subcorrente Norte do Brasil, a qual dará origem à Corrente Norte do Brasil em $\sim 5^{\circ} \mathrm{S}$ (Silveira et al., 1994; Stramma et al., 1995). A CB contorna o talude continental até as proximidades de $20^{\circ} \mathrm{S}$, onde recebe o aporte do ramo sul da BiCSE em nível picnoclínico (entre 100 e 500 m - domínio da ACAS), espessando-se verticalmente (Figura 1.1, painel superior direito); nesse nível, a Subcorrente Norte do Brasil se origina a partir do ramo norte (Stramma et al., 1995). Em $28^{\circ} \mathrm{S}$, o espessamento da CB decorre da contribuição em nível intermediário (entre 500 e 1200 m) a partir do ramo sul da BiCSE (também denominada na literatura por Bifurcação de Santos) e está associada ao transporte da AIA (Figura 1.1, painel inferior esquerdo) (Boebel et al., 1999; Rocha et al., 2014); nesse nível, a Corrente de Contorno Intermediária (CCI) se origina a partir do ramo norte da bifurcação.

Assim, ao norte da Bifurcação de Santos (BiSan), forma-se um padrão de escoamento baroclínico singular no oceano mundial composto pelo fluxo da CB em superfície para sul e pelo fluxo da CCI em nível intermediário para norte (Silveira et al., 2004). Embora não se soubesse precisar o sítio de origem do escoamento da CCI (da bifurcação), Boebel et al. (1999) evidencia a presença de AIA fluindo para sul na Bacia de Santos e 
Müller et al. (1998) observa AIA fluindo para norte ao norte de $25^{\circ} \mathrm{S}$. Essas evidências foram corroboradas por Legeais et al. (2013), quando analisando conjunto de dados de flutuadores com duração de aproximadamente 10 anos, observaram que a BiSan ocorre relativamente distante à margem continental, verificando o aporte para a $\mathrm{CB}$ em $28^{\circ} \mathrm{S}$ e a formação da CCI em $27^{\circ} \mathrm{S}$.

Cabe ainda ressaltar que ao sul da BiSan, encontra-se tanto o fluxo para sul associado à $\mathrm{CB}$ quanto o fluxo da $\mathrm{CCP}$, ambos com mesmo sentido. A partir disso, a CB ocupa toda a coluna de água do oceano superior e segue seu caminho até $33-38^{\circ} \mathrm{S}$ onde conflui com a Corrente das Malvinas e se separa da margem continental sul-americana para formar a CAS.

O padrão de circulação de grande escala descrito até aqui corresponde a um padrão médio baseado dominantemente em estimativas da velocidade geostróficas baroclínicas através da temperatura e salinidade climatológicas. No entanto, no âmbito da circulação de mesoescala, a CB apresenta rica atividade vortical ao largo da costa brasileira, desde sua origem até a região da Confluência Brasil-Malvinas. Essa atividade é representada pelos meandros e vórtices (frontais e de borda), que ocorrem de forma recorrente ou semi-permanente ao longo da extensão da CB. Como exemplo, podemos citar os vórtices frontais recorrentes denominados por Vórtice de São Tomé, Vórtice de Cabo Frio e Vórtice de Santa Marta (Figura 1.2). Os vórtices de mesoescala já foram razoavelmente investigadas ao largo da margem leste e sudeste brasileira assim como na região da Confluência Brasil-Malvinas, como descreveremos a seguir. 


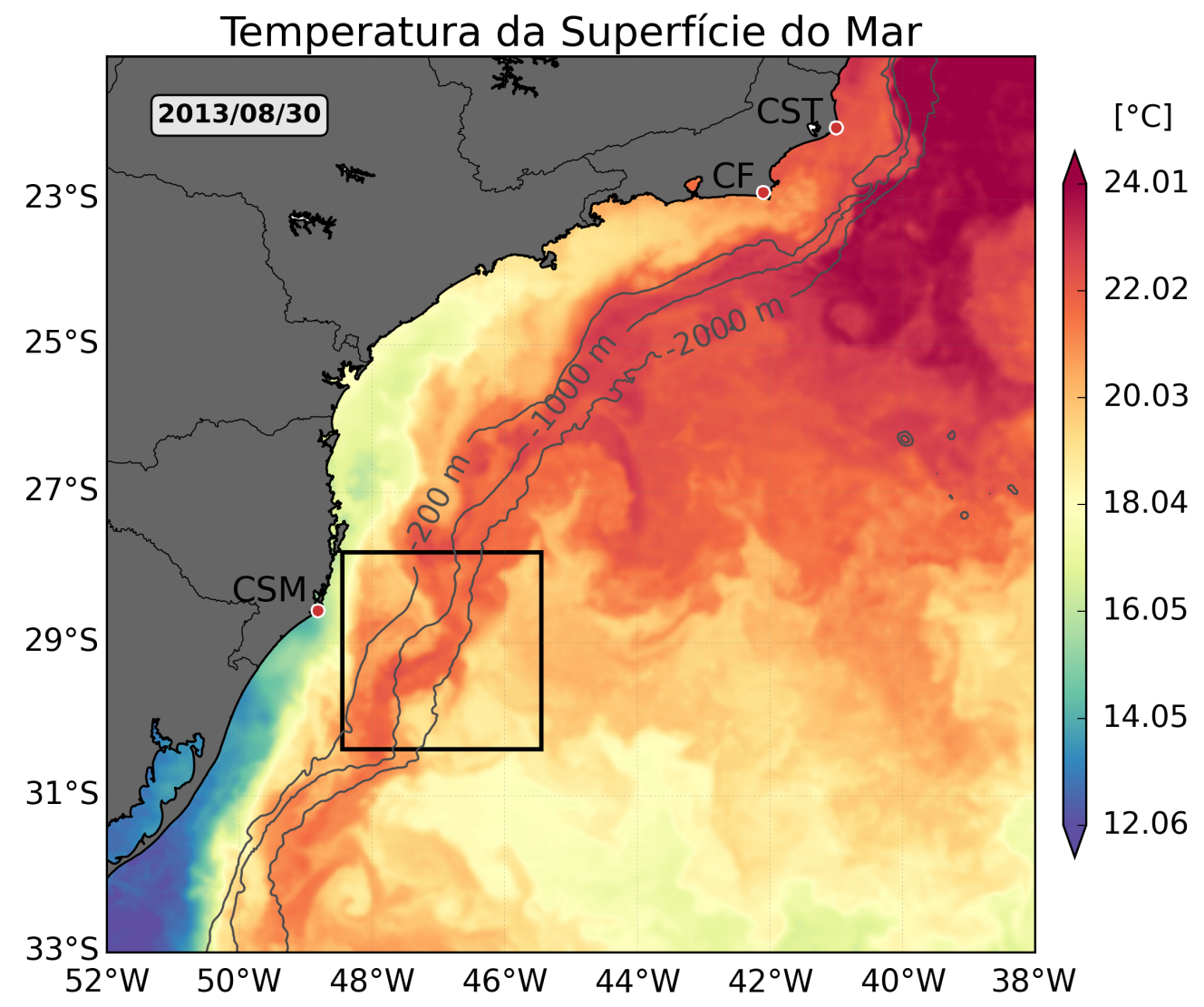

Figura 1.2: Meandros ciclônicos recorrentes da Corrente do Brasil ao largo do Cabo de São Tomé (CST), de Cabo Frio (CF) e do Cabo de Santa Marta (CSM). A área demarcada corresponde ao local de origem e desenvolvimento do meandro do CSM.

\subsection{Meandramento na Margem Leste}

Estudos recentes mostram que a região da Margem Leste, região compreendida ao norte de $20^{\circ} \mathrm{S}$ (região do aporte da CSE em nível picnoclínico) e ao sul de $15^{\circ} \mathrm{S}$ (região de origem da CB em superfície) apresenta uma rica atividade de mesoescala (1.3). O Vórtice de Vitória foi a primeira estrutura reportada na literatura, o qual ocorre logo ao sul da Cadeia Vitória-Trindade. Essa estrutura foi descrita por Schmid et al. (1995) quando analisaram um conjunto de dados diverso, dos quais observaram a propagação dessa estrutura inicialmente para norte/nordeste, antes de se propagar para sul no período final dos dados.

Baseado nas inforções acima, Campos (2006) reproduziu a formação do Vórtice 
de Vitória assim como sua propagação utilizando um modelo com resolução suficiente para resolver processos de mesoescala, além disso, verificou o padrão de propagação relatado por Schmid et al. (1995), sendo ele um deslocamento para norte, podendo permanecer estacionário, antes de se propagar para sul e ser reabsorvido pelo fluxo principal, ou ainda se propagar em direção ao equador através da Cadeira Vitória-Trindade.

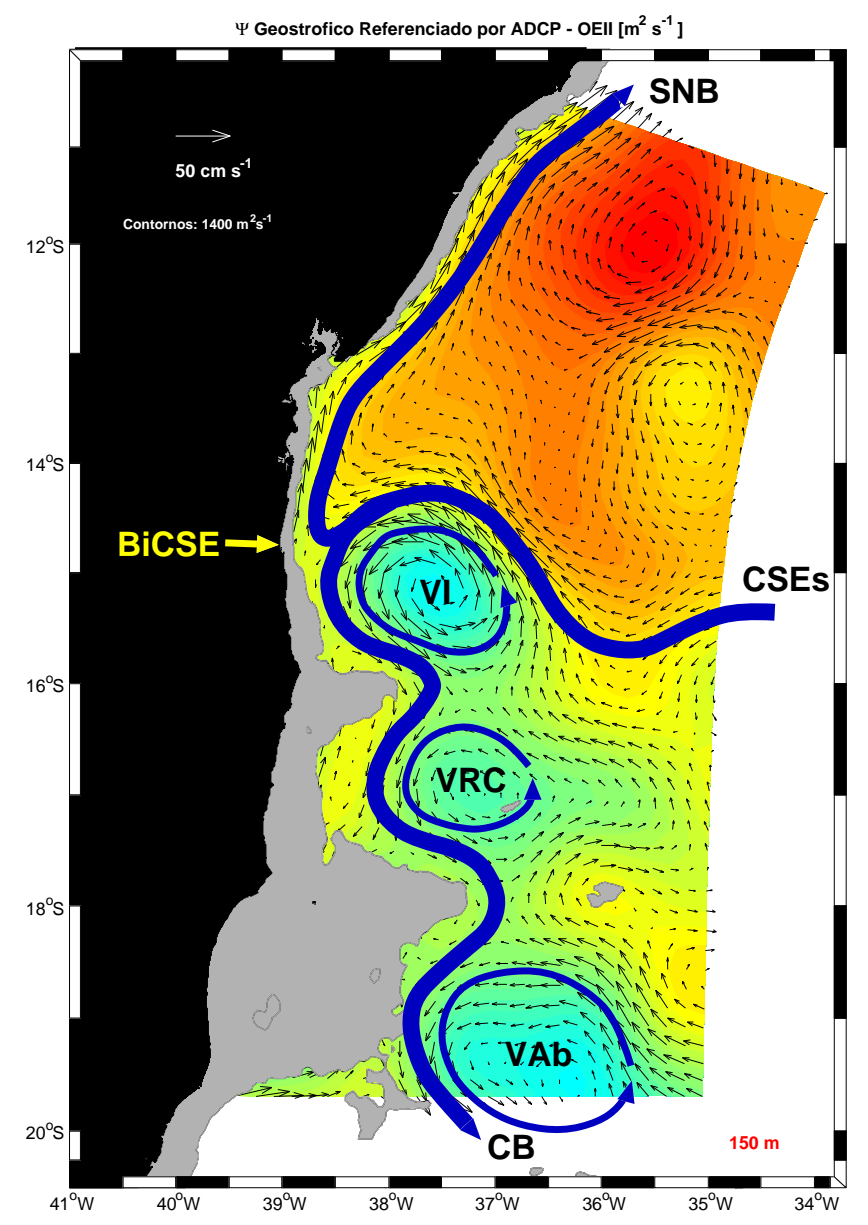

Figura 1.3: Exemplo do meandramento da Corrente do Brasil na Margem Leste. Nesta imagem estão representados o Vórtice de Ilhéus (centrado $\left.\sim 15^{\circ} \mathrm{S}\right)$, o Vórtice de Royal-Charlotte $\left(\sim 17^{\circ} \mathrm{S}\right)$ e o Vórtice de Abrolhos ( $\sim 19^{\circ}$ S). Retirado de Soutelino et al. (2011).

Essa possibilidade de propagação através da Cadeia Vitória-Trindade foi corroborada por Arruda et al. (2013). Esses autores utilizando um modelo regional que assimila dados da altura da superfície do oceano, mostraram que a propagação através da Cadeia Vitória-Trindade é favorecida quando o anticiclone (Vórtice de Abrolhos), logo ao norte da barreira topográfica, está ausente ou enfraquecido. Além disso esses autores observa- 
ram o destacamento do Vórtice de Vitória quando este está entre o Vórtice de Abrolhos, ao norte, e o Vórtice do Sul de Vitória, ao sul, provocando sua emissão.

Soutelino et al. (2011), analisando mapas de velocidades observadas por Acoustic Doppler Current Profiler (ADCP) de casco de diferentes épocas, descreveram os três anticiclones denominados como Vórtice de Ilhéus $\left(\sim 15^{\circ} \mathrm{S}\right)$, Vórtice de Royal-Charlotte $\left(\sim 17^{\circ} \mathrm{S}\right)$ e Vórtice de Abrolhos $\left(\sim 19^{\circ} \mathrm{S}\right)$. Embora os resultados apresentados não correspondessem ao padrão de circulação de grande escala descrito por Stramma \& England (1999) (origem da CB em superfície a partir da BiCSE em $\sim 15^{\circ} \mathrm{S}$ e a CB como uma CCO contínua), os autores ainda apresentaram mapas de velocidades (tanto da média anual como das médias mensais), resultantes de modelo numérico global, semelhantes aos mapas contendo essas estruturas.

A existência desses três anticlones foi corroborada por Soutelino et al. (2013). Esses autores utilizaram modelo de feição para parametrizar o cisalhamento vertical composto pelo fluxo em direção opostas da CB (em superfície para sul) e da Subcorrente Norte do Brasil (em nível intermediário para norte) assim como a BiCSE em $\sim 15^{\circ} \mathrm{S}$ (em superfície). Em seus experimentos, verificaram que somente o cisalhamento vertical entre CB e Subcorrente Norte do Brasil não reproduz o padrão de anticiclones observados. Esse padrão somente foi reproduzido quando a complexa topografia da região foi considerada junto com cisalhamento realístico de correntes, sendo essas as condições necessárias para gerar os anticiclones. Cabe ressaltar que essas estruturas também foram observadas por Arruda et al. (2013).

\subsection{Meandramento na Margem Sudeste}

A região compreendida entre $20^{\circ} \mathrm{S}$ e $28^{\circ} \mathrm{S}$ possui intensa atividade de mesoescala. Especificamente, ocorre o desenvolvimento recorrente de meandros cilônicos instáveis ao largo do Cabo de São Tomé (CST) em $\sim 22^{\circ} \mathrm{S}$, e do Cabo Frio (CF) em $\sim 23^{\circ} \mathrm{S}$, além do eventual fechamento destes em vórtices (frontais). Na Bacia de Santos (ao sul desses cabos), também é relativamente comum se observar a presença de dipolos (vórtices de borda) (Campos et al., 1996; Pereira, 2009; de Miranda, 2013).

As primeiras estruturas de mesoescala observadas nessa região foram feitas por 
Mascarenhas et al. (1971). Esses autores, através de mapas de topografia dinâmica da região ao largo do CF, observaram estruras ciclônicas e anticlônicas alternadas semelhantes a um padrão de onda de vorticidade. Posteriormente Signorini (1978), capturou um anticiclone ao sul do CF em suas observações hidrográficas.

Embora haja o relato de estruturas anticiclônicas ao largo do CF, estruturas ciclônicas são formadas com recorrência nessa região. Garfield (1990) sugere, ao analisar 405 imagens satelitárias do sensor The Advanced Very High Resolution Radiometer (AVHRR) entre 1982 e 1987, a ocorrência de uma estrutura bimodal associada ao meandramento da CB no CST e em CF. Essa estrutura foi obtida por meio da posição média da frente térmica da CB (borda interna da corrente), posicionada de forma geral sob a isóbata de $200 \mathrm{~m}$ e deslocada em direção ao interior da bacia oceânica, devido ao desenvolvimento dos meandramentos ciclônicos, nesses dois cabos.

Esses meandros se desenvolvem de forma quase-estacionária (Garfield, 1990; da Silveira et al., 2008), e podem eventualmente se fechar em vórtices. Garfield (1990) observou uma maior frequência do desenvolvimento dos meandros em vórtices em CF e pelo rastreamento destes, obteve valores para a velocidade de fase de 0,02-0,04 $\mathrm{m} \mathrm{s}^{-1}$, na direção à jusante do escoamento. Esse autor ainda destaca a possibilidade do desenvolvimento dos meandros de CST e CF estarem associados ao processo de instabilidade devido à alta variabilidade da CB nesses locais.

Fernandes et al. (2009) baseado nas evidências da formação de ondas vorticidade por possíveis processos de instabilidade, fez uma análise dinâmica dessas ondas isolando a estrutura modal do sistema CB-CCI. A partir do cisalhamento vertical formado entre CB e CCI, o autor considerou que esse sistema seria dominado pelo primeiro modo baroclínico e utilizou um modelo de duas camadas de densidades homogêneas, forçado por campo de densidade climatológico, para simular o meandramento.

Fernandes et al. (2009) obteve um padrão meandrante semelhante ao observado (meandramento ciclônico ao largo de CST, CF e Bacia de Santos) em seus experimentos tanto com topografia realística quanto idealizada (representada por uma parede vertical), por essa razão, o autor concluiu que os meandros observados não são resultantes da topografia de fundo sugerindo que estivessem relacionados à da linha de costa. No experimento com topografia realística, o autor obteve na primeira camada a formação de estruturas vorticais com período de aproximadamente 25 dias, que se propagavam para 
sudoeste com velocidade de fase de $0,2 \mathrm{~m} \mathrm{~s}^{-1}$, e comprimento de onda da ordem de 430 $\mathrm{km}$, a partir de $20^{\circ} \mathrm{S}$. No experimento com topografia idealizada, os meandros se propagavam para sudoeste com velocidade de fase de $0,23 \mathrm{~m} \mathrm{~s}^{-1}$ e comprimento de onda da ordem de $450 \mathrm{~km}$. As velocidades de fase de propagação dos meandros diferiram de resultados anteriores, isto é, de que essas estruturas seriam quase-estacionárias.

Calado (2001) investigou a importância da estrutura vertical do sistema CB-CCI no processo de crescimento dos meandros, utilizando modelagem numérica inicializado com campo termohalino climatológico. Para tal, o autor dividiu seus experimentos naqueles forçados apenas pela tensão de cisalhamento do vento e em experimentos contendo a estrutura vertical do sistema CB-CCI através da prescrição da estrutura termohalina desse sistema nos contornos abertos ao norte e ao sul do domínio. Para o primeiro conjunto de experimentos, o autor obteve um meandramento semi-estacionário discreto dado por pequenas amplitudes da CB e obteve um padrão de corrente dominantemente barotrópica, que satisfez as condições de instabilidade barotrópica (Teorema de Rayleigh), embora não suficientes (barotropicamente estáveis). No segundo conjunto, o autor obteve o desenvolvimento dos meandros ciclônicos do CST e CF, como um padrão de ondas de Rossby superpostas ao escoamento básico com comprimento de onda da ordem de $390 \mathrm{~km}$, e ainda a formação do Vórtice de São Tomé a partir da inclusão da estrutura do sistema CB-CCI. A partir disso, o autor inferiu que o mecanismo de instabilidade está associado ao cisalhamento vertical entre $\mathrm{CB}$ e $\mathrm{CCI}$. As ondas obtidas se mostram dispersivas que se propagavam para sudoeste com velocidade de fase de $0,23 \mathrm{~m} \mathrm{~s}^{-1}$ e velocidade de grupo de $0,05 \mathrm{~m} \mathrm{~s}^{-1}$.

Ainda nesse segundo conjunto de experimentos, Calado (2001) mostrou a importância da topografia do fundo quando, utilizando uma topografia idealizada, não fora obtido o padrão de ondas observado pelo experimento com topografia realística. A partir da topografia idealizada representada por uma parede vertical junto à isóbata de $50 \mathrm{~m}$, foi obtido apenas o padrão de meandramento no CST e a formação do respectivo vórtice. Assim sendo, o autor conclui que a linha de costa e a batimetria são responsáveis pelo início do meandramento da CB (a partir do padrão de ondas obtido através somente pelo forçamento do vento), ao contrário dos resultados obtidos por Fernandes et al. (2009) (verificou que o padrão meandrante não era influênciado pela topografia), e que o processo de instabilidade baroclínica é responsável pelo crescimento temporal dos meandros. 
O processo de ressurgência costeira na região da Margem Sudeste (principalmente em CF e CST onde esse processo tem maior recorrência) ocorre como resposta à predominância dos ventos de nordeste na região, fato que proporciona transporte de Ekman em direção ao interior da bacia oceânia e consequente divergência junto à costa, que é compensada por bombeamento de Ekman em direção à superfície. No entanto, esse processo pode ser potencializado pelo meandramento ciclônico da $\mathrm{CB}$, o que favorece ressurgência na quebra da plataforma continental e instrusão de ACAS sob a plataforma continental (Campos et al., 1995, 2000; Castelão et al., 2004; Calado et al., 2010).

Campos et al. (1995) observaram, através de dados hidrográficos e fazendo uso do cálculo geostrófico (no qual consideraram o nível de movimento nulo entre 750 e $900 \mathrm{~m}$ - profundidade máxima perfilada), a intrusão de ACAS sob a plataforma continental no interior da Bacia de Santos $\left(\sim 25^{\circ} \mathrm{S}\right)$ associada ao meandramento da CB. Esses autores, formularam um modelo conceitual, utilizando as ideias de Osgood et al. (1987), para explicar o papel do meandramento da CB no processo de ressurgência costeira. Nesse modelo, o desenvolvimento do meandro ciclônico induz a presença de um domo frio, caracterizado por águas ressurgidas (abaixo da CCO), entre o meandro e a plataforma continental. Na porção dianteira do meandro, ocorre divergência favorecendo o afloramento de água e em sua porção traseira, convergêngia favorecendo o afundamento, e a medida em que o meandro se desloca, águas ressurgidas são advectadas sob a plataforma continental e águas costeiras são carreadas, nas respectivas porções.

Campos et al. (2000) corroboraram esse modelo por meio da comparação entre observações e resultados de modelo numérico. Esses autores verificaram ao simular o desenvolvimento de meandro ciclônico em CF (crescendo em amplitude e se propagando para sul) que a intrusão de ACAS sob a plataforma continental ocorre devido à ressurgência de quebra da plataforma induzida pelo meandro, no inverno (quando o vento de nordeste se enfraquece), ou devido à combinação da ressurgência de quebra da plataforma e do vento de nordeste, no verão.

Castelão et al. (2004) evidenciam o efeito combinado entre vento e meandramento como mecanismo potencializador para a intrusão de ACAS sob a plataforma continental. Em seus experimentos, esses autores mostram que somente o processo de ressurgência forçado pelo vento não é suficiente para conectar ACAS encontrada ao largo do talude com o mesmo tipo de massa de água encontrado sob a plataforma, assim como, o 
processo de ressurgência forçada pelo meandramento ciclônico da CB isoladamente. Os autores verificaram que o efeito isolado do vento gera velocidades verticais relativamente intensas junto à costa, enquanto que o efeito isolado do meandramento fica confinado à quebra da plataforma continental. Dessa forma, os dois efeitos combinados permite que ACAS seja ressurgida na quebra da plataforma e advectada para profundidades mais rasas sob a plataforma continental e fique exposta ao efeito do vento, proporcionando um maior volume de água ressurgida.

Embora, a forçante pelo vento em conjunto com o crescimento em amplitude e a propagação do meandro potencializem o processo de ressurgência sob a plataforma continental, Calado et al. (2010) mostram, através somente de modelagem numérica utilizando modelo de feições, que os meandros ciclônicos instáveis e quase-estacionários em CST podem isoladamente proporcionar ressurgência costeira nessa região, onde a plataforma é estreita.

Cabe ainda ressaltar que na Bacia de Santos, estruturas provenientes de processos de instabilidade barotrópica são observadas. No entanto, são poucos os trabalhos sobre essas estruturas nessa região. Campos et al. (1996) foram os primeiros a relatarem a existência de dipolos vorticais na região da Bacia de Santos. Pereira (2009) por meio de observações in situ e modelo quase-geostrófico de $1 \frac{1}{2}$-camadas observou que os pares vorticais associados ao escoamento médio se intensificam pela indução de circulação entre eles, causando o crescimento barotrópico dessas estruturas.

\subsection{Meandramento na Confluência Brasil-Malvinas}

A região da Confluência Brasil-Malvinas apresenta vigorosa atividade vortical de mesoescala associada ao processo de separação da CB e da Corrente das Malvinas da costa (Gordon \& Greengrove, 1986; Garzoli, 1993; Lentini et al., 2002; Garcia et al., 2004; Lentini et al., 2006). Nessa região, a separação da CB ocorre de forma abrupta característica como uma estrutura de retroflexão. A parte mais costeira dessa estrutura é caracterizada por um meandro anticlônico relativamente grande sucedido por outros menores que diminuem em amplitude em direção ao interior da bacia oceânica. Embora ocorra variação na posição meridional da Confluência Brasil-Malvinas (Garzoli, 1993; 
Garcia et al., 2004), o padrão de ondas observado nessa região é quase-estacionário.

Campos \& Olson (1991) investigaram circulação entre $20^{\circ} \mathrm{S}$ e $55^{\circ} \mathrm{S}$ utilizando modelo numérico de duas camadas e linha de costa inclinada. Esses autores, obtiveram como resultado o padrão de ondas semelhante ao observado na Confluência BrasilMalvinas com consequente emissão de vórtices anticiclônicos, a partir do crescimento em aplitude dos dois primeiros meandros. Embora, esses autores não tivessem isolado o mecanismo dinâmico responsável pelo processo de instabilidade, eles apresentam explicação qualitativa de que tanto instabilidade baroclínica como barotrópica participam do mecanismo de formação dessas estruturas.

Lentini et al. (2002) observou, analisando conjunto de imagens satelitárias com duração de aproximadamente 6 anos de temperatura da superfície do oceano AVHRR, a emissão de vórtices anticlônicos a partir da retroflexão a uma taxa de $\sim 7$ vórtices por ano, que tinham uma vida média de $\sim 35$ dias e velocidade de translação de $\sim 4-27 \mathrm{~km} \mathrm{dia}^{-1}$. Esse autor observou que a maioria dos vórtices tinham formato elíptico com uma variação de 56-226 km e de 23-108 km para os eixos maior e menor, respectivamente, e que esses vórtices se propagavam para sul e poucos eram reabsorvidos pelo escoamento. Esses resultados foram corroborados por Lentini et al. (2006), quando fizeram uso de imagens satelitárias da anomalia da altura da superfície do oceano do mesmo período de 6 anos que os autores anteriores. Além disso, Lentini et al. (2006) verificaram que a variação no transporte associado à CB está correlacionada à quantidade de vórtices emitidos, de forma que, um aumento no transporte é acompanhado pelo aumento de vórtices emitidos e vice-versa.

Interessados no importância do processo de instabilidade baroclínica na formação de perturbações de mesoescala observadas, Bonatti \& Rao (1999) utilizaram um modelo quase-geostrófico linear e um modelo de balanço não-linear de 36 camadas para descrever o padrão de ondas. A partir do modelo linear, os autores obtiveram para as ondas mais instáveis um comprimento de onda de $250 \mathrm{~km}$, taxa de crescimento de $5,410^{-7} \mathrm{~s}^{-1}$, velocidade de fase de $0,11 \mathrm{~m} \mathrm{~s}^{-1}$ e velocidade de grupo de $0,13 \mathrm{~m} \mathrm{~s}^{-1}$. No entanto, esses autores não tinham a intensão de reproduzir, como não obtiveram, o padrão da retroflexão (onda que diminui em amplitude). Esse fato resulta das características do modelo, que calcula analiticamente as estruturas temporais (horizontais e verticais) quando superimpõe os resultados do modelo não-linear aos do modelo linear para analisar a evolução das 
perturbações com amplitude finitas, embora o modelo responda pelas perturbações nessa região (vide o estudo Teórico de da Silveira et al. (1999)).

\subsection{Meandramento na Margem Sul: Lacunas de Conhe- cimento}

Na região da Margem Sul, há uma carência de estudos em relação à dinâmica da circulação de mesoescala associada à $\mathrm{CB}$, havendo poucos trabalhos descritivos que caracterizem essas estruturas de mesoescala em termos de sua estrutura vertical, velocidades máximas e valores de transporte de volume. Essa região é oceanograficamente compreendida ao norte pelo aporte da BiCSE em nível intermediário, o qual ocorre para sul em $\sim 30^{\circ} \mathrm{S}$ no domínio vertical da AIA (Boebel et al., 1999; Legeais et al., 2013). O escoamento associado à AIA é incorporado à CB quando esta tem sua espessura vertical aumentada, fato acompanhado pelo aumento no transporte de volume (Gordon \& Greengrove, 1986; Garfield, 1990; Zemba, 1991; Legeais et al., 2013).

Zemba (1991) calculou, utilizando dados hidrográficos amostrados sinoticamente e perpendiculares ao talude em $27^{\circ} \mathrm{S}, 31^{\circ} \mathrm{S}, 34^{\circ} \mathrm{S}$ e $36^{\circ} \mathrm{S}$, as velocidades do escoamento e seus respectivos transportes de volume, apontando a forte barotropicidade da CB nessa região. De fato, antes do aporte BiCSE, a CB é 70\% baroclínica e se torna $63 \%$ barotrópica, após esse aporte (Rocha et al., 2014). Na radial mais ao norte $\left(27^{\circ} \mathrm{S}\right)$, Zemba (1991) observou a CB com velocidades para sul maiores que $0,5 \mathrm{~m} \mathrm{~s}^{-1}$ em superfície e sua estrutura vertical se estendia até $700 \mathrm{~m}$, não contendo completamente o escoamento associado à AIA (fluia para norte como uma CCI incipiente, cujo transporte era menor que $1 \mathrm{~Sv}$ ), e transportando $11,7 \mathrm{~Sv}$. Em $31^{\circ} \mathrm{S}$, foi observado uma extensão vertical da CB de $1200 \mathrm{~m}$ com estrutura de velocidade decaindo com a profundidade (a partir do valor máximo de $0,7 \mathrm{~m} \mathrm{~s}^{-1}$ ), cujo transporte total para sul era de $22,8 \mathrm{~Sv}$. Em $34^{\circ} \mathrm{S}$, a autora encontrou um cisalhamento vertical oscilante o que foi atribuído ao meandramento da corrente e que este estaria associado à feição topográfica denominada por Cone do Rio Grande (situada $\sim 33^{\circ} \mathrm{S}$ ), a qual desestabilizaria o escoamento. Por essa razão, a autora descreveu separadamente a CB e CCI cujos valores de transporte para sul era respectivamente de $24,2 \mathrm{~Sv}$ e 9,0 Sv. Em $36^{\circ} \mathrm{S}$, a autora encontrou um valor de transporte de $80 \mathrm{~Sv}$, no entanto, consi- 
derou que a CB era todo o fluxo organizado fluindo para sul até a profundidade de $3000 \mathrm{~m}$ (incluiu o domínio da APAN).

Em aproximadamente $28^{\circ} \mathrm{S}$, Müller et al. (1998) observaram a CB confinada próxima à quebra da plataforma continental, quando analisaram uma radial de fundeios hidrográficos e de ADCP com duração de 23 meses. Nesse período a CB apresentou direção estável com poucas variações em superfície associadas a eventos extremos e o transporte médio calculado foi de 16,2 Sv para sul (avaliado nos domínios verticais da AT e ACAS). Os autores observaram a CB com velocidades para sul de $\sim 0,45 \mathrm{~m} \mathrm{~s}^{-1}$ em superfície e de $\sim 0,6 \mathrm{~m} \mathrm{~s}^{-1}$ em $670 \mathrm{~m}$, sugerindo que nessa latitude o escoamento associado à AIA não se encontrava completamente organizado ao escoamento da corrente. Os autores avaliaram o escoamento associado à AIA e Água Circumpolar Superior (ACS) separadamente e obtiveram velocidades médias para sul de $\sim 0,01 \mathrm{~m} \mathrm{~s}^{-1}$ e de $\sim 0,03 \mathrm{~m} \mathrm{~s}^{-1}$, respectivamente.

No âmbito da variabilidade da CB nessa região, há poucas informações. Garfield (1990) observou, através de medidas de velocidades absolutas obtidas por perfilador Pegasus, que o núcleo da CB se encontrava deslocada ao largo da plataforma continental em $31^{\circ} \mathrm{S}$, o que ele atribuiu ao meandramento da corrente, fato verificado através de imagens de satélite (Olson et al., 1988; Garfield, 1990). Oliveira (2003) utilizou os dados correntográficos da linha de fundeios do Projeto World Ocean Circulation Experiment (WOCE) e através da análise de Empirical Orthogonal Function (EOF) verificou uma maior variabilidade próxima à quebra da plataforma continental (eixo da $\mathrm{CB}$ ) com um período dominante de $\sim 76$ dias.

Além do deslocamento em direção ao largo da margem continental relatado anteriormente, Zemba (1991) sugere que conforme a CB se aproxima de seu limite austral, ela se afasta cada vez mais do contorno oeste e se alinha ao escoamento associado à APAN.

De forma análoga, o processo de ressurgência costeira ao largo do Cabo de Santa Marta (CSM) é potencializado quando a forçante pelo vento (de nordeste - favorável à ressurgência) e meandramento (ciclônico) da CB atuam em conjunto (Campos et al., 2013). Esses autores mostram que a plataforma estreita ao largo do cabo (mais larga ao norte e ao sul) favorece a intrusão de ACAS sob a plataforma média e o fluxo para sul sob a plataforma (devido ao vento de nordeste) favorece a ressurgência dessa massa de água ao sul do cabo.

Os trabalhos elencados até aqui, descrevem o padrão de circulação associado 
à $\mathrm{CB}$ e evidenciam uma importante atividade de mesoescala na região da Margem Sul. Nessa região, ocorre, de forma recorrente, o meandramento ciclônico da CB (Figura 1.4) ao largo do CSM e o respectivo fechamento dessa estrutura em vórtice (Vórtice de Santa Marta). Além do crescimento em amplitude dessa perturbação, essa estrutura apresenta propagação para sul, contrariamente aos vórtices de Cabo Frio e São Tomé, que são quaseestacionários. No entanto, essas estruturas ciclônicas ao largo do CSM carecem de estudos que as descrevam e investiguem os mecanismos dinâmicos quanto a origem e o crescimento em amplitude dos meandros.

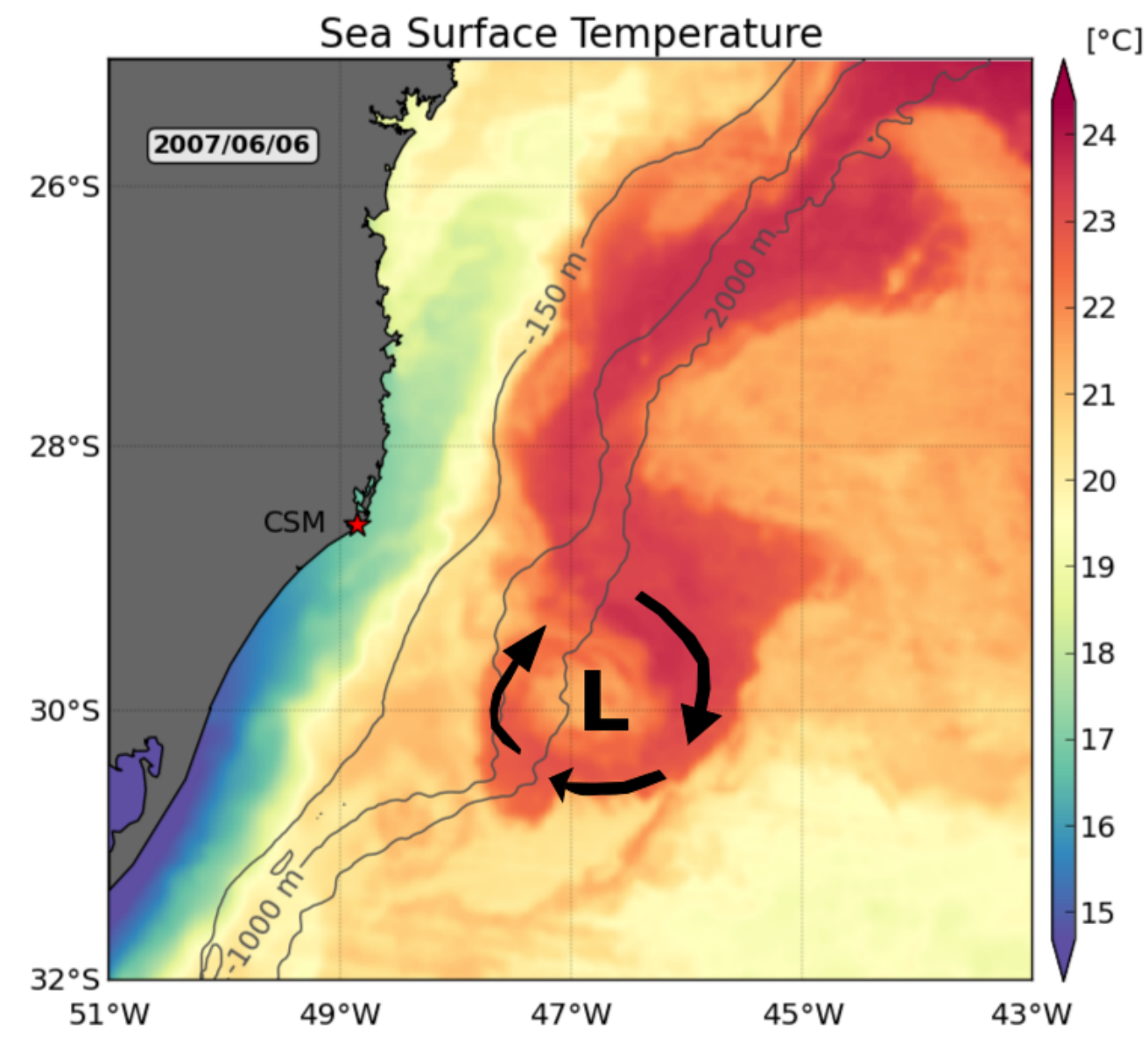

Figura 1.4: Evidência do meandro ciclônico da Corrente do Brasil ao largo do Cabo de Santa Marta (CSM). Trata-se de uma feição recorrente ao largo do CSM, a qual cresce em amplitude podendo se fechar em vórtice (Vórtice de Santa Marta). Imagem de Temperatura da Superfície do Mar correspondente ao dia 06 de junho de 2007. 


\subsection{Objetivos}

Motivado pela lacuna existente acerca da dinâmica associada à Corrente do Brasil ao largo do Cabo de Santa Marta, este trabalho tem como objetivo central fazer o estudo de processo da formação e do desenvolvimento do meandramento da Corrente do Brasil, tendo como hipóteses científicas: (i) o crescimento em amplitude dos meandros ciclônicos do Cabo de Santa Marta ocorrem devido ao processo de instabilidade baroclínica e (ii) a propagação dos meandros para sudoeste ocorre provavelmente devido ao aumento da componente barotrópica da Corrente do Brasil ao sul da Bifurcação de Santos.

Como objetivos específicos, têm-se:

- Caracterização de frequências de ocorrência, comprimentos de onda, velocidades de fase e taxas de crescimento dos meandros no Cabo de Santa Marta através da análise de compósitos de imagens satelitárias do conjunto MUR SST.

- Caracterização da estrutura vertical, transporte de volume e composição de massas de água dos meandros do Cabo de Santa Marta por meio de observações hidrográficas realizadas por CTD e L-ADCP.

- Estimativa dos padrões espaciais de variabilidade, à montante do Cabo de Santa Marta, a partir das séries temporais da linha de fundeios correntográficos do Projeto WOCE entre $28^{\circ} \mathrm{S}$ e $30^{\circ} \mathrm{S}$.

- Investigação do papel de instabilidade baroclínica no crescimento de amplitude dos meandros ao largo do Cabo de Santa Marta através da elaboração de um modelo semi-teórico de Dinâmica de Contornos.

- Investigação do papel da componente barotrópica do jato médio da Corrente do Brasil na propagação para sul dos trens de ondas instáveis de mesoescala. 


\section{Capítulo 2}

\section{Análise de Imagens Satelitárias}

Neste capítulo, apresentaremos o conjunto de imagens satelitárias utilizadas para estimar quantitativamente as propriedades dinâmicas associadas ao meandramento da Corrente do Brasil ao largo do Cabo de Santa Marta. Apresentaremos os aspectos metodológicos relativos à estimativa dessas propriedades. Além disso, a aplicação dessa metodologia será apresentada a um dos eventos observados do meandramento da CB e, por fim, descreveremos os resultados obtidos através dessa estimativa em termos dos valores médios das propriedades e seus respectivos valores de desvios padrão.

\subsection{Conjunto de dados MUR SST}

Neste trabalho utilizamos um conjunto de dados de Temperatura da Superfície do Mar (TSM) medidos por sensor infravermelho. Os sensores que operam na banda espectral do infravermelho possuem limitações amostrais tanto em relação à cobertura de nuvens quanto à contaminação por aerosóis e nuvens baixas que permitem e alteram a passagem da energia nessa banda espectral. A partir dessas limitações, o Group for High Resolution Sea Surface Temperature (GHRSST) lançou recentemente uma versão de imagens de TSM nivel L4 denominada por Multi-scale Ultra-high Resolution Sea Surface Temperature (MUR SST). Esses dados são publicamente disponibilizados pelo GHRSST. As imagens MUR SST são compósitos interpolados em uma grade com resolução espacial de 1 km e livres de regiões com ausência de dados por meio de técnicas de interpolação, do uso de dados in situ e de outros sensores. Esse conjunto de dados tem resolução temporal 
de 1 dia e possui atualmente uma série temporal de aproximadamente 14 anos que se estende de 1 de junho de 2002 até o presente.

Vazquez-Cuervo et al. (2013) compararam imagens MUR SST com outros tipos de imagens disponibilizas pelo GHRSST, a partir do cálculo do gradiente de temperatura em uma região de ressurgência na costa do Peru (entre $5^{\circ} \mathrm{S}-14^{\circ} \mathrm{S}$ e $75^{\circ} \mathrm{W}-81^{\circ} \mathrm{W}$ ). Os autores mostraram que as imagens MUR SST representam de forma mais realística a posição da frente térmica, assim como suas variações espaciais associadas a processos de escalas menores (mesoescala e submesoescala).

Neste trabalho, foi utilizada uma série temporal de imagens MUR SST de 11 anos do perído entre junho de 2002 e julho de 2013. Os eventos do meandramento da CB ao largo do CSM foram identificados visualmente através dos mapas horizontais de TSM (vide Figura 2.1 como exemplo).

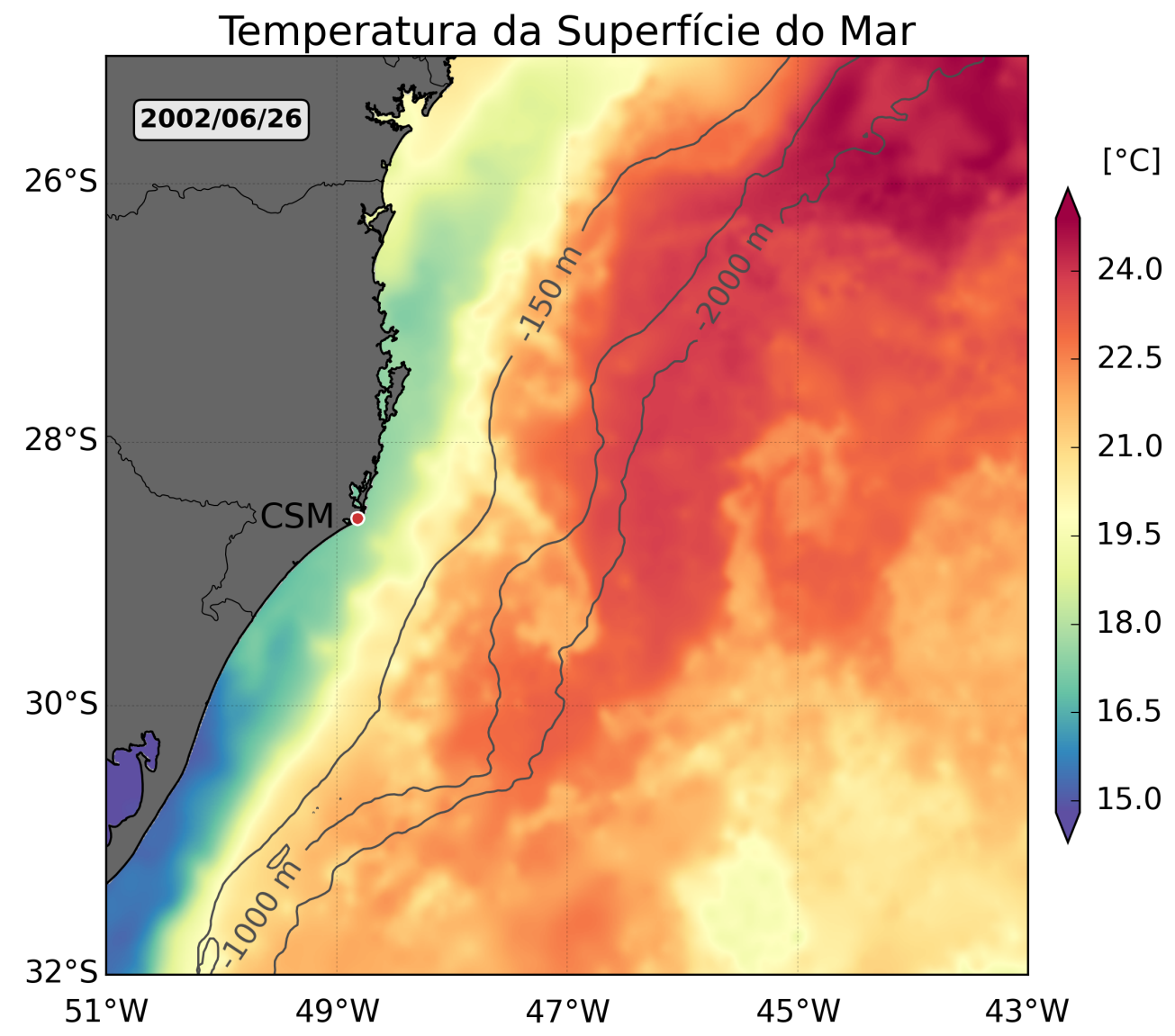

Figura 2.1: Mapa horizontal de Temperatura da Superfície do Mar com a presença do Vórtice de Santa Marta (VSM). O VSM se origina a partir do crescimento em amplitude do meandro ciclônico ao largo do Cabo de Santa Marta (CSM). Imagem referente ao dia 26 de junho de 2002.

Posteriormente à identificação dos eventos, almejamos acompanhar a evolução 
dos meandros da CB associados a variação espacial da Frente térmica (FT) da CB (como veremos na Seção 2.2). FTs são regiões frontais caracterizadas pelo pronunciado gradiente horizontal de temperatura associado à separação de águas com características distintas. A FT da CB demarca sua borda interna e delimita a separação entre águas costeiras (menor temperatura) e a $\mathrm{CB}$, a qual transporta $\mathrm{AT}$ em superfície (maior temperatura) (Lorenzzetti et al., 2009). Por essa razão, os mapas de TSM foram usados como alicerce para a identificação da FT da CB, como veremos a seguir.

\subsection{Aspectos Metodológicos e Resultados}

A partir dos mapas horizontais de TSM, foram produzidos mapas da magnitude do gradiente horizontal de temperatura $\left(\left\|\nabla_{H} T\right\|\right)$ para identificar objetivamente a FT da CB, conforme a Equação 2.1.

$$
\left\|\nabla_{H} T\right\|=\left[(\underbrace{\frac{\partial T}{\partial x}}_{(\mathrm{A})})^{2}+(\underbrace{\frac{\partial T}{\partial y}}_{(\mathrm{B})})^{2}\right]^{\frac{1}{2}}
$$

Seguindo as ideias de Saraceno et al. (2004), o cálculo da $\left\|\nabla_{H} T\right\|$ (Equação 2.1) foi realizado utilizando o esquema numérico de diferenças centradas no interior do domínio, dessa forma os termos (A) e (B) na Equação 2.1 são escritos como

$$
\left\|\nabla_{H} T_{i}\right\|=\left[(\underbrace{\frac{T_{x_{i+1}}-T_{x_{i-1}}}{x_{i+1}-x_{i-1}}}_{\text {(A) }})^{2}+(\underbrace{\frac{T_{y_{i+1}}-T_{y_{i-1}}}{y_{i+1}-y_{i-1}}}_{\text {(B) }})^{2}\right]^{\frac{1}{2}}
$$

onde $x_{i+1}$ e $x_{i-1}\left(y_{i+1}\right.$ e $\left.y_{i-1}\right)$ são os pontos que delimitam o $i$-ésimo pixel na direção zonal (meridional).

No entanto, diferentemente desses autores, nos contornos esse cálculo foi realizado utilizando-se o esquema numérico de diferenças avançadas ou retardadas (dependendo da posição relativa do contorno no domínio - respectivamente, início e final do domínio nas direções $x$ e $y$ ), por isso o mapa da $\left\|\nabla_{H} T\right\|$ cobre a mesma área que o mapa de TSM. Dessa maneira, os termos (A) e (B) na Equação 2.1 são escritos respectivamente 
nos esquemas avançado e retardado por

$$
\begin{gathered}
(\mathrm{A})= \begin{cases}\frac{T_{x_{i+1}}-T_{x_{i}}}{x_{i+1}-x_{i}}, & \text { contorno à esquerda } \\
\frac{T_{x_{i}}-T_{x_{i-1}}}{x_{i}-x i-1}, & \text { contorno à direita }\end{cases} \\
(\mathrm{B})= \begin{cases}\frac{T_{y_{i+1}}-T_{y_{i}}}{y_{i+1}-y_{i}}, & \text { contorno inferior } \\
\frac{T_{y_{i}}-T_{y_{i-1}},}{y_{i}-y i-1}, & \text { contorno superior }\end{cases}
\end{gathered}
$$

O cálculo do gradiente horizontal de temperatura $\left(\nabla_{H} T\right)$ foi realizado na linguagem de programação de código aberto Python através da função gradient do módulo NumPy (numpy.gradient), no qual é utilizado um esquema de diferenciação de primeira ordem em todo o domínio (acurácia preservada). Assim sendo, o esquema centrado (interior do domínio) e os esquemas avançado e retardado (contornos) no espaço são discretizados respectivamente, como por exemplo para a componente $x$, conforme

$$
\begin{gathered}
\left(\frac{\partial T}{\partial x}\right)_{i} \approx \frac{T_{x_{i+1}}-T_{x_{i-1}}}{2 \Delta x} \\
\left(\frac{\partial T}{\partial x}\right)_{i} \approx-\left(\frac{3 T_{x_{i}}-4 T_{x_{i+1}}+T_{x_{i+2}}}{2 \Delta x}\right) \\
\left(\frac{\partial T}{\partial x}\right)_{i} \approx \frac{3 T_{x_{i}}-4 T_{x_{i-1}}+T_{x_{i-2}}}{2 \Delta x}
\end{gathered}
$$

A partir dos mapas da $\left\|\nabla_{H} T\right\|$ (Figura 2.2), as frentes associadas à CB de cada evento foram digitalizadas manualmente. Cabe ressaltar que não utilizamos nenhum artifício para destacar ou isolar a FT. Para cada evento, as FTs foram digitalizadas em intervalos de imagens entre 2 a 9 dias, com um intervalo médio de $\sim 5$ dias, devido à cobertura por nuvens. Embora as imagens MUR SST sejam interpoladas para eliminar regiões com ausência de dados, a resolução espacial do sensor de infravermelho é maior que a dos outros dados usados para a interpolação, por essa razão as regiões interepoladas são mais 
"suavizadas", fato que dificulta sua digitalização nessas condições.

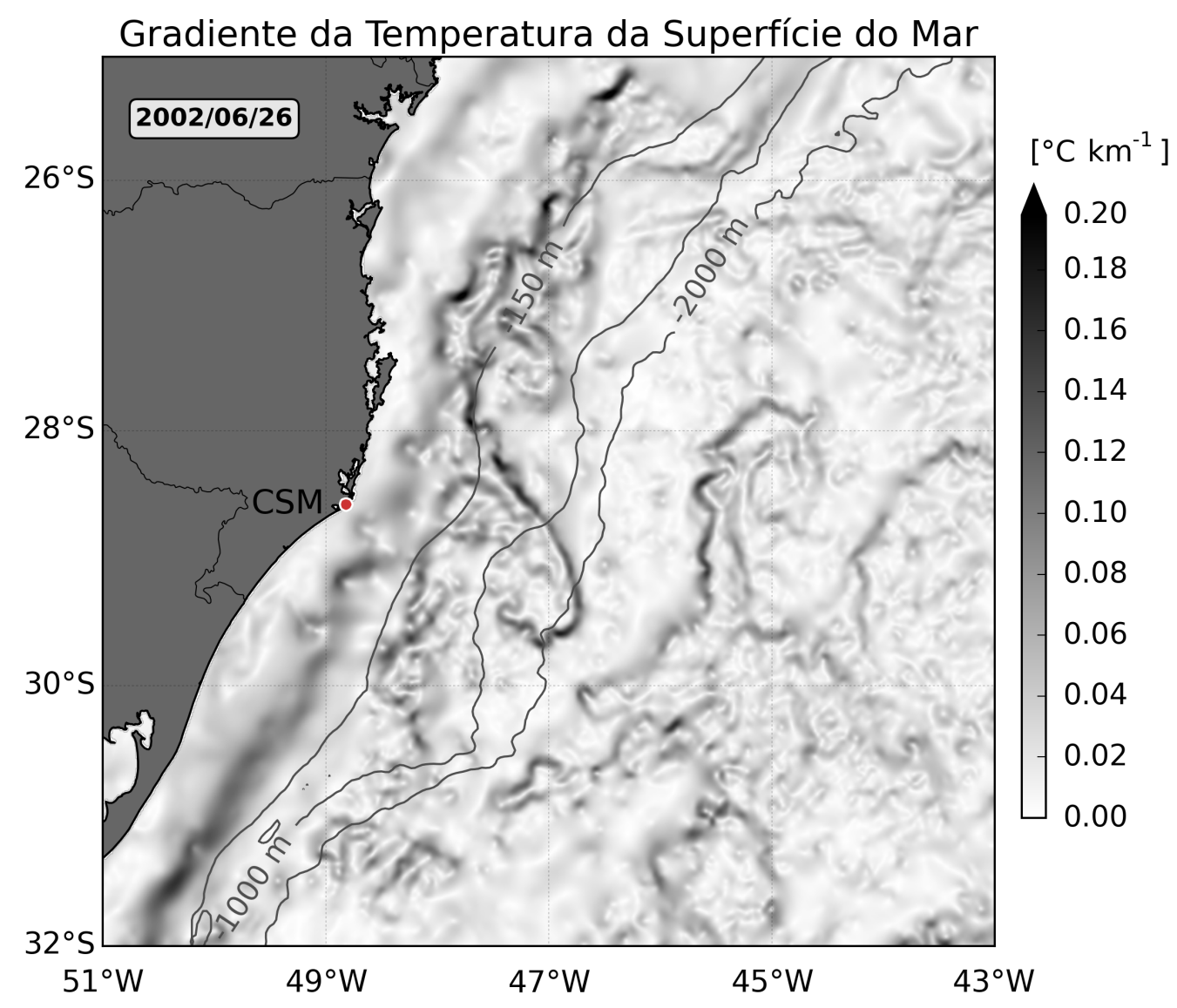

Figura 2.2: Mapa horizontal da magnitude do gradiente de Temperatura da Superfície do Mar. A frente térmica da Corrente do Brasil é demarcada pela contabilização dessa grandeza e está associada a borda interna da corrente. Nota-se o meandramento da corrente ao largo do Cabo de Santa Marta (CSM). Imagem referente ao dia 26 de junho de 2002 (correspondente à Figura 2.1).

Posteriormente à digitalização da frente, a amplitude do meandro (ou o crescimento em amplitude do meandroao longo de sua evolução) foi medido a partir da quebra da plataforma continental. Segundo Zembruscki (1979) a quebra da plataforma na região do CSM se encontra em torno de $140 \mathrm{~m}$ de profundidade e $160 \mathrm{~m}$ na região logo ao sul do CSM. Para medir a distância entre a quebra da plataforma e a FT da CB utilizamos a isóbata de $150 \mathrm{~m}$ como referência (já que o escoamento geostrófico tende a fluir paralelo às isóbatas). Essa medida de distância foi tomada do ponto mais ao largo do meandro à isóbata de referência.

Essa distância é assumida como proporcional à amplitude do meandro $(A) \mathrm{e}$ a partir disso, estimamos a taxa de crescimento $(\sigma)$ do meandro através de um ajuste exponencial recursivo (Equação 2.6) para minimizar o erro (usamos uma tolerância de 
$\left.10^{-8}\right)$, conforme

$$
\sigma=c_{1}+c_{2} \exp (A t)
$$

onde $c_{1}$ é o parâmetro linear, $c_{2}$ é o parâmetro quadrático, $A$ é a amplitude e $t$ é o tempo.

O procedimento para estimar $\sigma$ é exemplificado para um dos eventos observados ocorrido entre 04 a 10 de setembro de 2010. Os mapas de TSM e da $\left\|\nabla_{H} T\right\|$ são apresentados na Figura 2.3, as frentes digitalizadas e a $\sigma$ estimada são apresentadas respectivamente na Figura 2.4. Nota-se após a formação do meandro sua propagação para sul/sudoeste.

Na série temporal de imagens utilizadas foram observados um total de 13 eventos do quais 9 eventos foram possíveis de serem digitalizados, obtendo uma taxa de recorrência de $\sim 1,2$ eventos ano ${ }^{-1}$. No entanto, ficou evidente uma frequente cobertura por nuvens na região assim como a persistência destas. Por essa razão, esse fato sugere que a taxa de recorrência está subestimada. A estimativa das propriedades dinâmicas a partir dessas imagens são apresentadas na Tabela 2.1.

Tabela 2.1: Resultados quantitativos das propriedades dinâmicas, acerca do meandramento da Corrente do Brasil ao largo do Cabo de Santa Marta, estimados a partir da análise de imagens satelitárias (MUR SST).

\begin{tabular}{cc}
\hline Propriedade & Média \pm Desvio Padrão \\
\hline Recorrência do Meandro $\left(\right.$ eventos ano $\left.^{-1}\right)$ & $\sim 1,2$ \\
Taxa de Crescimento $\left(\mathrm{dia}^{-1}\right)$ & $0,05 \pm 0,02$ \\
Velocidade de Fase $\left(\mathrm{m} \mathrm{s}^{-1}\right)$ & $0,07 \pm 0,03$ \\
Comprimento de Onda $(\mathrm{km})$ & $219 \pm 46$ \\
\hline
\end{tabular}



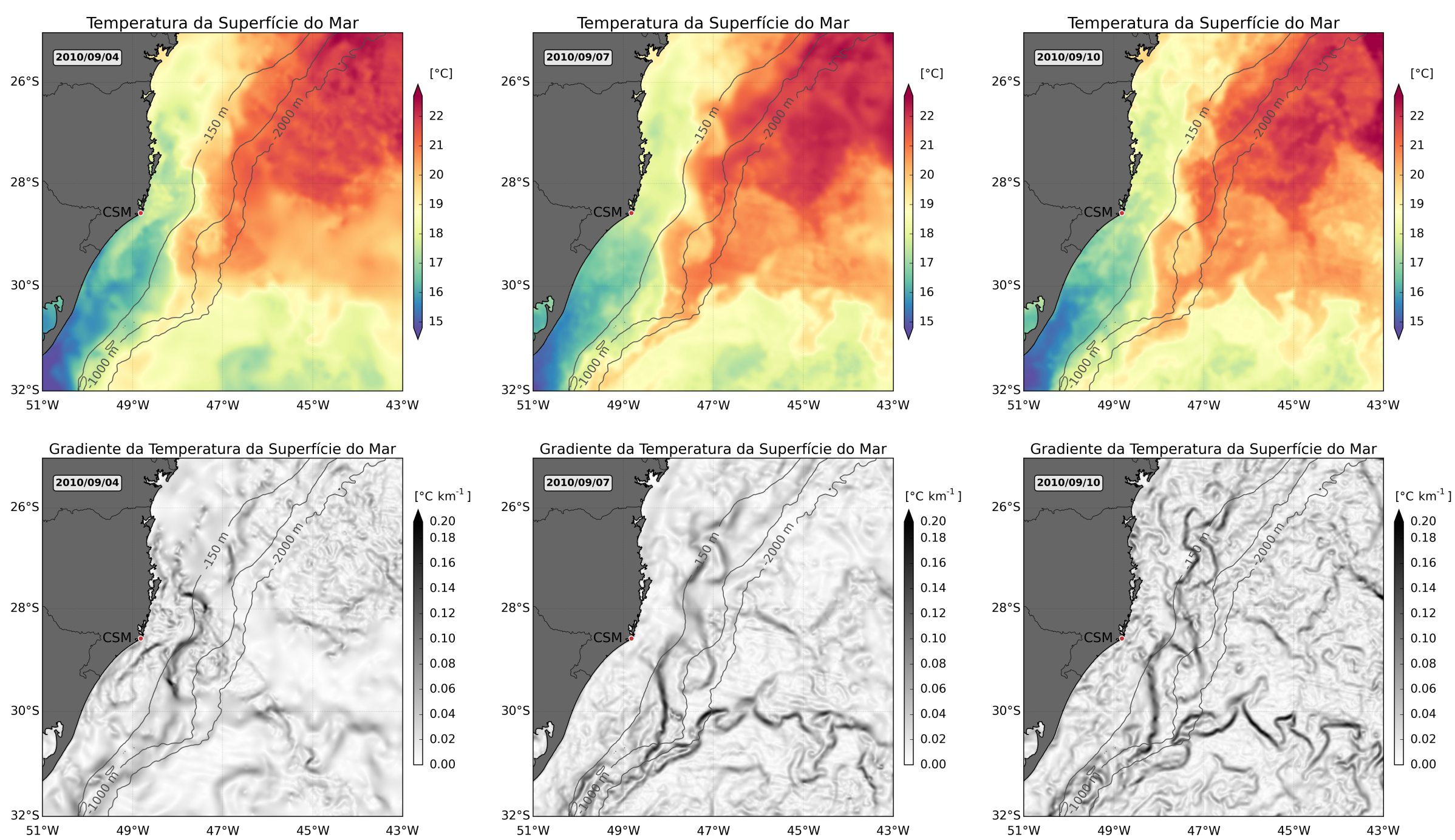

Figura 2.3: Paineis superiores: Mapas horizontais de Temperatura da Superfície do Mar (TSM) dos dias 04, 07 e 10 de setembro de 2009. Paineis inferiores: Respectivos mapas da magnitude do gradiente de TSM. 

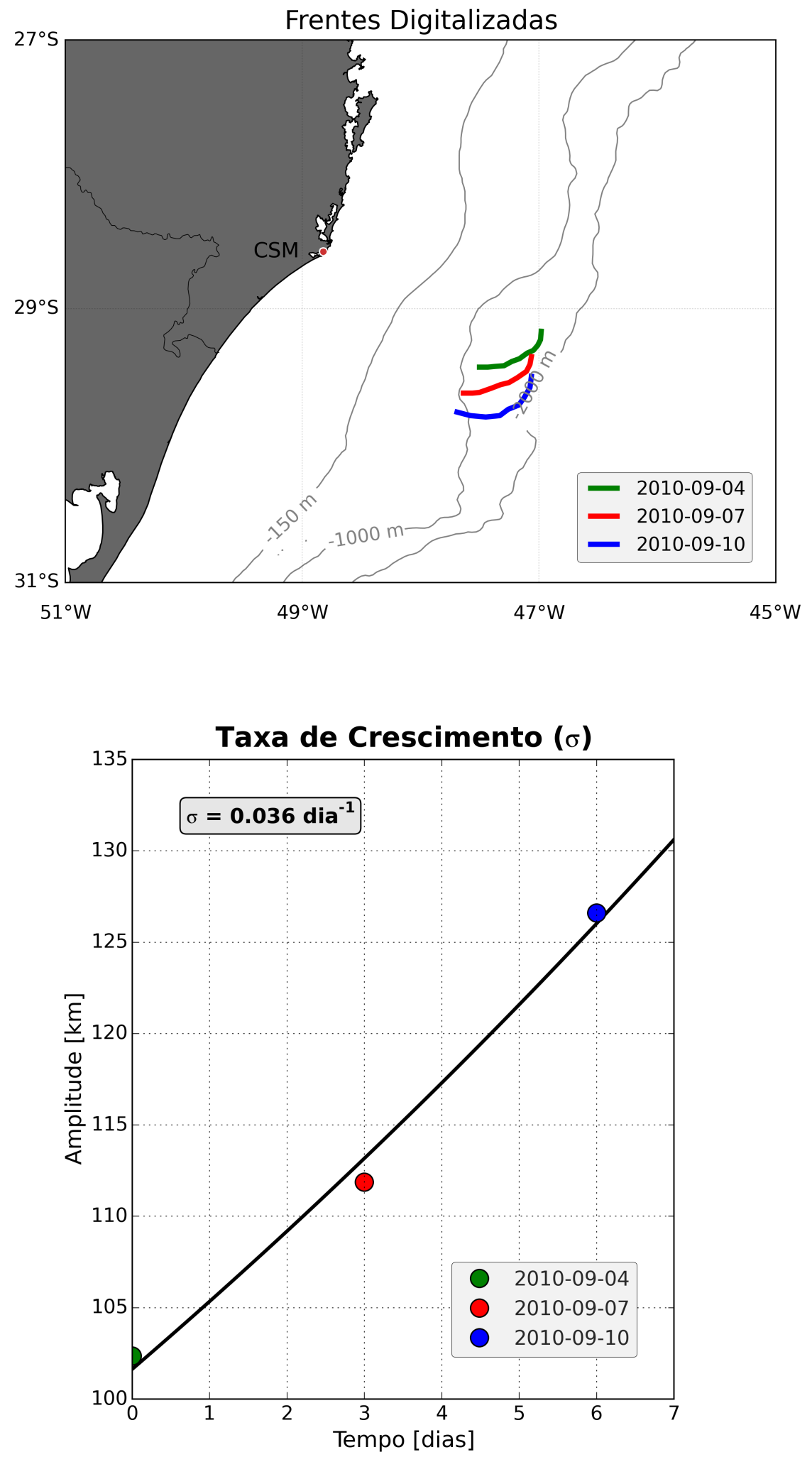

Figura 2.4: Painel superior: Resultados da digitalização da Frente Térmica associada ao meandro do Cabo de Santa Marta (CSM), referente ao evento ocorrido entre 04 e 10 de setembro de 2010. Nota-se nessas imagens, a propagação do meandro para sul/sudoeste. Painel inferior: Taxa de crescimento $\sigma$ estimada através de ajuste exponencial recursivo a partir da digitalização das frentes (amplitude do meandro). 


\subsection{Resultados e Discussão}

Neste capítulo analisamos imagens do conjunto de dados MUR SST de um período de 11 anos. Identificamos 13 eventos dos quais 9 deles puderam ser digitalizados. A digitalização da FT associada ao meandramento da CB é uma ferramenta alternativa para estimar as propriedades dinâmicas associadas ao meandro do CSM. A partir da identificação dos eventos de formação e crescimento do meandro, nota-se sua propagação para sul/sudoeste com velocidade de fase de $\sim 0,07 \pm 0,03 \mathrm{~m} \mathrm{~s}^{-1}$ cujo comprimento de onda foi de $\sim 219 \pm 46 \mathrm{~km}$. A taxa de crescimento encontrada foi de $\sim 0,05 \pm 0,02 \mathrm{dia}^{-1}$.

Como já dito, a recorrência de $\sim 1,2$ eventos por ano é provavelmente subestimada pela ocorrência de nuvens nas imagens e também pelo fato adicional de uma erosão do sinal térmico da feição em superfície. Esta segunda razão é provavelmente mais comum no verão, onde as águas costeiras mais frias entranhadas pelo meandro se esquentam rapidamente quando este se afasta da costa. Tal fato já foi observado no Vórtice de Vitória em $20^{\circ} \mathrm{S}$, onde apenas a assinatura halina estava presente em superfície (Ilson Silveira, comunicação pessoal).

Em relação ao comprimento de onda, o valor encontrado de $219 \pm 46 \mathrm{~km}$ se encontra próximo ao cerca de $180 \mathrm{~km}$ descritos para a região em torno de $28^{\circ} \mathrm{S}$ por Rocha et al. (2014), a partir de modelo quase-geostrófico e perfis de fundeio. Os valores de taxa de crescimento $\left(0,04 \mathrm{dia}^{-1}\right)$ e velocidade de fase $\left(0,15 \mathrm{~m} \mathrm{~s}^{-1}\right)$ calculados Teoricamente por esses mesmos autores são comparáveis com os nossos apresentados na Tabela 2.1.

Os resultados de Rocha et al. (2014) são os únicos disponíveis que comparam os vórtices nas imediações de Santa Marta $\left(\sim 28,5^{\circ} \mathrm{S}\right)$ com os Vórtices Quase-estacionários de São Tomé e Cabo Frio. No caso de São Tomé, as ondas mais instáveis têm o mesmo comprimento das ondas aqui encontradas. Porém, a velocidade de fase é cerca de apenas $35 \%$ do valor por nós encontrado. Ademais, além de mais baixa a celeridade é para norte, enquanto que, a que encontramos é para sul. Ou seja, a velocidade de fase das ondas instáveis em CSM tem a mesma direção que a CB, enquanto que as em CST além de mais lentas, são advectadas na direção da CCI.

O fato é que a CB se torna mais barotrópica na Margem Sul com o aporte da BiCSE em nível intermediário (Zemba, 1991; Rocha et al., 2014). Considerando esse fato, derivamos um modelo quase-geostrófico na Seção 5 para o estudo de processo de 
instabilidade do meandro do CSM. Por essa razão, estimativas das propriedades dinâmicas se fazem importantes, fundamentalmente, a estimativa da velocidade de fase e taxa de crescimento, pois o modelo permite a investigação do papel da componente barotrópica na dinâmica destas ondas e meandros. 


\section{Capítulo 3}

\section{Análise de Observações Quase-Sinóticas}

Neste capítulo, apresentaremos os três conjuntos de dados quase-sinóticos utilizados com a finalidade de se caracterizar a estrutura vertical da $\mathrm{CB}$, em termos de velocidade e composição termohalina, assim como as estruturas associadas ao meandramento dessa corrente. Dentre esses conjuntos de dados, foram utilizados dados de hidrografia e velocidades observadas. Além disso, a descrição dessas estruturas se faz necessária pois através delas, são obtidos os parâmetros necessários ao modelo semi-analítico utilizado neste trabalho (formulação teórica descrita na Seção 5). Posteriormente, apresentamos os aspectos metodológicos referentes à obtenção, apresentação e caracterização das estruturas observadas e por fim os resultados e discussão.

\subsection{Conjunto de Dados}

\subsubsection{Conjunto MIRAI}

Designamos aqui por MIRAI o conjunto de dados coletados no âmbito do Projeto WOCE. Este previa no escopo do Programa Mundial de Pesquisas Climáticas (World Climate Research Programme (WCRP)), obter o estado do oceano mundial através da coleta de dados in situ em seções transversais em todos os oceanos e em suas conexões. Nesse sentido, o conjunto de dados MIRAI possui dados coletados em seções zonais e meridionais transversais (costa-a-costa) ao longo de todo o oceano austral com o objetivo de se detectar e quantificar mudanças na Célula de Circulação Antártica (Antartic 
Overturn System).

Os dados utilizados neste trabalho são da campanha MR03-K04 e corresponde à travessia do Oceano Atlântico Sul (4 ${ }^{\mathrm{a}}$ pernada) no sentido oeste-leste. Esse conjunto de dados é composto de 111 estações hidrográficas nas quais foram coletados dados de temperatura, salinidade, velocidade observada, entre outros. Neste trabalho utilizamos os dados de Condutivity-Temperatura-Depth Profiler (CTD) e Lowered-Acoustic Doppler Current Profiler (L-ADCP) das 12 primeiras estações (Figura 3.1). Esses dados foram coletados entre 06 de novembro de 2003 e 05 de dezembro de 2003 e são publicamente disponibilizados pela agência japonesa Japan Agency for Marine-Earth Science and Technology (JAMSTEC).

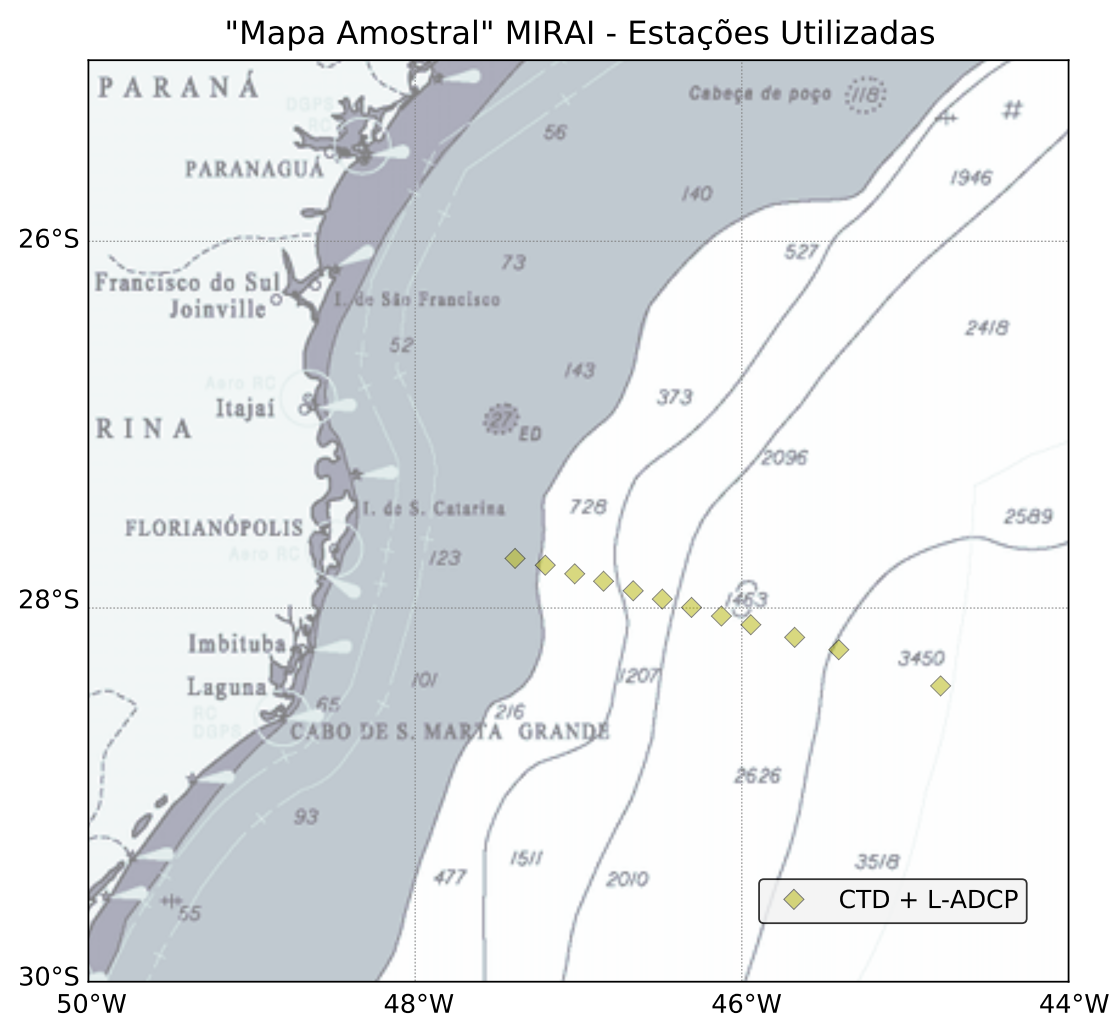

Figura 3.1: Localização das 12 estações hidrográficas coletadas pelo R/V MIRAI (JAMSTEC) no âmbito do Projeto WOCE durante travessia do Oceano Atlântico Sul. Neste trabalho utilizamos os dados de CTD e L-ADCP desse conjunto de dados, que foram coletados na campanha MR03-K04 entre 06 de novembro de 2003 e 05 de dezembro de 2003. 


\subsubsection{Conjunto CARBOM}

O Projeto Caracterização Ambiental e Avaliação dos Recursos Biogênicos Oceânios e da Margem Continental Brasileira e Zona Oceânica Adjacente (CARBOM) é composto de 95 estações hidrográficas divididas em 7 radiais quase-perpendiculares à margem continental. Nesse conjunto de dados foram coletados dados por CTD, L-ADCP e Expendable Bathythermograph (XBT) conforme a distribuição na Figura 3.2, além de dados de ADCP de casco ao longo do trajeto da embarcação. Esses dados foram coletados pelo N/Oc. Alpha Crucis do Instituto Oceanográfico da Universidade de São Paulo (IOUSP) em 3 campanhas realizadas entre 29 de outubro de 2013 e 26 de novembro de 2013. Neste trabalho, foram utilizados os dados de CTD, L-ADCP e ADCP de casco das três últimas radias, designadas na direção sul-norte por Radial 7, 6 e 5.

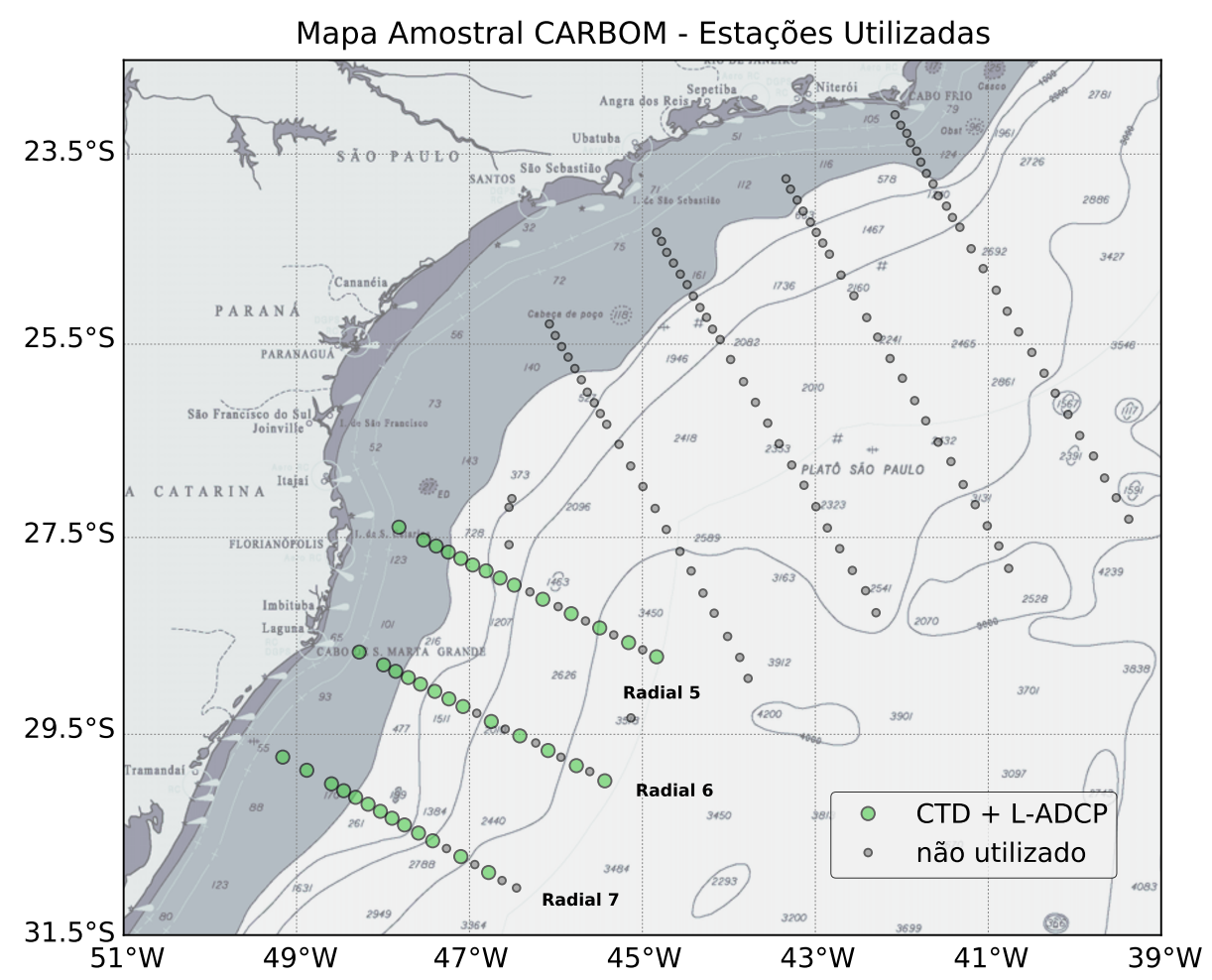

Figura 3.2: Localização das estações hidrográficas coletadas pelo N/Oc. Alpha Crucis (IOUSP) no âmbito do Projeto CARBOM. Neste trabalho utilizamos dados de CTD, L-ADCP e ADCP de casco das três radiais mais ao sul (na direção Sul-Norte, designadas como Radial 7, 6 e 5). Esse conjunto de dados foi coletado entre outubro de 2013 e novembro de 2013. 


\subsubsection{Conjunto EAOS}

O Projeto Estudos Ambientais em Áreas Oceânicas e Costeiras na Região Sul do País (EAOS) estabelecido em parceria entre PETROBRAS e Universidade Federal do Rio Grande (FURG) é composto de dados hidrográficos coletados por CTD em três campanhas com aproximadamente 52 estações em cada uma delas (esse conjunto de dados possui dados correntográficos de fundeio, porém não foram utilizados). Neste trabalho, utilizamos os dados da primeira campanha denominada por HBS1 (Figura 3.3). Essa campanha foi realizada em novembro de 1995.

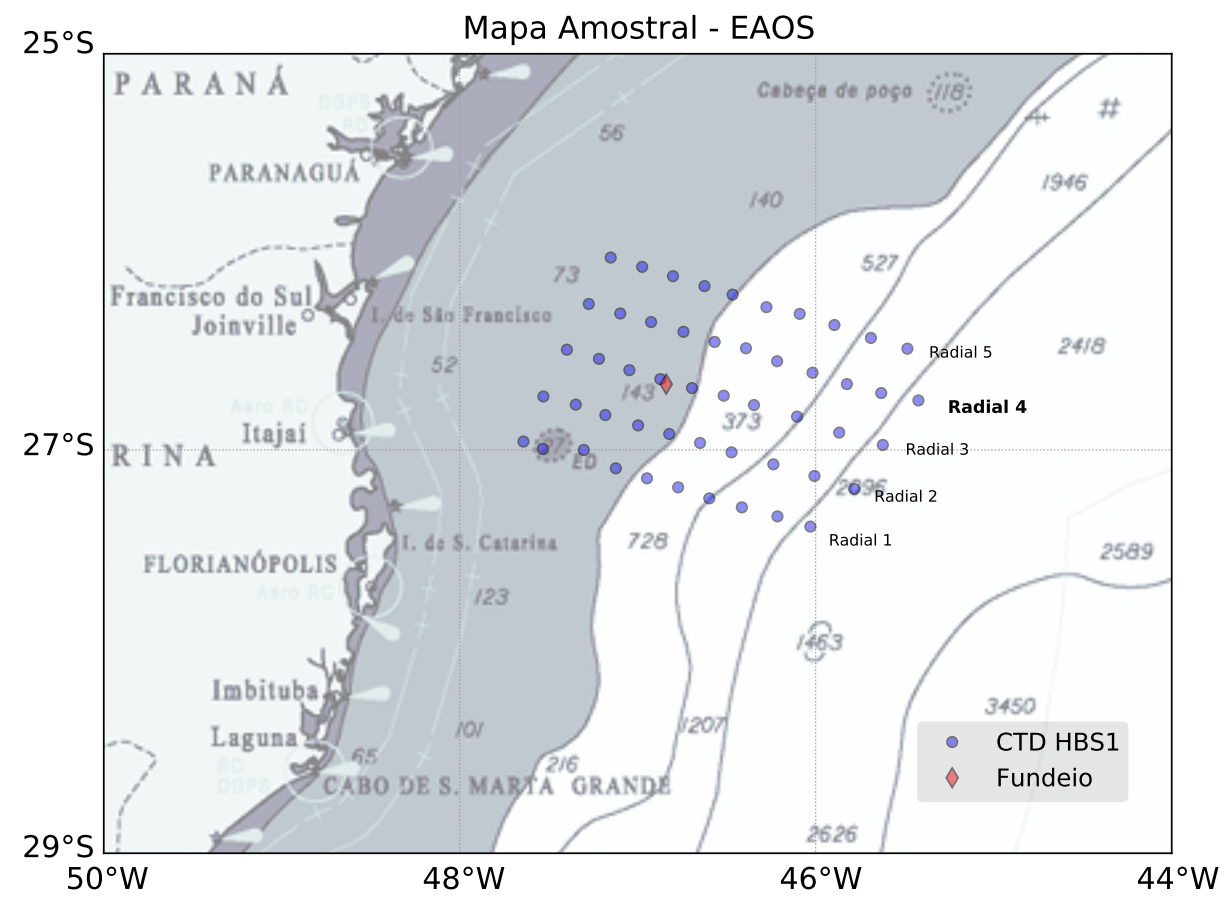

Figura 3.3: Localização das estações hidrográficas das campanhas HBS1 coletada em novembro de 1995 no âmbito do Projeto EAOS. Neste trabalho, utilizamos somente os dados de CTD.

\subsection{Aspectos Metodológicos}

\subsubsection{Processamento de Dados de CTD}

Durante a aquisição dos dados podem ocorrer falhas de comunicação entre instrumento (sensores) e unidade de controle do CTD (armazenamento dos dados), fato que 
introduz erros e ruídos aos dados. Além do que, os sensores podem sofrer desvios ao longo de uma campanha que prejudicam a qualidade dos dados. Esses ruídos podem ser sistemáticos ou aleatórios, sendo corrigíveis somente os desvios sistemáticos.

Após a verificação da qualidade dos dados, iniciamos seu tratamento básico. Esse procedimento consiste na suavização dos perfis hidrográficos, aplicação de média em caixas ("binagem" ou bin averaging) e, por último, o alisamento por janela móvel. O objetivo desse procedimento é obter perfis suavizados e contínuos das propriedades em intervalos regulares de pressão (ou profundidade). Essas etapas são descritas a seguir:

- Remoção de picos (spikes) - Processo de remoção de dados espúrios através de sua comparação com o desvio padrão dos valores que o envolve em um trecho de $10 \mathrm{~m}$. Dessa forma, se o valor for maior ou menor que 3 vezes o desvio padrão ele é substituído pelo valor correspondente ao da profundidade imediatamente acima.

- Média em caixas (bin averaging) - Processo de promediação dos dados dentro de um intervalo de profundidade pré-determinado para o equi-espaçamento vertical dos perfis. Uma vez que a frequência amostral do equipamento é constante, ao contrário da velocidade de perfilagem, os dados são coletados heterogeneamente. Foi estabelecido um intervalo (tamanho da caixa) de pressão de 1 dbar, no qual se atribui o valor médio dos valores dentro da caixa estabelecida.

- Alisamento por Janela Móvel - Procedimento de suavização do perfil vertical, com a finalidade de se estabelecer a continuidade do perfil para que se possa calcular sua primeira e segunda derivadas. Foi aplicado uma janela móvel do tipo Hanning nos perfis de temperatura e salinidade. Esse tipo de janela privilegia a medida central, onde o peso atribuído à observação na profundidade de interesse é maior que o atribuído às observações nas profundidades que a envolve. Esse tipo de janela se assemelha a uma distribuição gaussiana, dessa forma, o número de pontos da janela (intervalos de profundidade) deve ser ajustada em função da profundidade para que o gradiente vertical não seja alterado, sendo somente suavizado. 


\subsubsection{Processamento de Dados de ADCP}

O ADCP faz medidas de velocidades através do fenômeno do efeito Doppler. O equipamento instalado no casco do navio emite feixes sonoros, sendo esses feixes refletidos pelas partículas em suspensão na coluna de água (ou pelo fundo topográfico em regiões mais rasas) e retornam ao receptor de sinal numa frequência diferente da inicial. Pela diferença de frequência, é possível inferir a velocidade da água em termos de direção e intensidade, após a subtração da velocidade do navio.

Segundo Firing (1991), a velocidade do navio pode ser avaliada de duas maneiras. A primeira consiste no rastreamento do fundo (referencial fixo) quando em águas rasas, permitindo calcular a velocidade do navio. A segunda infere-se a velocidade por meio das posições geográficas simultâneas às medições de velocidade do instrumento, quando em águas profundas. A partir do conhecimento do tempo entre cada par de pontos de navegação é possível estimar o módulo e direção do vetor velocidade do navio. Por último, eliminam-se as medidas consideradas estaticamente não robustas, ou seja, os dados com qualidade inferior (devido às condições de mar). Comumente, a qualidade dos dados é diagnosticada pelo parâmetro percent good, que consiste em uma correlação entre os transdutores (emissores e receptores) do ADCP. Assim, os dados com correlação inferior à 50\% são eliminados do conjunto, pois em condições de mar ruim ocorre divergência nos dados de velocidade medidos pelos transdutores.

\subsubsection{Processamento de Dados de L-ADCP}

O sinal observado pelo L-ADCP consiste em uma velocidade composta por três componentes:

$$
U_{o b s}=U_{\text {ins }}+U_{\text {oce }}+U_{\text {noi }}
$$

onde $U_{o b s}$ é a velocidade total observada, $U_{i n s}$ é a velocidade da Rosette com os equipamentos, $U_{\text {oce }}$ é a velocidade do oceano e $U_{n o i}$ é a velocidade espúria. O processamento dos dados de L-ADCP $\left(U_{o b s}\right)$ consiste em estimar $U_{i n s}$ e $U_{n o i}$. O software do equipamento resolve a solução inversa do modelo de equações lineares proposta por Visbeck (2002), 
assumindo que a Equação 3.1 pode ser descrita na forma de equações lineares do tipo

$$
d=G m+n,
$$

onde $d$ representa a velocidade total observada $\left(U_{o b s}\right)$ em diferentes profundidades, $n$ é o ruído devido às imperfeições das medidas e das estimativas de velocidades do oceano, o qual é dado por $G m$. Dessa forma, a velocidade absoluta do oceano $\left(U_{\text {oce }}\right)$ e as velocidades do equipamento $\left(U_{\text {ins }}\right)$ são combinadas na variável $m$. Essas equações lineares são resolvidas pelo método dos mínimos quadrados de forma a se minimizar as diferenças entre $d$ e $G m$.

Ao longo da aquisição dos dados, durante a descida e subida do equipamento, o sistema CTD-Rosette está sujeito à deriva do navio, inclinação e rotação do sistema. Por essa razão, outros tipos de informações podem ser adicionados para que a estimativa da velocidade desse sistema $\left(U_{i n s}\right)$ seja feita com maior precisão. Com essa finalidade, os dados de velocidades observadas por ADCP de caso foram agregadas ao processamento dos dados de L-ADCP para se restringir a solução do problema inverso. Essa metodologia reduz os erros em função das restrições impostas às velocidades da camada superior, assim como a percepção do fundo (bottom tracking), já que forçam o perfil médio de velocidade a concordar com dados mais acurados (Visbeck, 2002; Schott et al., 2005).

\subsubsection{Método Dinâmico: Cálculo da Velocidade Geostrófica}

Neste trabalho, o campo de velocidade geostrófica obtido é baseado no método dinâmico clássico. Esse método consiste em obter velocidades geostróficas absolutas (relativas a determinado nível de referência) através da estimativa do gradiente horizontal de pressão, relativo a um nível de referência, assumindo que a velocidade absoluta da corrente é nula em algum nível de profundidade (nível de movimento nulo).

Seguindo Talley et al. (2011), a partir da relação do vento térmico (sob a aproximação de Boussinesq e a aproximação do plano $f$ ), dada por

$$
\frac{\partial v}{\partial z}=-\frac{g}{\rho_{0} f_{0}} \frac{\partial \rho}{\partial x}
$$




$$
\frac{\partial u}{\partial z}=\frac{g}{\rho_{0} f_{0}} \frac{\partial \rho}{\partial y}
$$

podemos obter uma relação entre a velocidade geostrófica $\left(\overrightarrow{\mathbf{v}}_{g}=(u, v)\right)$ e a anomalia do geopotencial $(\Delta \Phi)$, cujo gradiente horizontal representa o gradiente horizontal de pressão (anomalia do gepotencial ou altura dinâmica são proxies do mapa horizontal de pressão, por essa razão, são referidas como coordenadas isobáricas), dada por

$$
\Delta \Phi=-\int \delta \mathrm{d} p
$$

onde $\delta$ é a anomalia do volume específico, definida como

$$
\delta=\alpha(S, T, p)-\alpha(35,0, p)
$$

onde $\alpha(S, T, p)$ é o volume específico in situ e $\alpha(35,0, p)$ é o volume específico da água com salinidade de 35 ups e temperatura de $0^{\circ} \mathrm{C}$ na pressão $p$.

A relação entre a velocidade geostrófica e a anomalia do geopotencial é obtida ao integrarmos verticalmente (3.3), (3.4), (3.5) e (3.6) do nível de pressão $p$ ao nível isobárico de referência $p_{r}$ (adotado como o nível de movimento nulo), tal que

$$
\begin{gathered}
v-y_{r}^{\pi^{0}}=\frac{1}{f_{0}} \frac{\partial \Delta \Phi}{\partial x} \\
u-y_{r}^{{ }^{0}}=-\frac{1}{f_{0}} \frac{\partial \Delta \Phi}{\partial y},
\end{gathered}
$$

onde respectivamente, $u$ e $v$ são as componentes zonal e meridional no nível $p$ qualquer, $u_{r}$ e $v_{r}$ são as velocidades no nível de movimento nulo conhecido, $f_{0}$ é o parâmetro de Coriolis e $\Delta \Phi$ é a anomalia do geopotencial.

A partir do balanço geostrófico (sob a aproximação do plano $f$ e a aproximação de Boussinesq), dada por

$$
v=\frac{1}{\rho_{0} f_{0}} \frac{\partial p}{\partial x}
$$




$$
u=-\frac{1}{\rho_{0} f_{0}} \frac{\partial p}{\partial y}
$$

pode-se verificar que o campo de velocidade geostrófico é horizontal e aproximadamente não-divergente $\left(\nabla_{H} \cdot \overrightarrow{\mathbf{v}}_{g} \approx 0\right)$, tal que

$$
\frac{\partial u}{\partial x}+\frac{\partial v}{\partial y}=-\frac{\partial}{\partial x}\left(\frac{1}{\rho_{0} f_{0}} \frac{\partial p}{\partial y}\right)+\frac{\partial}{\partial y}\left(\frac{1}{\rho_{0} f_{0}} \frac{\partial p}{\partial x}\right)=0
$$

o que nos permite definir a velocidade geostrófica em termos da função de corrente $(\psi)$, que satisfaz (3.11), como

$$
u=-\frac{\partial \psi}{\partial y} \quad \text { e } \quad v=\frac{\partial \psi}{\partial x}
$$

Dessa maneira, podemos estabelecer uma relação entre a função de corrente e a anomalia do geopotencial utilizando (3.12) em (3.7) e (3.8), tal como

$$
\psi_{\text {rel }}=\frac{\Delta \Phi}{f_{0}}
$$

onde $\psi_{\text {rel }}$ é a função de corrente relativa ao nível isobárico de referência.

Portanto, podemos inferir as velocidades geostróficas relativas ao nível de movimento nulo a partir da estimativa do mapa horizontal da anomalia do geopotencial. Para mapear as velocidades geostróficas, adotamos o nível de movimento nulo baseado critério termodinâmico de distribuição de massas de água.

Ao sul da Bifurcação de Santos, a CB ocupa o oceano superior e transporta AT, ACAS e AIA (assim como a possibilidade de ACS) e abaixo dela se encontra a CCP, composta por APAN. Por essa razão, o nível de referência ideal, baseado no critério termodinâmico de massas de água, seria adotar o valor que delimita a interface entre AIA e APAN ou entre AIA e ACS. Mémery et al. (2000) estimaram valores isopicnais das interfaces (densidade potencial) entre essas massas de água no oceano Atlântico Sudoeste. Aqui, os valores etimados correspondem à anomalia da densiadde potencial $\left(\sigma_{0}\right)$ referenciada em relação à superfície (Tabela 3.1).

A partir dos valores isopicnais das interfaces estimados por Mémery et al. (2000), 
procuramos a isopicnal $\sigma_{0}=27,38 \mathrm{~kg} \mathrm{~m}^{-3}$, que demarca a interface entre AIA e ACS, no entanto, devido à limitação vertical dos dados foi adotado como o nível de referência a profundidade de 1200 m (a seguir na Seção 3.3.3).

Tabela 3.1: Valores isopicnais das interfaces (anomalia da densidade potencial, $\sigma_{0}$ ), entre Massas de Água no Oceano Atlântico Sudoeste, estimados por Mémery et al. (2000).

\begin{tabular}{cc}
\hline Interface & $\sigma_{0}\left[\mathbf{k g ~ \mathbf { ~ m } ^ { - 3 } ]}\right.$ \\
\hline AT-ACAS & 25,60 \\
ACAS-AIA & 26,90 \\
AIA-ACS & 27,38 \\
ACS-APAN & 27,53 \\
\hline
\end{tabular}

\subsection{Resultados e Discussão}

\subsubsection{Resultados do Conjunto MIRAI}

A seção vertical de velocidade observada por L-ADCP do MIRAI está centrada em $\sim 28^{\circ} \mathrm{S}$ e apresenta uma estrutura vertical coerente em forma de jato que atinge aproximadamente $2800 \mathrm{~m}$ de profundidade (Figura 3.4). Em relação à composição de massas de água, conforme os valores isopicnais das interfaces de massas de água estimados por Mémery et al. (2000) (Tabela 3.1), a AT é encontrada até aproximadamente $150 \mathrm{~m}$, ACAS entre 150 e 500 m, AIA entre 500 e 1200 m, ACS entre 1200 e 1400 m, e APAN abaixo de $1400 \mathrm{~m}$.

Em relação à composição de fluxos, esse escoamento é composto na camada superior pela $\mathrm{CB}$, cujo núcleo atinge velocidades maiores que $0,7 \mathrm{~m} \mathrm{~s}^{-1}$ em superfície. Essa corrente, que ao norte da BiSan ocupa originalmente o nível superficial e picnoclínico (domínio vertical da AT e ACAS, respectivamente), transporta AIA além dessas massas de água anteriores, o que indica espessamento vertical da corrente devido ao aporte em nível intermediário do ramo sul da bifurcação. Considerando o escoamento da CB composto por essas massas de água e o cisalhamento vertical associado até aproximadamente 750 
m (entre o máximo de velocidade em superfície e o submáximo intermediário), a CB transporta cerca de $17,89 \mathrm{~Sv}$.

O padrão de escoamento acima de $1500 \mathrm{~m}$, apresenta um submáximo de velocidade (maior que $0,25 \mathrm{~m} \mathrm{~s}^{-1}$ ) entre 1000 e $1500 \mathrm{~m}$, o que sugere estar associado ao ramo sul da BiCSE intermediária e que esse fluxo não se apresenta fundido à CB. Assim sendo, essa seção se encontra ao sul da bifurcação e esse fato corrobora as evidências apresentadas por Legeais et al. (2013) de que nessa latitude o escoamento associado à bifurcação já estaria organizado junto ao contorno oeste. Em relação à composição de massas de água, o escoamento associado ao ramo sul BiSan transporta AIA e ACS. Considerando a estrutura associada ao submáximo entre aproximadamente 750 e 1750 m, esse fluxo transporta cerca de $10,62 \mathrm{~Sv}$.

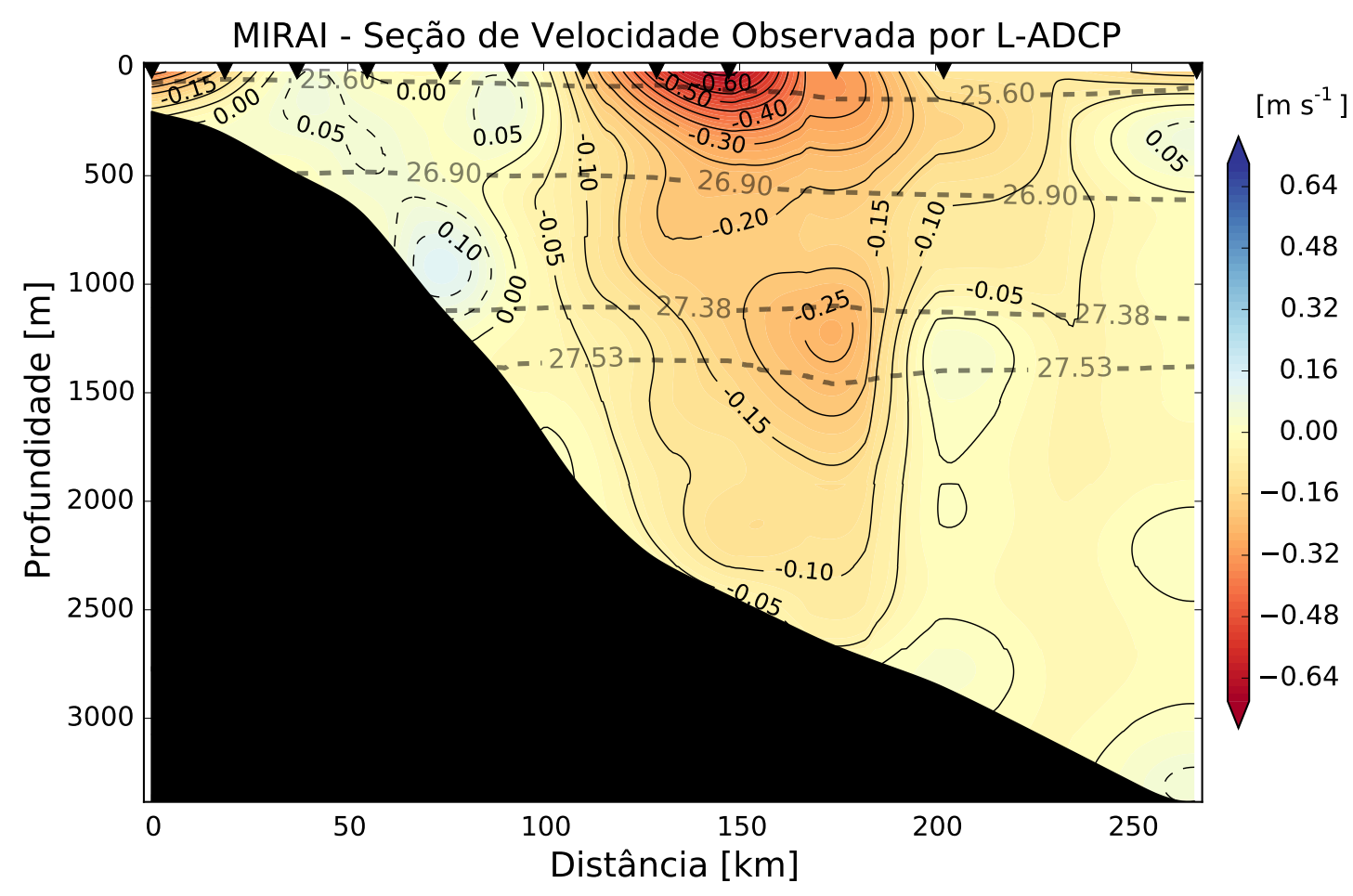

Figura 3.4: Seção de velocidade observada por L-ADCP do conjunto de dados MIRAI. Escala de cores e contornos com traço mais fino denotando velocidades e contornos com traço mais grosso denotando as interfaces de Massas de Água estimadas por Mémery et al. (2000).

Abaixo dos $1500 \mathrm{~m}$, o escoamento se estende até o fundo e é possivelmente composto por uma porção da CCP, cujo fluxo está associado ao transporte de APAN. O padrão apresentado até aqui é semelhante ao encontrado (padrão organizado da superfície até $3000 \mathrm{~m}$ ) por Zemba (1991) na latitude de $36^{\circ} \mathrm{S}$. O padrão de escoamento na Figura 3.4 
é condizente com aquele que foi apresentado com base nos fundeios WOCE descritos por Müller et al. (1998) e cujos dados utilizaremos de forma distinta no Capítulo 4.

Na porção mais costeira da seção, há um escoamento com sentido oposto (para norte) ao da CB e que possui extensão vertical semelhante (aproximadamente, até $1500 \mathrm{~m}$ ) ao padrão de escoamento observado composto entre CB e ramo sul da BiSan. Isso sugere que o padrão observado representa um cenário meandrante da $\mathrm{CB}$ com a captura de um meandro frontal ciclônico, que recircula AT, ACAS, AIA e ACS. Esse padrão meandrante com estrutura vertical atingindo os $1500 \mathrm{~m}$ difere dos meandros observados ao norte da BiCSE intermediária. Ao largo do CST, a atividade vortical é essencialmente confinada aos limites da ACAS (da Silveira et al., 2008; Rocha et al., 2014). A Figura 3.4 pode representar a primeira caracterização de um meandro ciclônico ao sul da BiCSE intermediária e com semelhanças àquelas detectadas na análise das imagens satelitárias do Capítulo 2.

\subsubsection{Resultados do Conjunto CARBOM}

As três Radiais do conjunto CARBOM permitem que avaliemos três seções em torno de um dos meandros da CB. Conforme ilustra a Figura 3.6 (imagem de TSM do dia 18 de novembro de 2013 e Radiais 5, 6 e 7 do CARBOM), é evidente que as Radiais 5 e 6 capturam as partes traseira e frontal do cavado da onda. A Radial 7 captura a região que parece ser de uma crista atrofiada. O padrão de escoamento observado, descrito a seguir, foi interpretado no esquema proposto na Figura 3.5 e baseado na imagem satelitária da Figura 3.6.

A seção de velocidade observada por L-ADCP da radial 5 do conjunto CARBOM (Figura 3.7) mostra a CB fluindo para sul como um jato em subsuperfície com velocidades maiores que $0,22 \mathrm{~m} \mathrm{~s}^{-1}$, cujo núcleo está centrado em $200 \mathrm{~m}$ de profundidade entre 120 e $150 \mathrm{~km}$ do início da radial. Essa estrutura apresenta características barotrópicas (cuja estrutura se estende na coluna de água). Nas adjacências da $\mathrm{CB}$, nota-se correntes para norte com intensidades de aproximadamente $0,1 \mathrm{~m} \mathrm{~s}^{-1}$ entre 100 e $500 \mathrm{~m}$. 


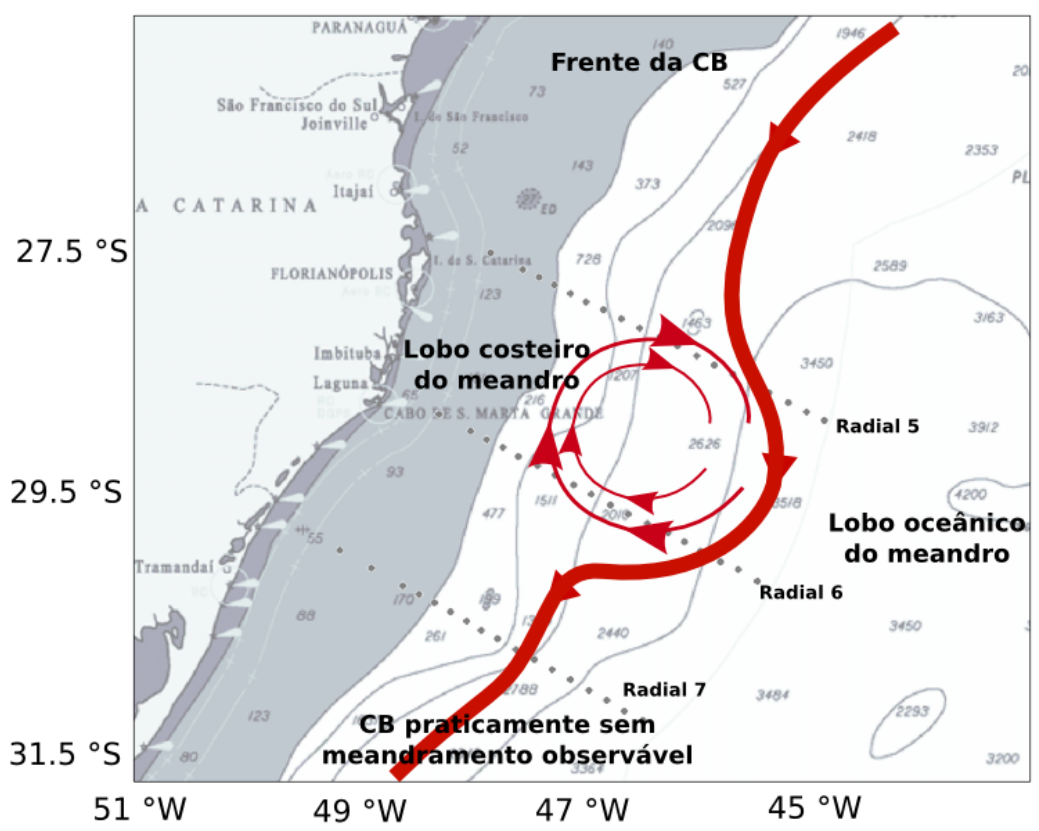

Figura 3.5: Esquema proposto para interpretação das seções de velocidades observadas do conjunto CARBOM. Presença de meandro ciclônico ao largo do Cabo de Santa Marta. As Radiais 5 e 6 capturam as partes traseira e frontal do cavado da onda. A Radial 7 captura região sem meandramento observável.

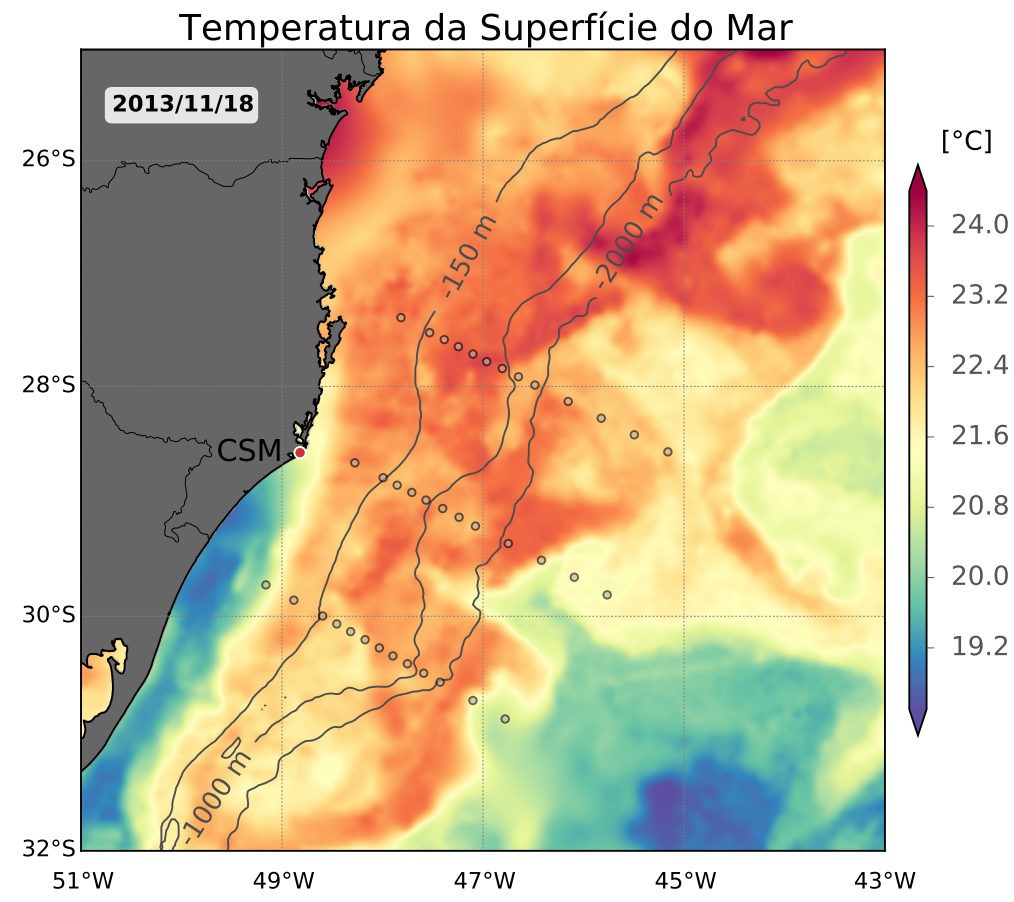

Figura 3.6: Imagem de Temperatura da Superfície do Mar (TSM) do dia 18 de novembro de 2013 com as estações hidrográficas (círculos em cinza) das Radias 5, 6 e 7 do conjunto CARBOM sobrepostas. A Radial 5 foi realizada nos dias 18 e 19 de novembro de 2013, a Radial 6, nos dias 20 e 21, e a Radial 7, nos dias 22 e 23. Nesse intervalo a imagem do dia 18 é a que não apresenta cobertura por nuvens. 


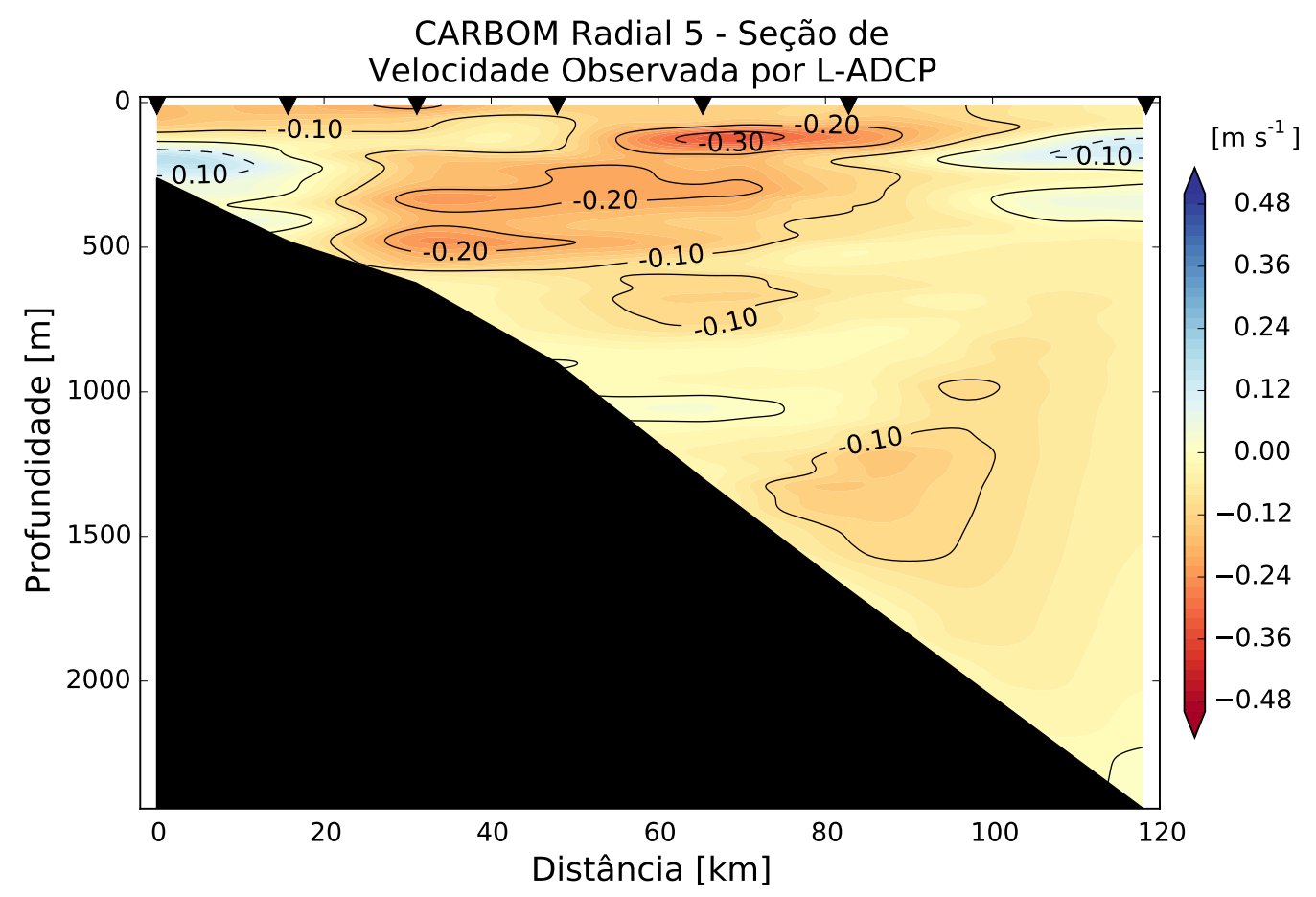

Figura 3.7: Seção de velocidade observada por L-ADCP da Radial 5 do conjunto CARBOM. Nota-se que a CB apresenta uma estrutura mais barotrópica.

A seção vertical de velocidade observada da radial 6 (Figura 3.8) apresenta um meandro ciclônico frontal associado ao meandramento da CB. Esta se localizada a partir de 115 km de distância do início da radial se estendendo até seu final, apresenta um núcleo em superfície com velocidades maiores que $0,34 \mathrm{~m} \mathrm{~s}^{-1}$ que cisalha verticalmente até cerca de $500 \mathrm{~m}$. Abaixo dela, ocorre um submáximo de velocidades maiores que $0,23 \mathrm{~m} \mathrm{~s}^{-1}$ entre 600 e 1000 m de profundidade. Esse submáximo está associado ao ramo sul da BiSan em nível intermediário. Nesta seção podemos observar a maior barotropicidade da $\mathrm{CB}$, relativamente ao norte da BiSan, conforme sua estrutura colunar até aproximadamente 1200 m. O fluxo para norte na porção costeira, apresenta estrutura vertical similar ao fluxo composto pela CB e ramo sul da bifurcação. Essa estrutura apresenta um núcleo em superfície e um núcleo em subsuperfície entre 600 e 800 m.

Nossa interpretação das seções das Radiais 5 e 6 é que se tratam, de fato, de porções do meandro ciclônico exibido na Figura 3.6. Na Radial 5, a estrutura parece pressionada contra a parte superior do talude. Já a Radial 6 ocupa porções mais centrais do meandro. 


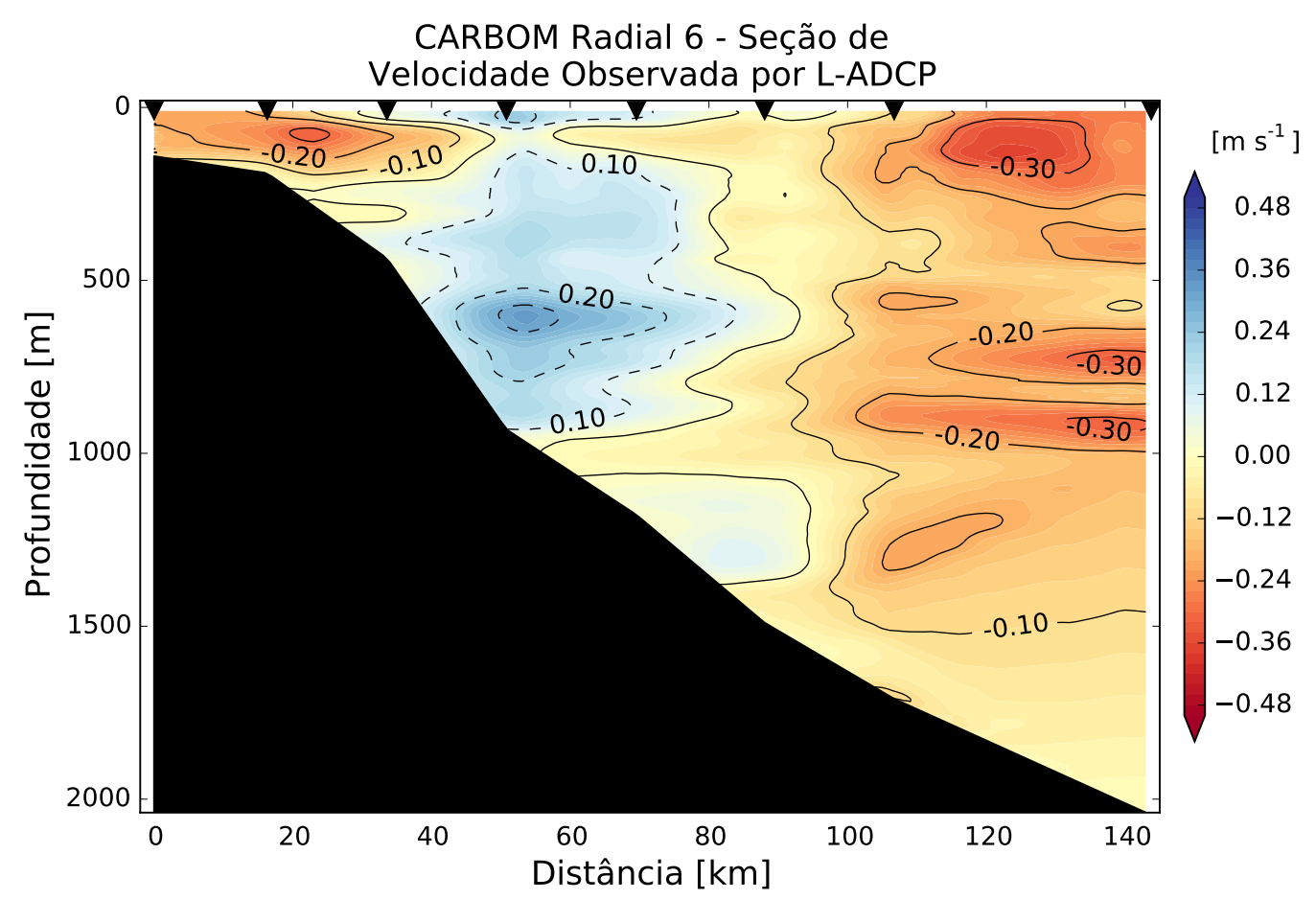

Figura 3.8: Seção de velocidade observada por L-ADCP da Radial 6 do conjunto CARBOM. Evidência de meandro ciclônico frontal.

A seção de velocidades observadas da Radial 7 (Figura 3.9) apresenta a CB junto à quebra da plataforma continental com intensidade máxima de $0,5 \mathrm{~m} \mathrm{~s}^{-1}$ e confinada nos primeiros $500 \mathrm{~m}$. Associamos esse confinamento da $\mathrm{CB}$ à presença do Cone do Rio Grande. Nota-se um escoamento predominantemente barotrópico para sul com baixa intensidade, até aproximadamente $160 \mathrm{~km}$ da costa, onde aparece um contra-fluxo, confinado à superfície, fluindo para norte.

Sintetizamos aqui que os resultados do conjunto CARBOM expandem os obtidos na seção anterior. O meandro ciclônico, como nos resultados da Radial do MIRAI, tem uma estrutura vertical que ocupa até porções intermediárias e se opõe àqueles encontrados ao norte da BiCSE intermediária. 


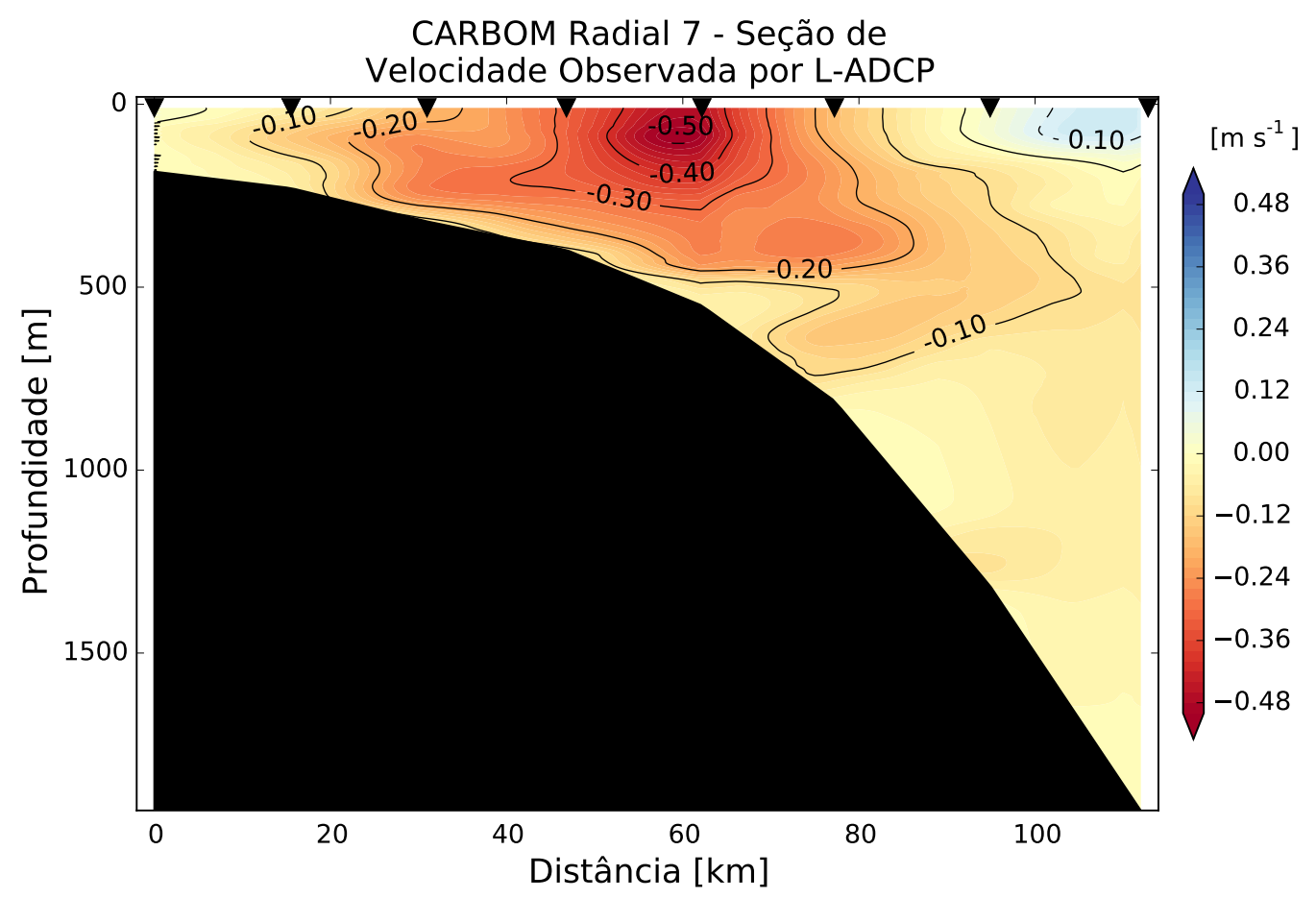

Figura 3.9: Seção de velocidade observada por L-ADCP da Radial 7 do conjunto CARBOM. Confinamento da CB associado à presença do Cone do Rio Grande.

\subsubsection{Resultados do Conjunto EAOS}

O conjunto EAOS apresenta uma resolução adequada em sua malha amostral para permitir o mapeamento horizontal das estruturas de mesoescala da $\mathrm{CB}$, o que os conjuntos anteriormente analisados não permitiram.

Por ser um conjunto de observações mais antigo, não há dados de velocidades observadas; apenas dados de perfilagens por CTD foram realizadas. Recorremos ao Método Dinâmico, em sua aplicação clássica, para o mapeamento dos vórtices e meandros geostróficamente. Obtemos aqui, a função de corrente geostrófica $(\psi)$ relativa a um nível de referência conhecido. Devido à limitação vertical na coleta de dados (coletados até aproximadamente $1000 \mathrm{~m}$ ), o dados foram extrapolados verticalmente (utilizando um ajuste polinomial), até a profundidade de $1200 \mathrm{~m}$ para a duas últimas estações de cada radial.

Ao sul da BiSan, a CB transporta AT, ACAS e AIA, e possivelmente ACS. Por essa razão, procuramos adotar um nível de referência baseado no critério termodinâmico conforme a distribuição de massas de água. Com essa finalidade, procuramos adotar o 
valor da isopicnal da interface entre a AIA e ACS estimado por Mémery et al. (2000) $\left(\sigma_{0}=\right.$ $27,38 \mathrm{~kg} \mathrm{~m}^{-3}$ ) através dos perfis extrapolados. No entanto, em razão da impossibilidade de se encontrar esse nível através da extrapolação, foi adotado o nível de 1200 m como nível de referência para o mapeamento da função de corrente geostrófica.

A partir da escolha do nível de referência, empregamos o método de Reid \& Mantyla (1978) para estimar as velocidades geostróficas nas estações com profundidade menor que o nível de referência. Esse método consiste em extrapolar a anomalia do geopotencial de acordo com seu gradiente utilizando um fator de decaimento em direção à região mais rasa. Utilizamos um fator constante de 0,5 , o que significa em uma redução da inclinação da isopicnal extrapolada à metade da inclinação da isopicnal adjacente (oceânica).

Por fim, o mapeamento da função de corrente foi realizado por meio do método de Análise Objetiva descrito em Bretherton et al. (1976). Trata-se de um método estatístico baseado no ajuste por mínimos-quadrados, cujas funções-peso são aproximadas por uma função gaussiana, que considera a correlação entre as observações minimizando a variância do erro entre o valor estimado e o valor medido (Carter \& Robinson, 1987). Neste trabalho, assumimos uma função de correlação espacialmente isotrópica (Silveira et al., 2000b) tal que

$$
C(r)=\left(1-\varepsilon^{2}\right) e^{-r^{2} / L_{c}^{2}},
$$

onde $r=\sqrt{x^{2}+y^{2}}$ é a distância radial entre os pontos de grade, $\varepsilon$ é a variância do erro das medidas e $L_{c}$ é o comprimento de correlação. Aqui, utilizamos um comprimento de correlação $L_{c}=0,55$ e variância do erro $\varepsilon=0,05$. Além de ser utilizado como um interpolador, esse método funciona como um filtro dinâmico através da escolha dos comprimentos de onda. Além do mais, utilizamos como condição de contorno de escorregamento (free slip) para o mapeamento das velocidades geostróficas a isóbata de 150 $\mathrm{m}$, isto é, essa condição de contorno impõe que não há fluxo perpendicular ao contorno (somente tangente, de forma a auxiliar o fechamento das isolinhas próximas ao contorno). 


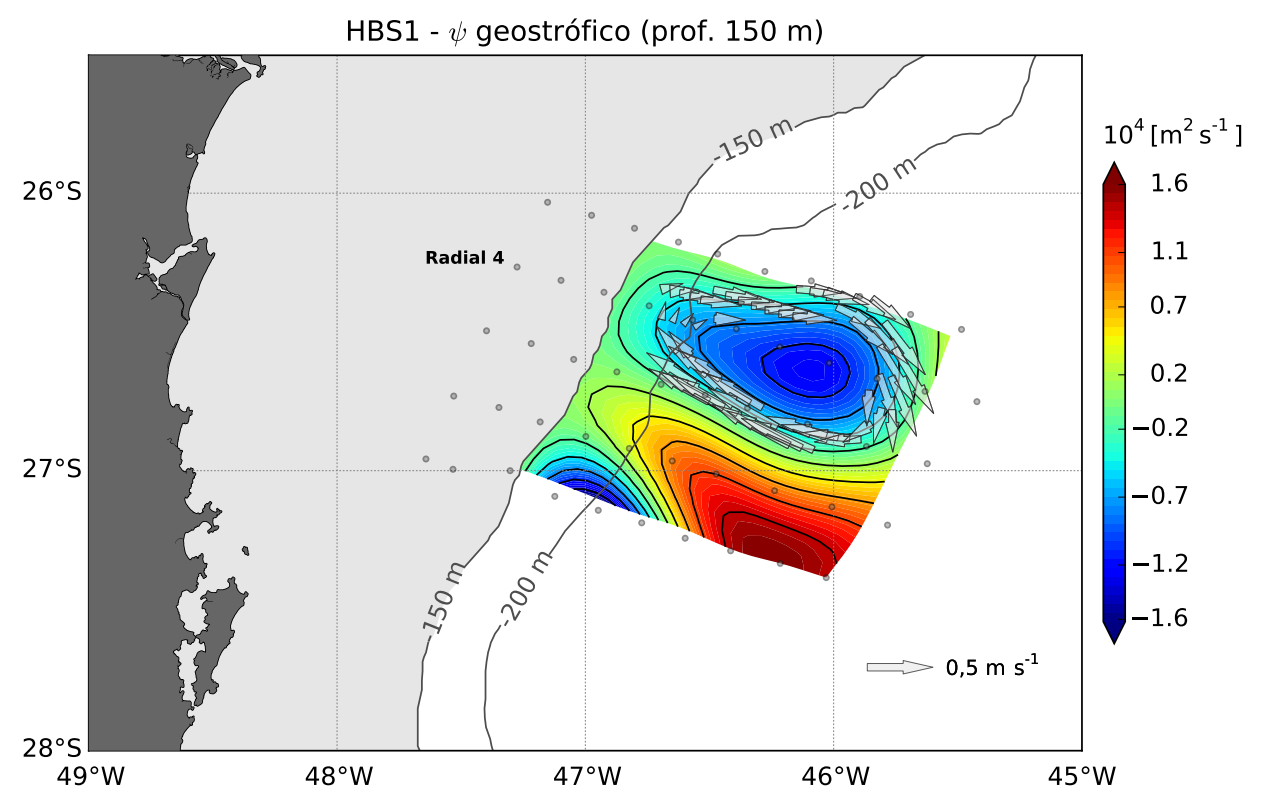

Figura 3.10: Mapa horizontal da função de corrente geostrófica $(\psi)$ em 150 m de profundidade da campanha HBS1 do conjunto de dados EAOS. Valores negativos representam circulação ciclônica e positivos, anticiclônica. Isóbata de $150 \mathrm{~m}$ utilizada como condição de contorno de Dirichlet. Círculos na cor cinza representam a posição das estações hidrográficas, distribuídas em 5 radiais numeradas em sequência crescente na direção Sul-Norte.

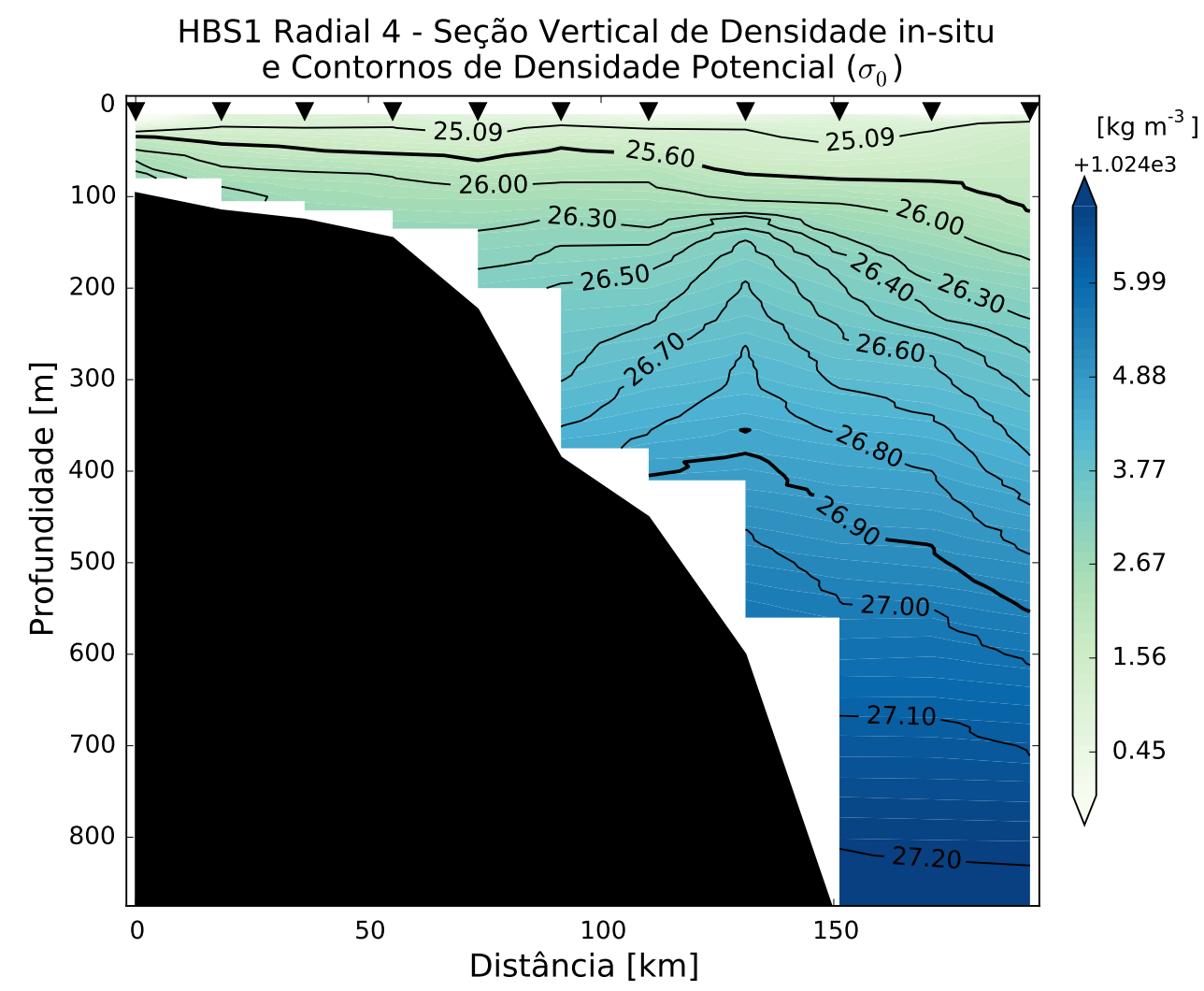

Figura 3.11: Seção vertical de densidade in-situ $\left[\mathrm{kg} \mathrm{m}^{-3}\right.$ ] da Radial 4, em escala de cores. Contornos de densidade potencial $\left(\sigma_{0}\left[\mathrm{~kg} \mathrm{~m}^{-3}\right]\right)$ sobrepostos à densidade in-situ. Triângulos invertidos na superfície indicam a posição das estações hidrográficas. 
Durante a campanha HBS1 foi capturado uma estrutura com circulação ciclônica fechada na porção norte do domínio da coleta dos dados (Figura 3.10). Essa estrutura está associada ao meandramento da CB e apresenta soerguimento das isopicnais em seu centro devido ao ajustamento geostrófico. Esse conjunto de dados possui uma malha amostral composta por 5 radiais e, conforme a distribuição destas na Figura 3.10, a Radial 4 (4 ${ }^{\text {a }}$ radial na direção Sul-Norte) está situada próxima ao centro dessa estrutura. Dessa forma, apresentamos o campo de densidade in-situ dessa radial (Figura 3.11), na qual podemos observar o soerguimento das isolinhas de densidade potencial (contornos na Figura 3.11) numa região próxima à $8^{\mathrm{a}}$ estação hidrográfica (na direção costa-oceano), entre aproximadamente 100 e $400 \mathrm{~m}$.

O soerguimento das isopicnais no centro dessa estrutura ciclônica, associado ao ajustamento geostrófico, estabelece um centro de baixa pressão oceanográfica. Esse fato por conseguinte, favorece o soerguimento recíproco das isotermas formando um vórtice de núcleo frio (domo frio representado na Figura 3.12). Devido ao decaimento monotônico da salinidade no Oceano Atlântico Ocidental até cerca de 900 m, em decorrência da presença de AIA (relativamente menos salina), as superfícies isohalinas soerguidas no centro da estrutura apresentam valores menores (região do contorno de $14,95^{\circ} \mathrm{C}$ ) que os valores de sua adjacência (Figuras 3.13). Portanto, os vórtices ciclônicos da CB além de serem centros de baixa temperatura são igualmente centros de baixa salinidade.

Avancemos na caracterização dinâmica destas estruturas vorticais. Segundo CushmanRoisin \& Beckers (2011), podemos avaliar a importância do efeito da estratificação na presença de rotação por meio do número de Burger ( $B u$; razão entre os números de Rossby e de Froude), tal que

$$
B u=\left(\frac{R o}{F r}\right)^{2}
$$

onde os número de Rossby ( $R o$ ) e de Froude $(F r)$ são definidos respectivamente como

$$
\begin{aligned}
& R o=\frac{U}{\Omega L} \\
& F r=\frac{U}{N H}
\end{aligned}
$$




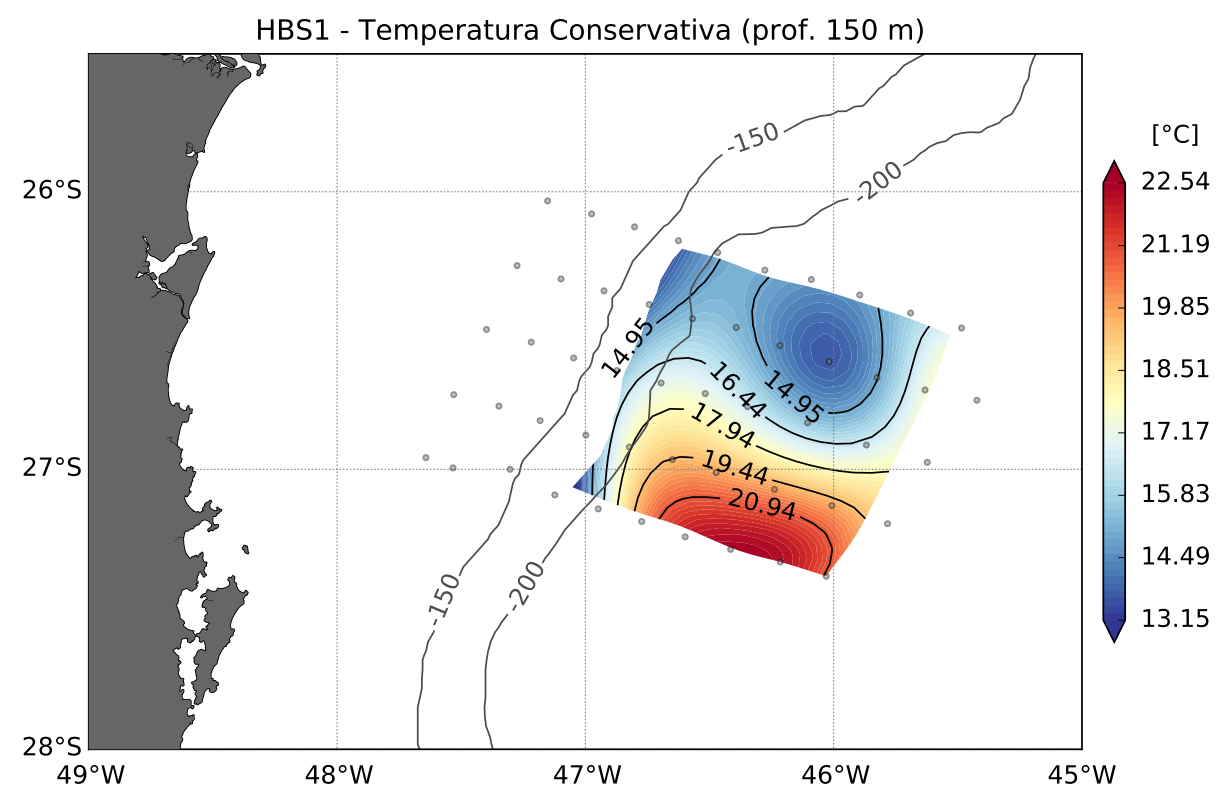

Figura 3.12: Mapa horizontal de temperatura conservativa em $150 \mathrm{~m}$ de profundidade da campanha HBS1 do conjunto de dados EAOS. Núcleo frio centrado em torno de $26,5^{\circ} \mathrm{S}$ devido à presença de vórtice ciclônico associado ao meandramento da CB.

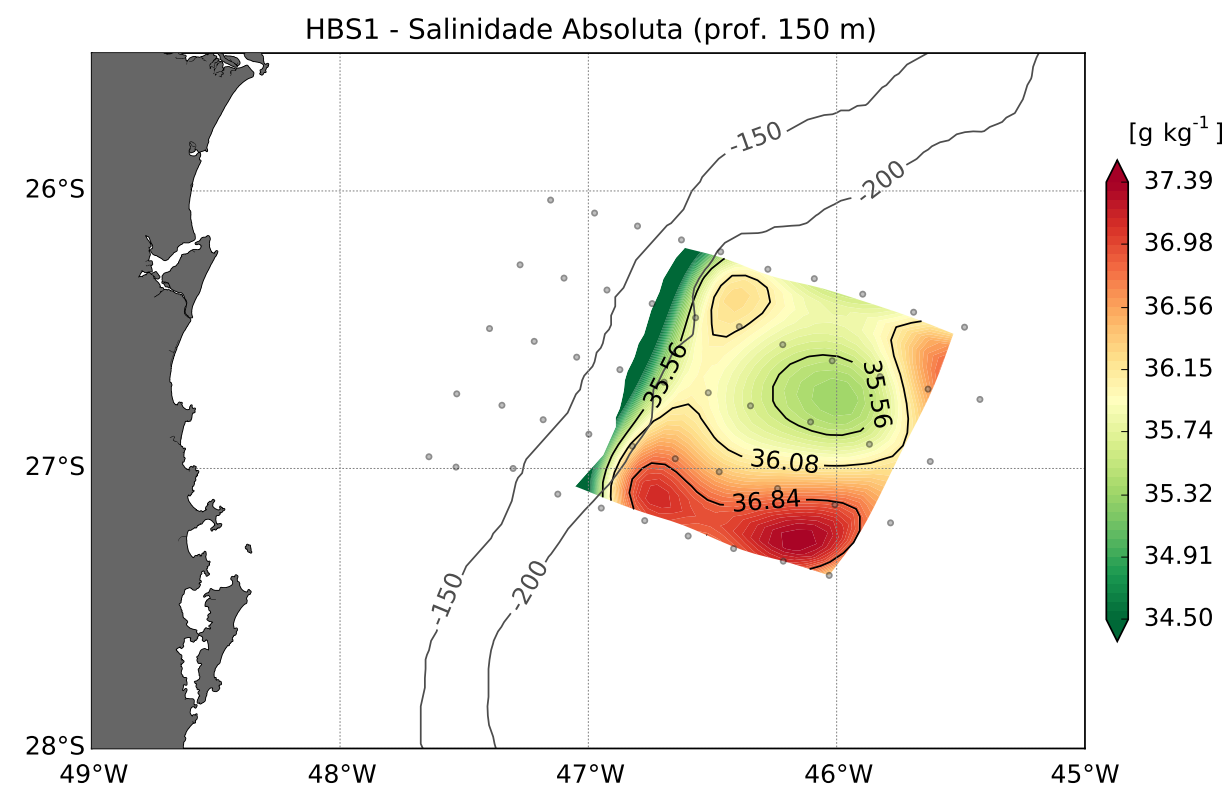

Figura 3.13: Mapa horizontal de salinidade absoluta em $150 \mathrm{~m}$ de profundidade da campanha HBS1 do conjunto de dados EAOS. Núcleo de baixa salinidade centrado em torno de $26,7^{\circ} \mathrm{S}$ devido à presença de vórtice ciclônico associado ao meandramento da CB. 
onde $U$ é a escala de velocidade horizontal, $\Omega$ é a rotação ambiente $\left(\Omega=2 f_{0} \sin \varphi\right.$, onde $f_{0}$ é o parâmetro de Coriolis e $\varphi$ é a latitude), $L$ é a escala espacial horizontal, $N$ é a frequência de estratificação (frequência de Brunt-Väisälä) e $H$ é a escala espacial vertical.

Para caracterizar o ciclone capturado em termos Ro (Equação 3.16), utilizamos como escala de velocidade horizontal o valor médio das velocidades, $U=0,35 \mathrm{~m} \mathrm{~s}^{-1}$, calculadas a partir do campo de de função de corrente (conforme a Equação 3.12) em $150 \mathrm{~m}$ delimitado pelo contorno de $\psi=-0,3510^{4} \mathrm{~m}^{2} \mathrm{~s}^{-1}$, como escala de comprimento horizontal $L \approx 78,3 \mathrm{~km}$ (valor do raio médio da feição - formato elíptico delimitado pelo contorno de $\psi$ anterior) e como escala de rotação ambiente $\left(\Omega \approx 6,5310^{-5} \mathrm{~s}^{-1}\right)$ o valor do parâmetro de Coriolis, calculado na latitude média da feição $\left(\sim 26,6^{\circ} S\right)$. Utilizando os valores característicos da feição de interesse, obtivemos o valor para o número de Rossby de $R o \approx 0,07$.

Para o cálculo do $\operatorname{Fr}$ (Equação 3.17), utilizamos como escala da frequência de estratificação o valor médio dessa propriedade na camada compreendida pela estrutura ciclônica de interesse. Esse valor médio $\left(N \approx 0,4510^{2} \mathrm{~s}^{-2}\right)$ foi obtido a partir do perfil médio da propriedade, utilizando as estações hidrográficas contidas nessa feição (Figura 3.14). Já a escala de comprimento vertical da feição $(H=290 \mathrm{~m})$, foi definida conforme o soerguimento das isopicnais $\left(\sigma_{0}\right)$ de densidade potencial na Figura 3.11. Através das inclinações de $\sigma_{0}$, definimos que a feição compreende a camada entre 110 e 400 m. Utilizando esses valores característicos, obtivemos o valor para o número de Froude de $F r \approx 0,28$.

Portanto, utilizando os valores $\operatorname{Ro}$ e $F r$ obtidos, estimamos o número de Burger dessa feição (conforme a Equação 3.15), obtendo o valor de $B u \approx 0,06$. Através do número de Burger podemos quantificar qualitativamente a importância relativa da estratificação quando comparada à rotação. Dessa forma, conforme o valor obtido temos que essa estrutura é mais influenciada pelo efeito da rotação do que pelo da estratificação. Além disso, o número de Burger pode ser escrito, ao comparar o termo de vorticidade relativa com o termo de vorticidade de estiramento, como

$$
B u=\frac{N^{2} H^{2}}{f_{0} L^{2}} .
$$

Conforme o valor encontrado para o número de Burger $(B u \ll 1)$, a partir de 
(3.18), caso em que a estratificação é fraca ou o comprimento horizontal é longo $(N H \ll$ $f_{0} L$ ), assim sendo o estiramento vertical é dominante e consequentemente, o escoamento é aproximadamente geostrófico (Cushman-Roisin \& Beckers, 2011).

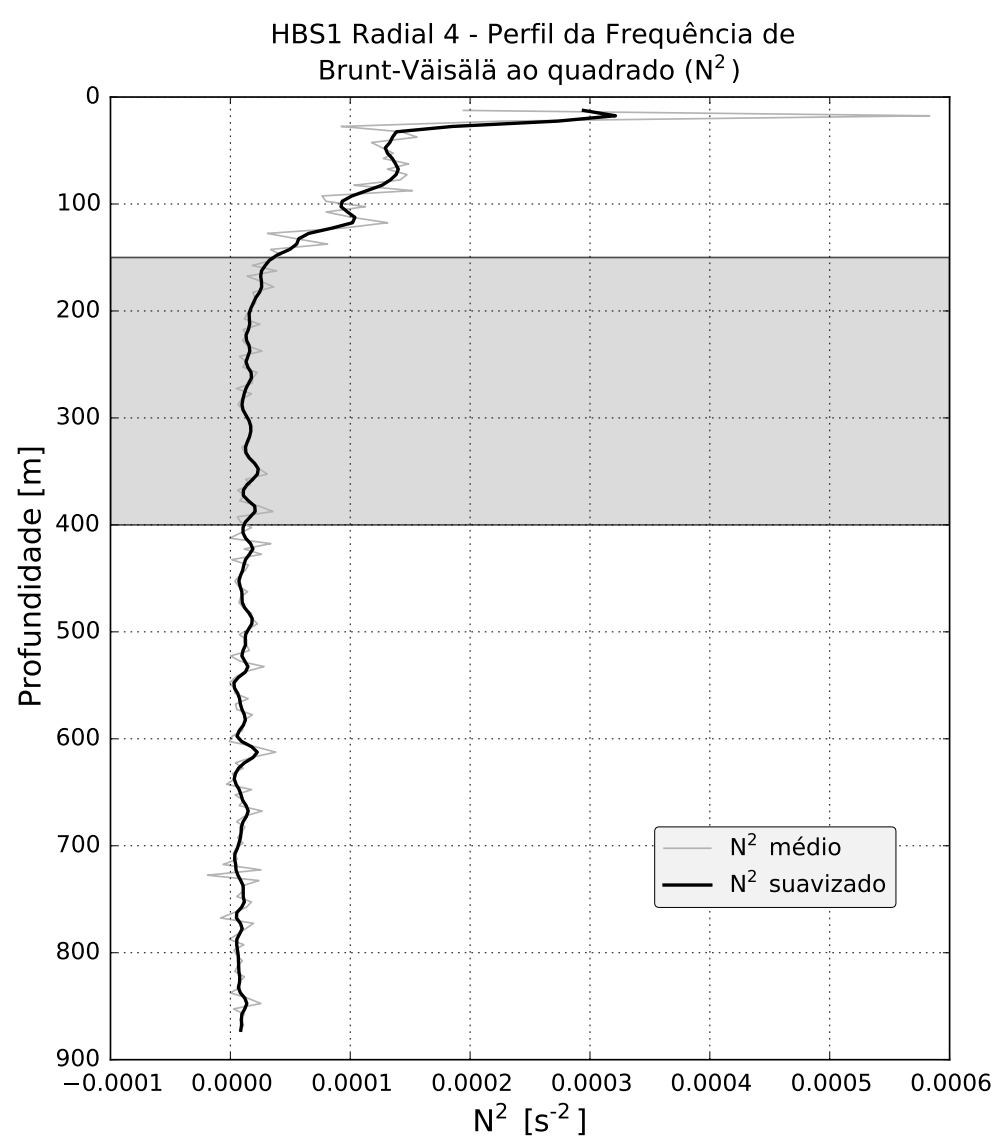

Figura 3.14: Perfil vertical médio da frequência de Brunt-Väisälä ao quadrado (frequência de estratificação ao quadrado) utilizando as estações hidrográficas da radial $\mathbf{4}$ compreendidas pelo ciclone. Área hachurada delimita a camada compreendida pela estrutura ciclônica, na qual foi calculado o valor característico dessa frequência. 


\section{Capítulo 4}

\section{Análise de Séries Temporais Correntográficas}

Neste capítulo, apresentaremos o conjunto de dados de velocidades observadas utilizado na análise da variabilidade da CB. Com o estudo da variabilidade pretendemos encontrar o período das ondas características associadas ao meandramento da CB assim como obter os respectivos modos de variabilidade. Com essa finalidade, apresentaremos os aspectos metodológicos da análise de EOFs bidimensionais e por fim os resultados obtidos.

\subsection{Conjunto de dados WOCE}

Neste trabalho, utilizamos os dados de velocidades observadas pela linha de fundeios do Projeto WOCE no Atlântico Sudoeste, tal qual descrito por Müller et al. (1998) e Hogg et al. (1999). Os fundeios foram lançados em uma linha quase-perpendicular à quebra da plataforma continental entre $28^{\circ} \mathrm{S}$ e $32^{\circ} \mathrm{S}$ (Figura 4.1). Esses dados fazem parte do programa Deep Basin Experiment (DBE), cujo propósito principal foi o de melhorar o conhecimento, tanto descritivo quanto dinâmico, a cerca da circulação profunda (no entanto, há instrumentos acima da termoclina) na região oeste do Oceano Atlântico Sul desde a sua região equatorial (ao largo da costa do Ceará) até as proximidades do Platô de Santos e a Elevação do Rio Grande (ao largo da costa do Rio Grande do Sul). Os dados do Projeto WOCE são disponibilizados publicamente pela National Oceanic and Atmospheric 


\section{Administration (NOAA).}

Essa Radial de fundeios contém 13 fundeios subdivididos em 2 conjuntos de dados que foram lançados em parceria entre Woods Hole Oceanographic Institute (WHOI) e Institute for Marine Science (IFM-Kiel) da Universidade de Kiel. O conjunto lançado pelo WHOI é composto por 6 fundeios designados por Atlantic Current Meter Array 3 (ACM3), círculos amarelos na Figura 4.1, enquanto o conjunto lançado pelo IFM-Kiel é composto por 7 fundeios designados por Atlantic Current Meter Array 12 (ACM12), círculos verdes na Figura 4.1. Esses dados foram coletados entre janeiro de 1991 e dezembro de 1992, porém alguns instrumentos possuem uma série temporal reduzida devido à falta de registros.

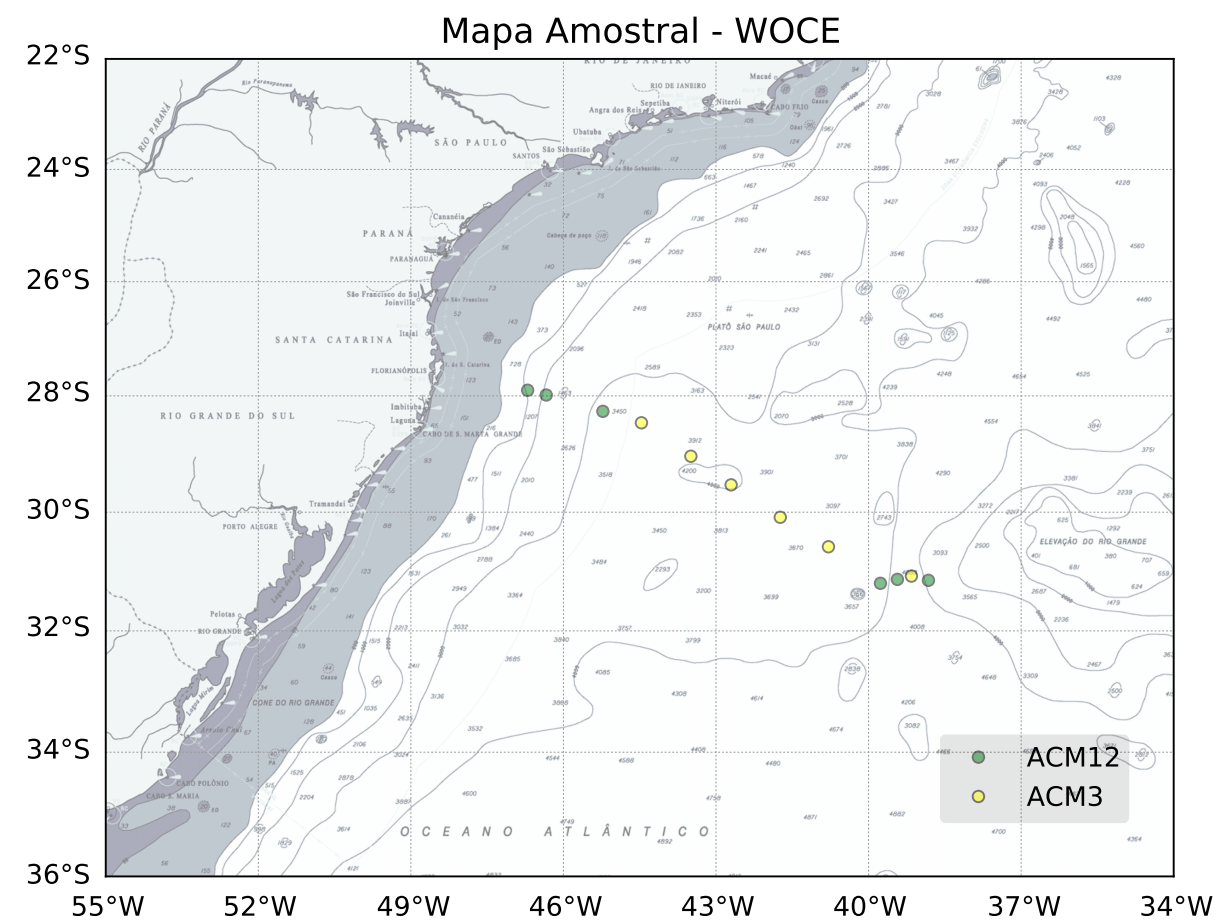

Figura 4.1: Localização da Radial de fundeios do Projeto WOCE. Esse conjunto de dados é composto pelos conjuntos ACM12 (círculos verdes) e ACM3 (círculos amarelos) coletados, respectivamentem pelo WHOI e pelo IFM-Kiel entre janeiro de 1991 e dezembro de 1992. Neste trabalho foram utilizados os 4 fundeios mais próximos à costa.Na direção da região mais rasa para o interior da bacia oceânica, esses fundeios são denominados, respectivamente: ACM12/333, ACM12/334, ACM12/335 e ACM3/906.

Por não haver CCO à leste do fundeio ACM12/335 (Tarbell et al., 1994; Müller et al., 1998), utilizamos os 4 fundeios mais próximos à margem continental, sendo os 3 primeiros pertencentes ao conjunto ACM12 e o último ao conjunto ACM3. Uma descrição 
detalhada e estatística do conjunto ACM12 é forneceida por Müller et al. (1998), enquanto para o conjunto ACM3, por Hogg et al. (1999). Na direção da região mais rasa para o interior da bacia oceânica, esses 4 primeiros fundeios são denominados, respectivamente, por ACM12/333, ACM12/334, ACM12/335 e ACM3/906. A quantidade de correntômetros em cada fundeio varia de 4 a 6 instrumentos e além disso, os fundeios ACM12/333 e ACM12/335 possuem em seu topo um ADCP apontado para a superfície com célula de amostragem de $\sim 25 \mathrm{~m}$. Um sumário da estrutura de cada fundeio e de seus respectivos instrumentos é apresentado na Tabela 4.1.

\subsection{Aspectos Metodológicos}

Em detrimento do instrumento ACM3 WHOI 906 situado na profundidade de $509 \mathrm{~m}$ possuir a menor série temporal (registros de 05 de janeiro a 01 de agosto de 1992), todos os outros instrumentos foram limitados pelo instante final desse instrumento e a série temporal com a qual fizemos nossa análise é de aproximadamente 1 ano e meio de dados (19 meses). Os instrumentos do tipo Aanderaa Rotor-type Current Meters (RCM) possuem frequência amostral de 120 min enquanto os instrumentos Vector Averaging Current Meter (VACM), de 20 min. Por essa razão, os instrumentos VACM foram subamostrados para a resolução temporal dos instrumentos Aanderaa RCM.

O tratamento básico dos dados foi realizado eliminando-se dados espúrios (spikes) maiores que $1 \mathrm{~m} \mathrm{~s}^{-1}$. Posteriormente, as componentes de velocidades zonal $(u) \mathrm{e}$ meridional $(v)$ foram rotacionadas do sistema de coordenadas geográficas para o sistema de coordenadas naturais para se trabalhar com a componente transversal à seção do fundeio e concentrar a varialidade da escoamento nessa componente, já que as correntes geostróficas tendem a fluir paralela à costa.

Nas vizinhanças da Radial dos fundeios, a CB tende a fluir próxima à quebra da plataforma continental ocupando pelo menos os primeiros $500 \mathrm{~m}$ da coluna de água, embora o aporte da BiSan ocorra entre $25^{\circ} \mathrm{S}$ e $28^{\circ} \mathrm{S}$ (Müller et al., 1998; Boebel et al., 1999; Legeais et al., 2013). Por essa razão, utilizamos um ângulo de rotação de $\sim 31,7^{\circ}$, calculado a partir do ângulo médio dos instrumentos do fundeio ACM12/333 (próximo 
Tabela 4.1: Descrição da Radial de fundeios do Projeto WOCE, composta pelo conjunto de dados ACM12 e ACM3, e seus respectivos instrumentos.

\begin{tabular}{|c|c|c|c|}
\hline Fundeio & Tipo & Profundidade & Período Amostral \\
\hline ACM12/333 & ADCP & $51 \mathrm{~m}$ & 03/Jan/1991 - 26/Nov/1992 \\
\hline ACM12/333 & $\mathrm{ADCP}$ & $77 \mathrm{~m}$ & 03/Jan/1991 - 26/Nov/1992 \\
\hline ACM12/333 & $\mathrm{ADCP}$ & $95 \mathrm{~m}$ & 03/Jan/1991 - 26/Nov/1992 \\
\hline ACM12/333 & $\mathrm{ADCP}$ & $112 \mathrm{~m}$ & 03/Jan/1991 - 26/Nov/1992 \\
\hline ACM12/333 & $\mathrm{ADCP}$ & $138 \mathrm{~m}$ & 03/Jan/1991 - 26/Nov/1992 \\
\hline ACM12/333 & $\mathrm{ADCP}$ & $155 \mathrm{~m}$ & 03/Jan/1991 - 26/Nov/1992 \\
\hline ACM12/333 & $\mathrm{ADCP}$ & $173 \mathrm{~m}$ & 03/Jan/1991 - 26/Nov/1992 \\
\hline ACM12/333 & Aanderaa RCM8 & $230 \mathrm{~m}$ & 03/Jan/1991 - 26/Nov/1992 \\
\hline ACM12/333 & Aanderaa RCM8 & $475 \mathrm{~m}$ & 03/Jan/1991 - 26/Nov/1992 \\
\hline ACM12/333 & Aanderaa RCM8 & $680 \mathrm{~m}$ & 03/Jan/1991 - 26/Nov/1992 \\
\hline ACM12/333 & Aanderaa RCM8 & $885 \mathrm{~m}$ & 03/Jan/1991 - 26/Nov/1992 \\
\hline ACM12/334 & Aanderaa RCM8 & $230 \mathrm{~m}$ & 03/Jan/1991 - 26/Nov/1992 \\
\hline ACM12/334 & Aanderaa RCM8 & $470 \mathrm{~m}$ & 03/Jan/1991 - 26/Nov/1992 \\
\hline ACM12/334 & Aanderaa RCM8 & $870 \mathrm{~m}$ & 03/Jan/1991 - 26/Nov/1992 \\
\hline ACM12/334 & Aanderaa RCM8 & $1370 \mathrm{~m}$ & 03/Jan/1991 - 26/Nov/1992 \\
\hline ACM12/334 & Aanderaa RCM8 & $2140 \mathrm{~m}$ & 03/Jan/1991 - 26/Nov/1992 \\
\hline ACM12/335 & $\mathrm{ADCP}$ & $55 \mathrm{~m}$ & 04/Jan/1991 - 25/Nov/1992 \\
\hline ACM12/335 & $\mathrm{ADCP}$ & $81 \mathrm{~m}$ & 04/Jan/1991 - 25/Nov/1992 \\
\hline ACM12/335 & $\mathrm{ADCP}$ & $115 \mathrm{~m}$ & 04/Jan/1991 - 25/Nov/1992 \\
\hline ACM12/335 & $\mathrm{ADCP}$ & $141 \mathrm{~m}$ & 04/Jan/1991 - 25/Nov/1992 \\
\hline ACM12/335 & $\mathrm{ADCP}$ & $176 \mathrm{~m}$ & 04/Jan/1991 - 25/Nov/1992 \\
\hline ACM12/335 & $\mathrm{ADCP}$ & $203 \mathrm{~m}$ & 04/Jan/1991 - 25/Nov/1992 \\
\hline ACM12/335 & $\mathrm{ADCP}$ & $237 \mathrm{~m}$ & 04/Jan/1991 - 25/Nov/1992 \\
\hline ACM12/335 & Aanderaa RCM8 & $275 \mathrm{~m}$ & 04/Jan/1991 - 25/Nov/1992 \\
\hline ACM12/335 & Aanderaa RCM8 & $515 \mathrm{~m}$ & 04/Jan/1991 - 25/Nov/1992 \\
\hline ACM12/335 & Aanderaa RCM8 & $915 \mathrm{~m}$ & 04/Jan/1991 - 25/Nov/1992 \\
\hline ACM12/335 & Aanderaa RCM8 & $1415 \mathrm{~m}$ & 04/Jan/1991 - 25/Nov/1992 \\
\hline ACM12/335 & Aanderaa RCM8 & $2510 \mathrm{~m}$ & 04/Jan/1991 - 25/Nov/1992 \\
\hline ACM12/335 & Aanderaa RCM8 & $3215 \mathrm{~m}$ & 04/Jan/1991 - 25/Nov/1992 \\
\hline ACM3/906 & VACM & $509 \mathrm{~m}$ & 05/Jan/1991 - 01/Ago/1992 \\
\hline ACM3/906 & VACM & $908 \mathrm{~m}$ & 05/Jan/1991 - 03/Dez/1992 \\
\hline ACM3/906 & VACM & $2609 \mathrm{~m}$ & 05/Jan/1991 - 03/Dez/1992 \\
\hline ACM3/906 & VACM & $3532 \mathrm{~m}$ & 05/Jan/1991 - 03/Dez/1992 \\
\hline
\end{tabular}


à quebra da plataforma) nas pronfundidades de 173, 230 e 475 m. A rotação se deu no sentido horário e o valor ângulo de rotação é semelhante ao ângulo calculado $\left(\sim 32,7^{\circ}\right)$ a partir da orientação das isóbatas entre $28^{\circ} \mathrm{S}$ e $30^{\circ} \mathrm{S}$.

Por conseguinte, filtramos os dados utilizando um filtro tipo Lanczos para eliminar as altas frequências e reter somente os fenômenos subinerciais, que são de nosso interesse neste trabalho. Utilizamos um filtro com período de corte de $40 \mathrm{~h}$ (considerando a latitude média de $\sim 28,15^{\circ} \mathrm{S}$ entre os fundeios, o período inercial é de $\sim 25,36 \mathrm{~h}$ ). O resultado da filtragem para a componente transversal $v$ do correntômetro em $230 \mathrm{~m}$ do fundeio ACM12/333 é apresentado na Figura 4.2.

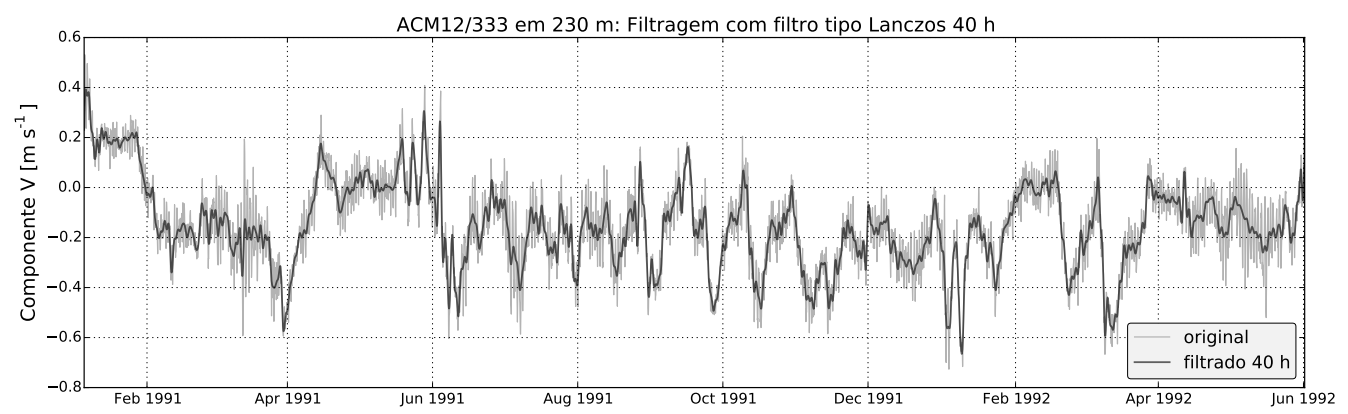

Figura 4.2: Série original (linha cinza) e filtrada (linha preta) do instrumento em $230 \mathrm{~m}$ do fundeio ACM12/333. Filtragem utilizando-se filtro do tipo Lanczos de $40 \mathrm{~h}$.

Após a filtragem dos dados, fizemos a análise da variabilidade da CB através do uso de EOFs. A vantagem dessa análise consiste em reduzir em alguns poucos modos (funções ortogonais), a variabilidade espacial e temporal dos dados (Emery \& Thomson, 2001). Essa análise é estatística e os modos de variabilidade podem estar relacionados a processos dinâmicos, "embora não seja necessária nenhuma relação física ou matemática direta entre as EOFs estatíticas e qualquer modo dinâmico relacionado" (Emery \& Thomson, 2001).

Aqui, seguimos o uso de EOFs conforme descrito por Preisendorfer (1988) e Emery \& Thomson (2001). O procedimento da análise de EOFs, no domínio do tempo, parte do princípio de que a variação temporal de uma variável escalar em um ponto $m$ qualquer $\left(\Phi_{m}(t) \equiv \Phi\left(x_{m}, t\right)\right)$, pode ser escrita como uma soma de $M$ funções espaciais ortogonais $\left(\phi_{i}\right)$ tal que

$$
\Phi_{m}(t)=\sum_{i=1}^{M} a_{i}(t) \phi_{i m}
$$


onde $a_{i}(t)$ é a amplitude do $i$-ésimo modo ortogonal no instante $t$. Nota-se da Equação 4.1 que a variação temporal da variável escalar $\left(\Phi_{m}(t)\right)$ em cada posição $m$ é dependente da variação temporal das amplitudes $\left(a_{i}(t)\right)$, as quais ponderam as $M$ funções espaciais $\left(\phi_{i}\right)$. Dessa maneira, obtém-se uma quantidade de funções igual a quantos pontos houverem, resultante da combinação linear entre esses termos.

Desejando obter um conjunto de funções ortogonais e que a variabilidade temporal das amplitudes sejam não correlacionadas, de forma que a covariância entre as amplitudes satisfaça a condição de ortogonalidade, recaímos num problema de autovalor. Assim, ao retirar a média da variável escalar $\Phi_{m}(t)$ de suas respectivas séries temporais, o problema a ser resolvido é dado por

$$
C \phi-\lambda I \phi=0
$$

onde $C$ é a matriz convariância, $\phi$ são as autofunções (EOFs), $\lambda$ são os autovalores e $I$ é a matriz identidade. Ao resolver 4.2 obtemos um conjunto de $M$ autovalores correspondentes à $M$ funções ortogonais linearmente independentes (as EOFs são modos de variabilidade estatísticos e independentes).

Assim sendo, os autovalores são as amplitudes das autofunções e estão associados à variância temporal dos dados, enquanto as EOFs são as estruturas de variabilidade (ou os modos de variabilidade) e estão associados à variação espacial dos dados. Além disso, obtém-se através da resolução desse problema a variância explicada de cada modo, de forma que, cada autovalor explica determinada porcentagem da variância total.

Para determinar quais EOFs (modos) são estatisticamente significativos, realizamos as simulações de Monte Carlo, método que possibilita separar esses modos dos modos espúrios (reproduzidos por séries aleatórias) (Preisendorfer, 1988). Esse processo consiste no cálculo recursivo de EOFs de um número de séries randômicas suficientemente grande (da ordem de $10^{3}$ ), com tamanho igual ao da série temporal dos dados. Ao final desse processo, obtém-se o mesmo número de modos (para cada simulação) que o obtido anteriormente com os dados. Dessa forma, a variância de cada modo estatístico é obtida do valor médio das simulações e o intervalo de significância de 95\% do desvio padrão. Somente os modos estatísticos acima do nível de significância de 2 desvios padrões são considerados estatisticamente confiáveis. 
A partir da determinação dos modos estatisticamente significativos, partimos para a análise espectral desses modos a fim de se determinar os períodos dominantes de cada modo. Isto é, temos como objetivo determinar os comprimentos de ondas das ondas que governam a variabilidade da CB em nossa série temporal. Posto isso, apresentamos os resultados obtidos pela análise de EOFs dos fundeios do Projeto WOCE na Seção 4.3 a seguir.

\subsection{Resultados e Discussão}

Como relatado na seção anterior, inicialmente filtramos as séries temporais utilizando um filtro tipo Laczos com período de corte de 40 h com o propósito de filtrar os períodos subinerciais. Aqui apresentamos tanto as séries "originais" (dados espúrios foram eliminados) assim como as séries filtradas (respectivamente, Figuras 4.3 e 4.4) do fundeio mais costeiro (ACM12/333) entre os utilizados neste trabalho (relação dos instrumentos apresentada na Tabela 4.1 e posição de cada fundeio na Figura 4.1). Os dados utilizados neste trabalho já foram apresentados por outros autores e podem ser consultados em Tarbell et al. (1994), Müller et al. (1998) e Hogg et al. (1999).

Posteriormente à filtragem, estabelecemos a seção vertical de velocidade média normal à Radial (Figura 4.5) a partir da série temporal comum a todos os instrumentos utilizados (janeiro de 1991 à agosto de 1992). Após sua obtenção, a seção média foi ainda interpolada pelo método de Análise Objetiva (na Seção 3.3.3 empregamos sua forma isotrópica). Como no oceano as escalas horizontal e vertical são relativamente diferentes, utilizamos a forma anisotrópica da função de correlação desse método (Silveira et al., 2004), tal que

$$
C(\Delta x, \Delta z)=\left(1-\varepsilon^{2}\right) e^{-\left(\frac{\Delta x^{2}}{L_{x}^{2}}+\frac{\Delta z^{2}}{L_{z}^{2}}\right)},
$$

onde $\Delta x$ e $\Delta z$ representam respectivamente as distâncias horizontal e vertical dos pontos de grade, $L_{x}$ e $L_{z}$ são os comprimentos de correlação horizontal e vertical, e $\varepsilon^{2}$ é a variância do erro randômico. Aqui utilizamos um comprimento de correlação horizontal de $L_{x}=25 \mathrm{~km}$, comprimento de correlação vertical de $L_{x}=400 \mathrm{~m}$ e variância do erro 


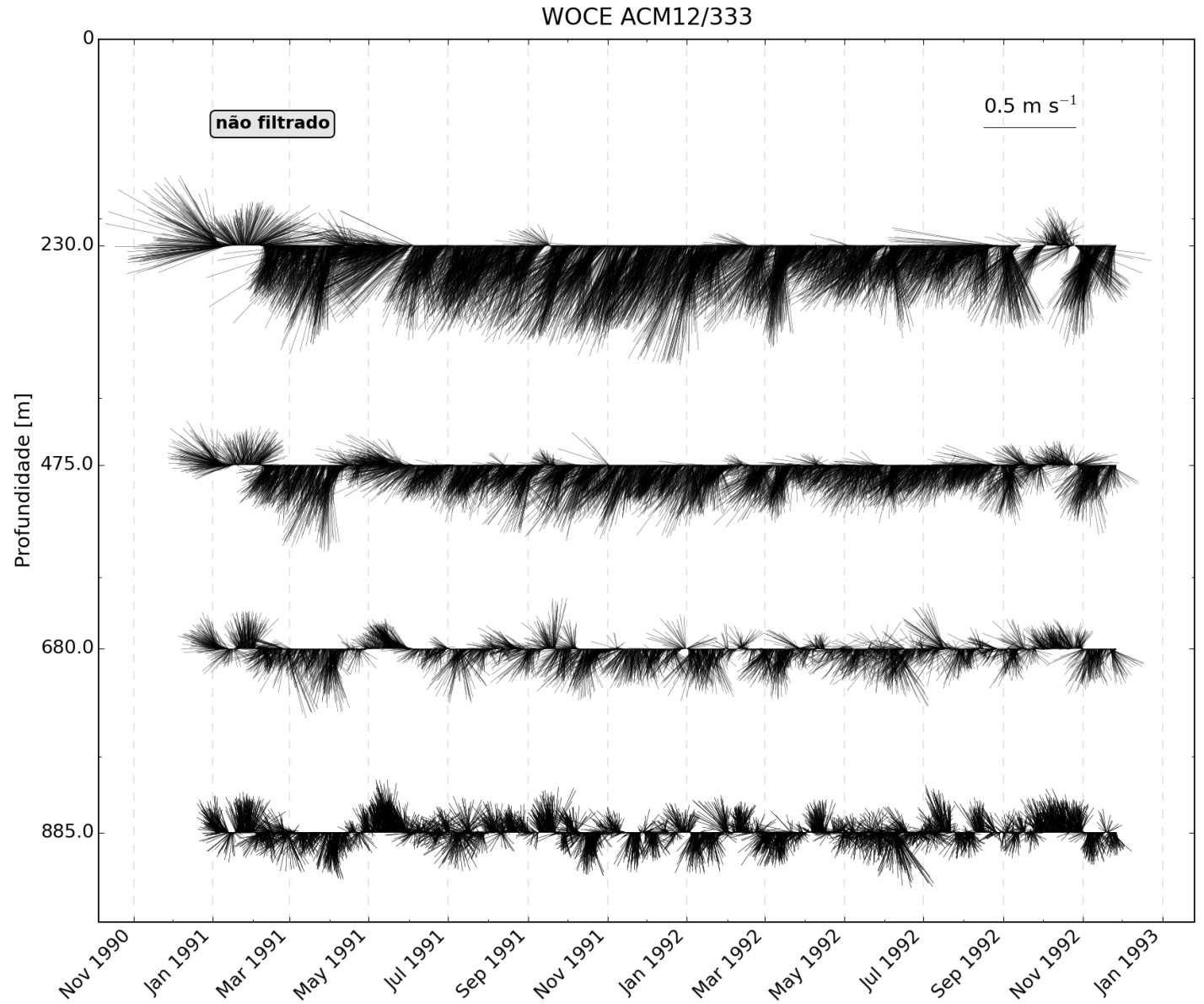

Figura 4.3: Séries temporais "originais" (retirada de dados espúrios) de velocidades observadas dos respectivos correntômetros do fundeio $\mathrm{ACM12/333} \mathrm{(instrumento} \mathrm{mais} \mathrm{próximo} \mathrm{à} \mathrm{costa} \mathrm{entre} \mathrm{os} \mathrm{utili-}$ zados) do Projeto WOCE. 


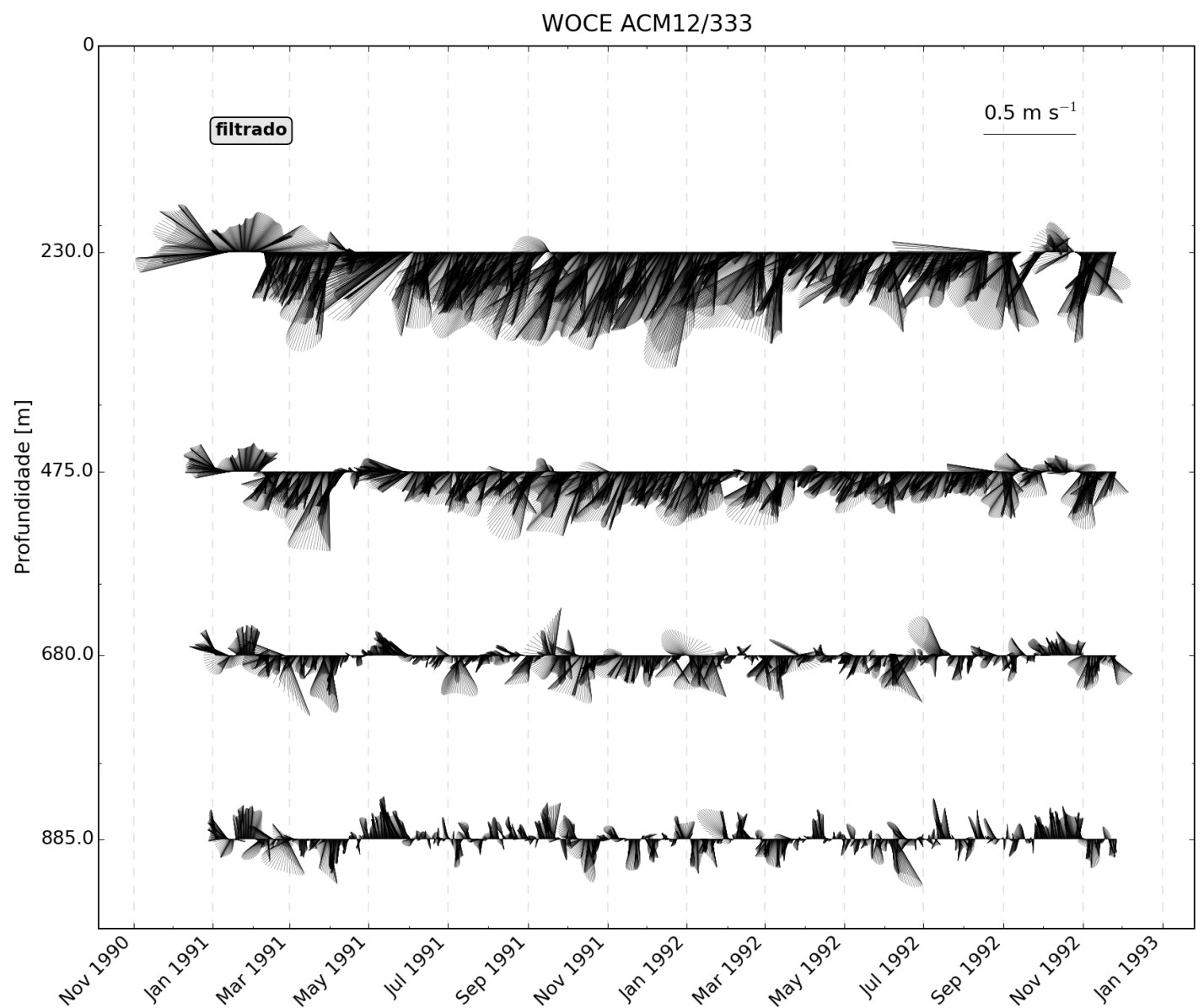

Figura 4.4: Séries temporais filtradas (filtro tipo Lanczos de 40 h) de velocidades observadas dos respectivos correntômetros do fundeio $\mathrm{ACM12/333} \mathrm{(instrumento} \mathrm{mais} \mathrm{próximo} \mathrm{à} \mathrm{costa} \mathrm{entre} \mathrm{os} \mathrm{utili-}$ zados) do Projeto WOCE. 
de $\varepsilon^{2}=0,02$. Além disso, utilizamos como condição de contorno a condição de não escorregamento (no-slip), isto é, essa condição impõe que não há fluxo tangente ao contorno. Ademais, essa seção média (Figura 4.5) será utilizada para a realização da análise de EOFs, pela resolução do problema autovalor dado pela Equação 4.2.

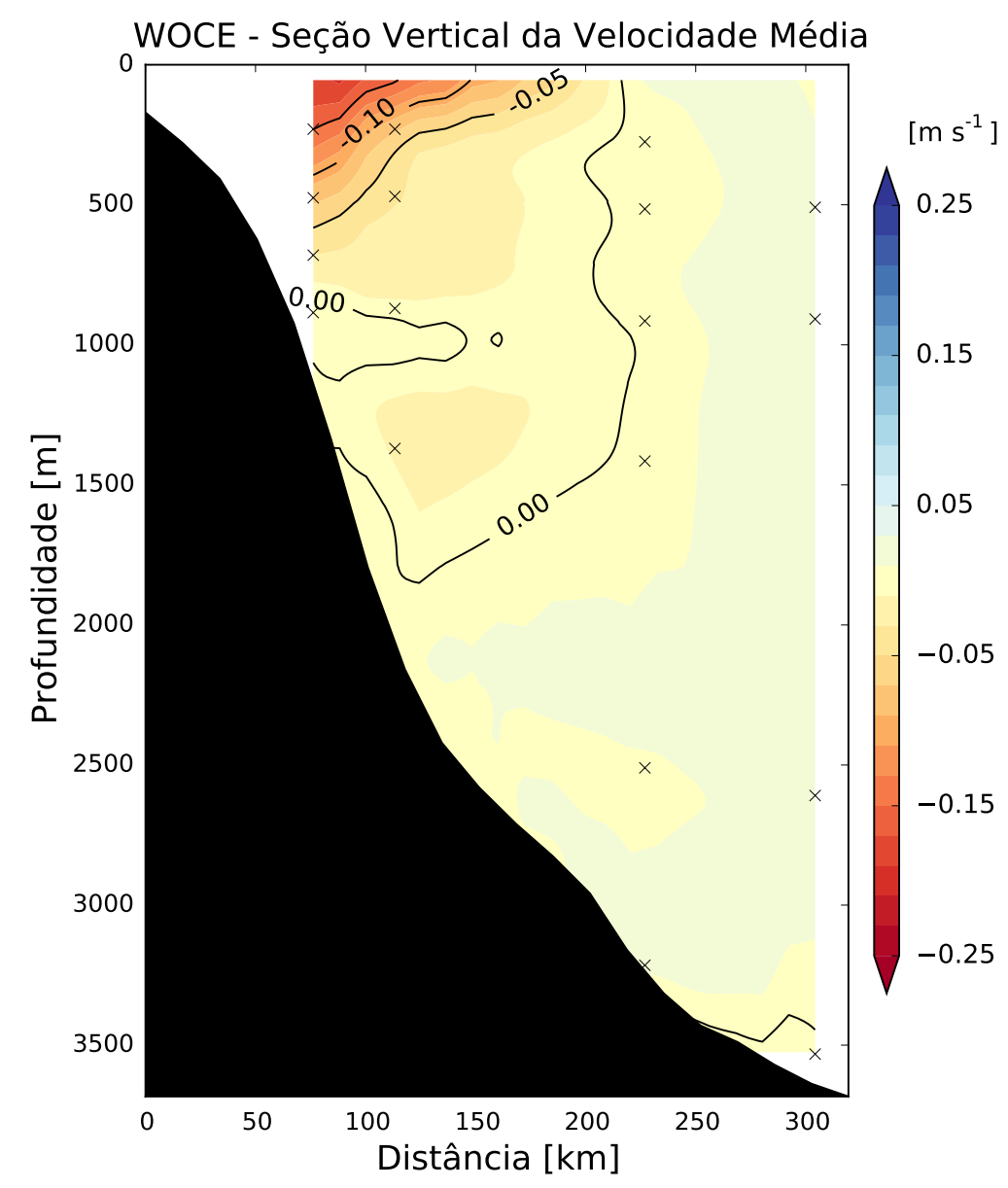

Figura 4.5: Seção vertical de velocidade média normal à Radial de fundeios, utilizando as séries temporais de aproximadamente 18 meses dos 4 primeiros fundeios do Projeto WOCE, obtida após a filtragem dos dados com filtro tipo Lanczos de $40 \mathrm{~h}$.

Na seção média (Figura 4.5), notamos a presença da CB na porção superficial próxima à quebra da plataforma continental, porém sua estrutura aparece incompleta e se estende em direção à plataforma, sugerindo uma posição média junto à quebra da plataforma. Essa feição apresenta cisalhamento vertical confinado aos primeiros $500 \mathrm{~m}$, no entanto abaixo dessa profundidade, a CB se apresenta mais fraca com núcleo secundário de velocidades baixas (aproximadamente $0,05 \mathrm{~m} \mathrm{~s}^{-1}$ ), sugerindo a possibilidade de 
estar associada ao aporte do ramo sul da bifurcação da CSE intermediária nessa latitude $\left(\sim 28^{\circ} \mathrm{S}\right)$.

Em nossa análise de EOFs, realizamos a decomposição bidimensional dos modos de variabilidade da velocidade normal à Radial de fundeios, de acordo com a solução do problema de autovalor dado pela Equação 4.2. Consecutivamente, a fim de se determinar os modos estatisticamente significativos, realizamos $n=1000$ simulações de Monte Carlo, utilizando o intervalo de significância de 95\% do desvio padrão dos valores médios obtidos ao final das simulações. A partir dos resultados das simulações (Figura 4.6), obtivemos que os dois primeiros modos são estatísticamente confiáveis. O percentual de variância explicada pelo primeiro modo é de $\sim 54,3 \%$ e para o segundo modo, de $\sim 29,8 \%$. Portanto, os dois primeiros modos explicam conjuntamente $\sim 84 \%$.

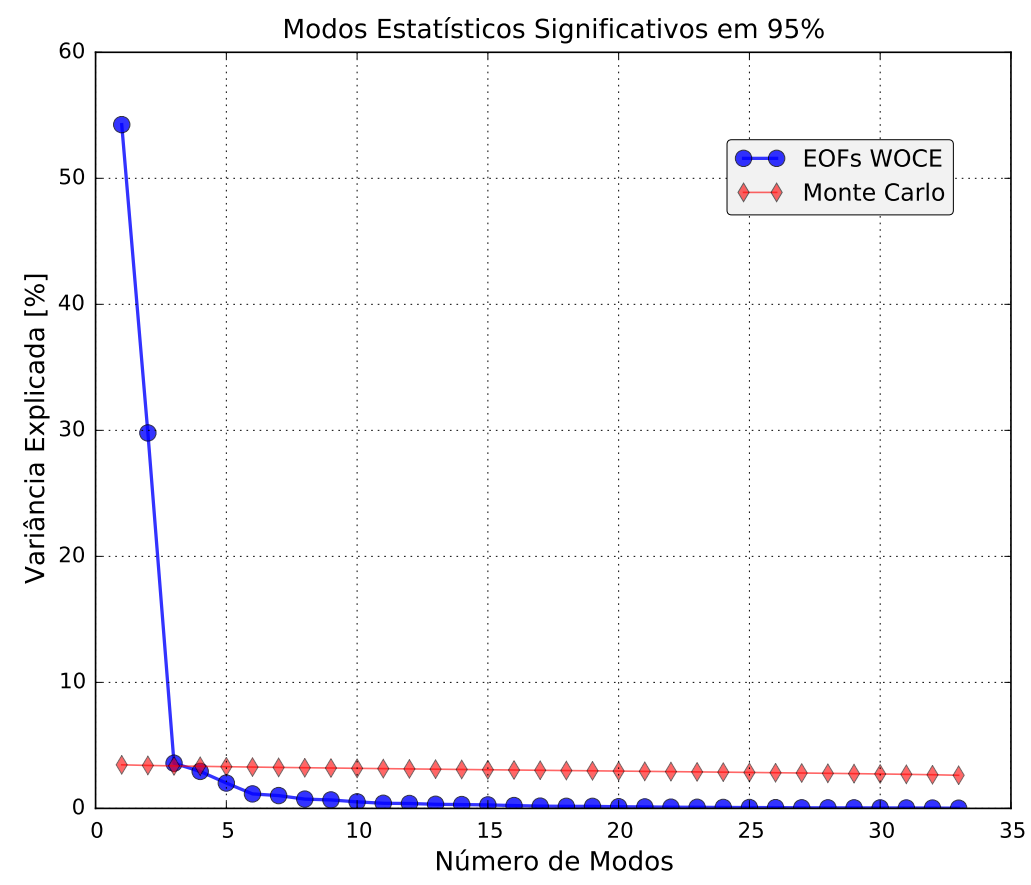

Figura 4.6: Resultado da análise de EOFs bidimensionais dos fundeios do Projeto WOCE e determinação dos modos estatisticamente significativos através das simulações de Monte Carlo. Nota-se que o primeiro e segundo modos explicam respectivamente $\sim 54,3 \%$ e $\sim 29,8 \%$ da variabilidade, e conjuntamente explicam $\sim 84 \%$.

A estrutura vertical obtida para o primeiro modo (Figura 4.7), a qual explica a maior parte da variabilidade, apresenta uma estrutura confinada na porção mais próxima à costa (até os primeiros $200 \mathrm{~km}$ de distância) e com perfil cisalhante da superfície (local onde serão encontradas as maiores velocidades) até aproximadamente $1500 \mathrm{~m}$. Esse 
padrão espacial possui estrutura similar à da $\mathrm{CB}$, por essa razão, associamos o primeiro modo ao meandramento da CB. Com o intuito de obter o período das ondas associadas a esse modo, realizamos a análise espectral da série temporal de amplitude do respectivo modo. Através dessa análise, obtivemos que essas ondas possuem período característico de $\sim 26$ dias (Figura 4.8).

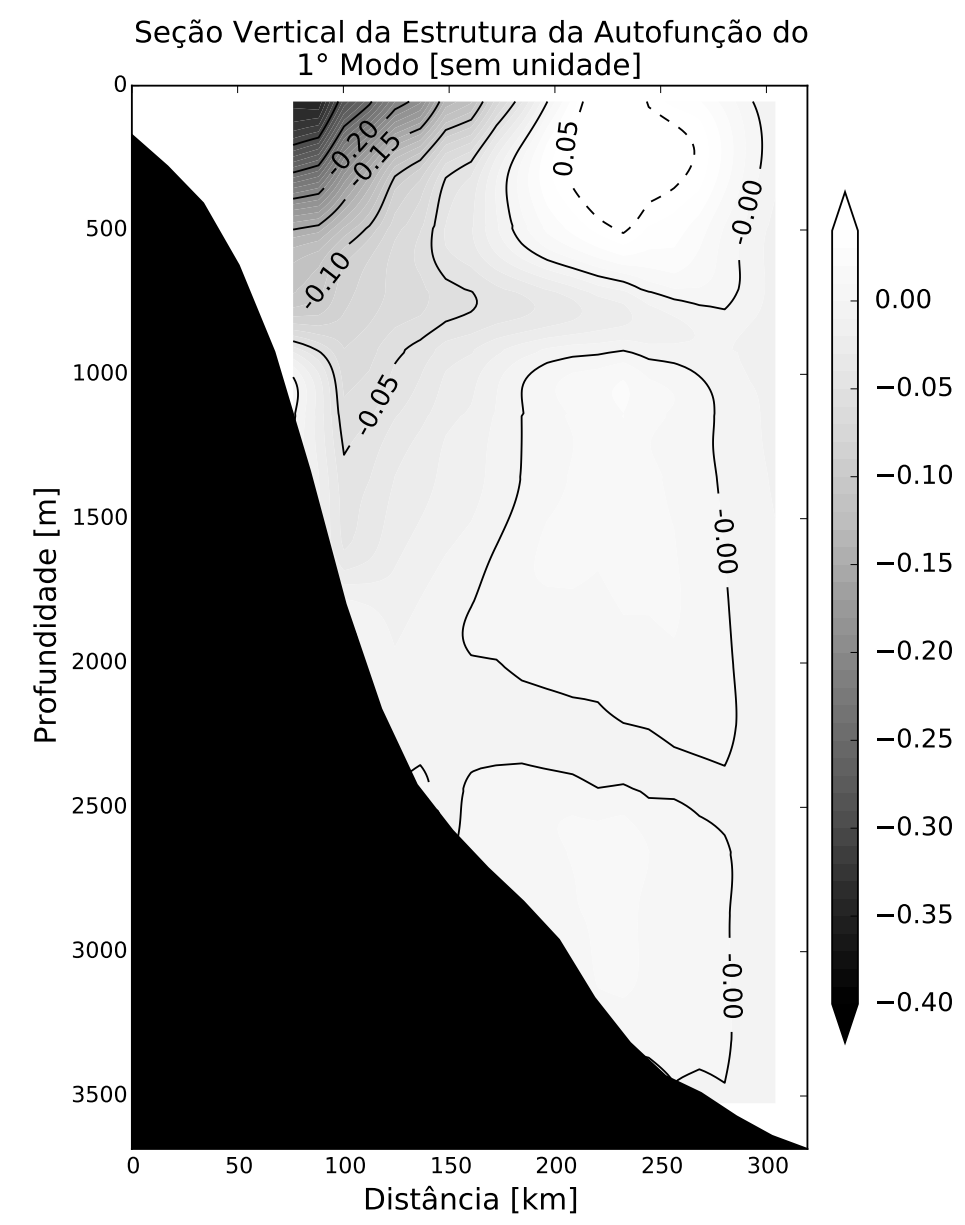

Figura 4.7: Estrutura vertical do primeiro modo. Nota-se um padrão espacial confinado na porção mais próxima à quebra da plataforma continental e com cisalhamento vertical até $\sim 1500 \mathrm{~m}$ de profundidade.

Cabe ressaltar, que o valor encontrado difere do valor obtido por Oliveira (2003) para o primeiro modo ( $\sim 76$ dias), no entanto, esse autor fez sua análise considerando todos os fundeios da Radial do Projeto WOCE (localização dos fundeios se encontra na Figura 4.1). Como não há evidências de CCO à leste do fundeio ACM12/335 (Tarbell et al., 1994; Müller et al., 1998), utilizamos em nossa análise somente os 4 primeiros fundeios dessa Radial, portanto, isolamos consequentemente a variabilidade associada à 
CB. Além do que, os processos de mesoescala no oceano, como o meandramento da CCO e vórtices, possuem uma escala temporal entre dias a meses.

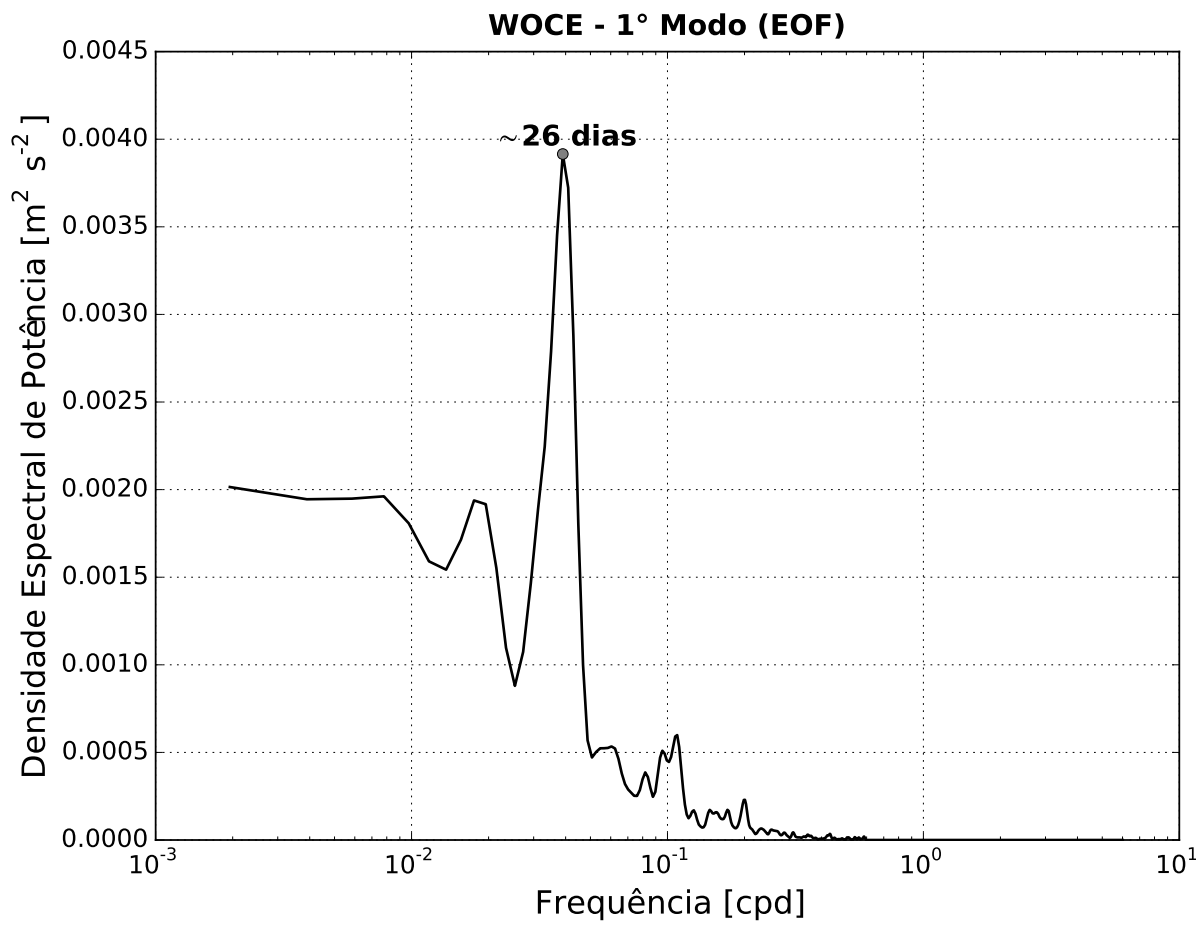

Figura 4.8: Espectro de potência que conserva a variância para a primeira EOF. Através da análise espectral da série de amplitude correspondente ao primeiro modo, foi obtido um comprimento de onda com período característico de $\sim 25$ dias.

Para o segundo modo, a estrutura vertical obtida (Figura 4.9) possui forma horizontalmente alongada (a longo da extensão da seção) com valores maiores confinados na superfície e com cisalhamento vertical até aproximadamente $800 \mathrm{~m}$ e centrados em torno de $230 \mathrm{~km}$ de distância. Atribuímos ao padrão de variabilidade do segundo modo à recirculação da $\mathrm{CB}$, a qual pode ocorrer à leste da $\mathrm{CB}$ como uma corrente de retorno dessa corrente (Tsuchiya, 1985; Vianna \& Menezes, 2005). Por meio da análise espectral da série de amplitudes, obtivemos um período característico de 103 dias (Figura 4.10). 


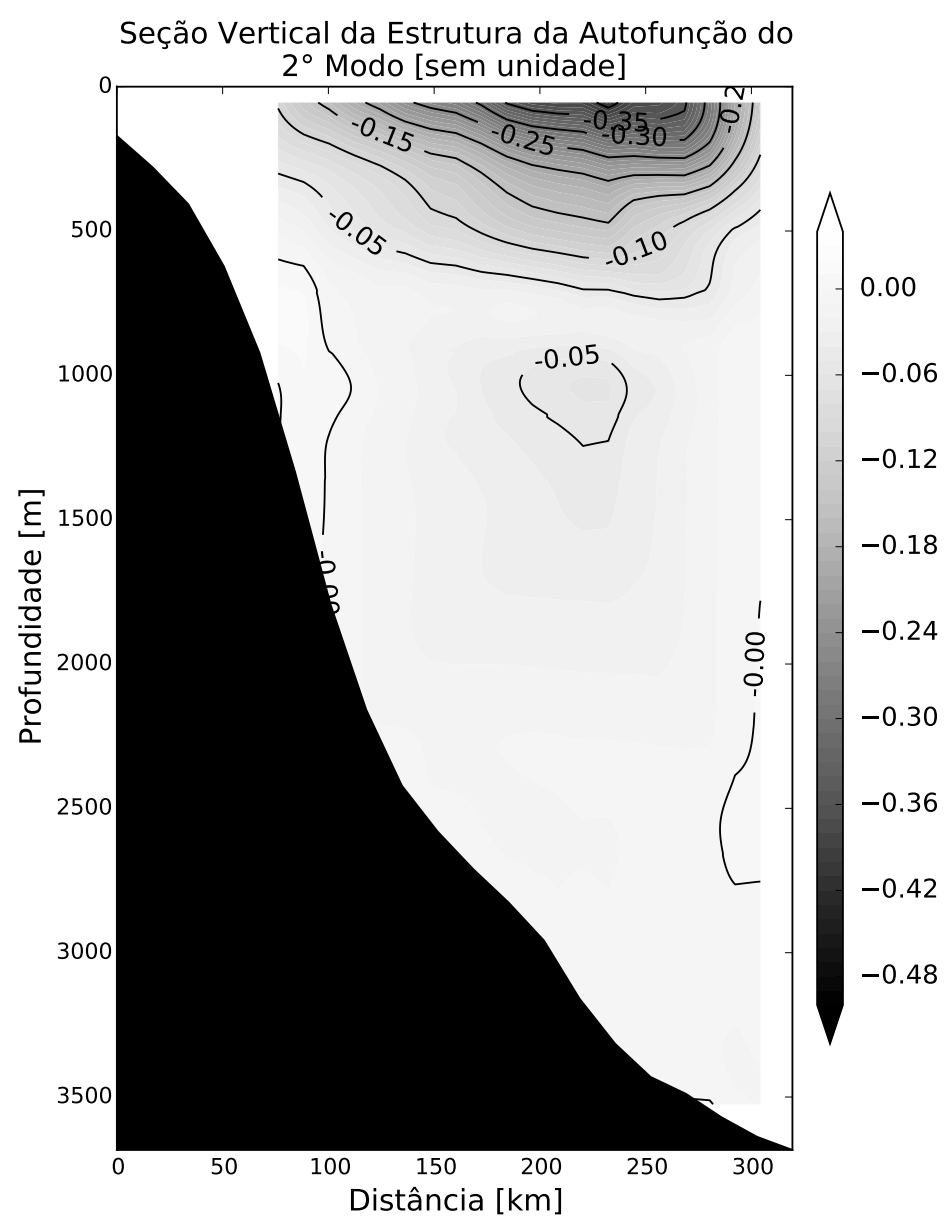

Figura 4.9: Estrutura vertical do segundo modo. Nota-se um padrão espacial alongado e mais raso (cisalhamento vertical até $\sim 600 \mathrm{~m}$ ) que o primeiro modo. 


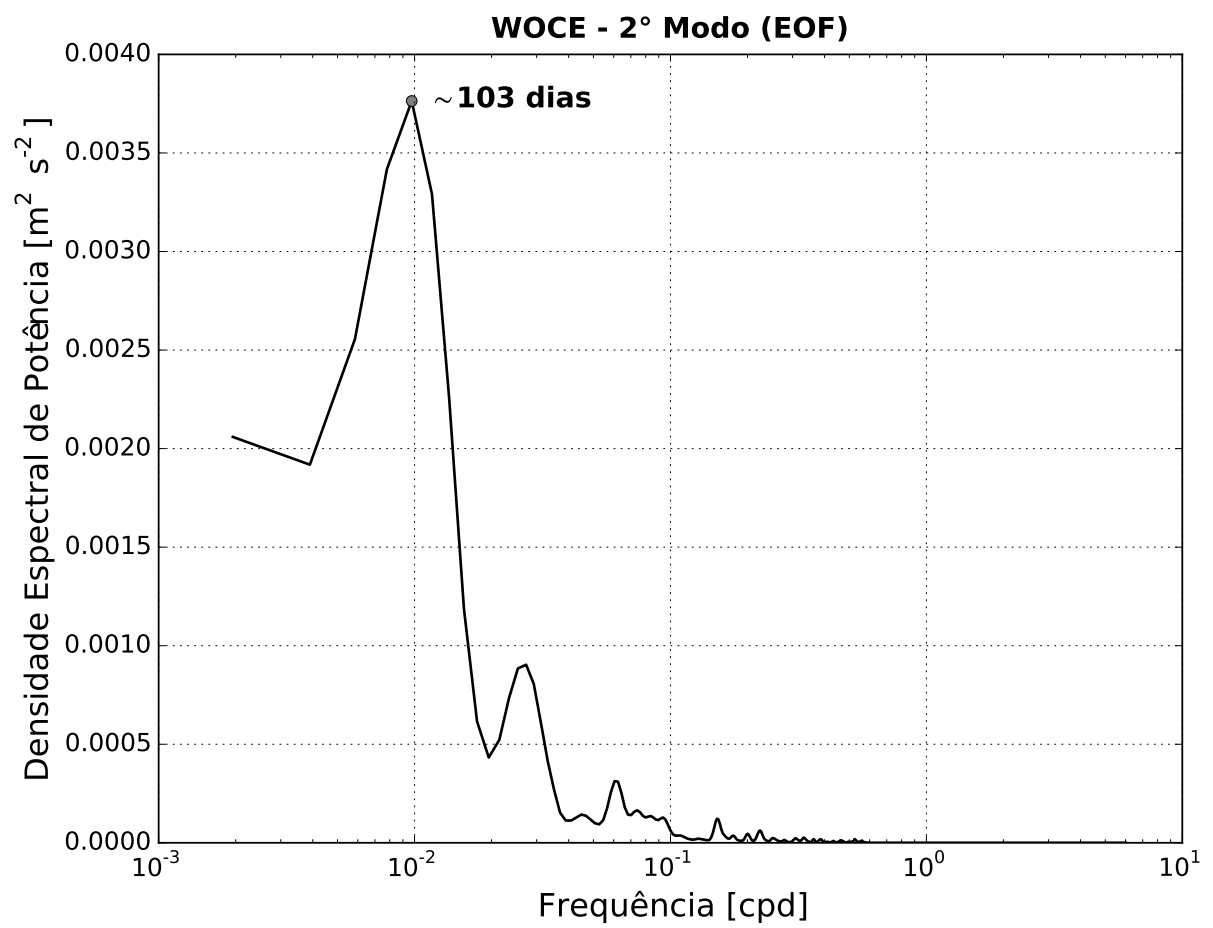

Figura 4.10: Espectro de potência que conserva a variância para a segunda EOF. Através da análise espectral da série de amplitude correspondente ao segundo modo, foi obtido um comprimento de onda com período característico de $\sim 102$ dias. 


\section{Capítulo 5}

\section{Modelo Dinâmico}

Neste capítulo, aplicamos o Modelo de Dinâmica de Contornos desenvolvido por da Silveira \& Flierl (2002) ao sistema CB-CCI ao sul da Bifurcação de Santos.

Em termos do arcabouço Teórico, trata-se de um modelo quase-geostrófico num oceano de camadas. da Silveira \& Flierl (2002) utilizaram uma configuração de 2 - $\frac{1}{2}$ camadas. Neste trabalho, consideraremos um oceano de duas camadas com a presença do modo barotrópico tanto na corrente básica quanto nas perturbações (ondas de vorticidade).

O intuito dessa abordagem é (i) isolar o efeito da instabilidade baroclínica e (ii) analisar a propagação de fase das ondas de fase relativamente ao jato básico.

\subsection{Formulação do Modelo Quase-Geostrófico de 2-camadas}

A Teoria quase-geostrófica lida com movimentos aproximadamente geostróficos cuja evolução temporal é dada por pequenas perturbações sob seu escoamento, isto é, o escoamento básico sofre pequenos desvios (correções ageostróficas).

A partir da aproximação geostrófica $\left(R o \ll 1, R o_{T} \ll 1, \delta \ll 1\right.$ e $\left.E_{k} \ll 1\right)$ e a aproximação do plano $\beta\left(\beta y \ll\left|f_{0}\right|\right)$, podemos chegar à Equação de Vorticidade Potencial Quase-Geostrófica para o oceano continuamente estratificado dada por

$$
\frac{\partial q}{\partial t}+J(\psi, q)=0 \Longleftrightarrow \frac{D_{g}}{D t} q=0
$$


onde a vorticidade potencial $(q)$ é definida por

$$
q=\underbrace{\nabla^{2} \psi}_{\text {(A) }}+\underbrace{\frac{\partial}{\partial z}\left(\frac{f_{0}^{2}}{N^{2}} \frac{\partial \psi}{\partial z}\right)}_{(\mathrm{B})}+\underbrace{\beta_{0} y}_{(\mathrm{C})}
$$

onde (A) é o termo de vorticidade relativa, (B) é o termo de estiramento do tubo de vórtice e (C) é o termo da variação de vorticidade planetária, $J(\psi, q)$ é o operador Jacobiano definido como

$$
J(\psi, q)=\frac{\partial \psi}{\partial x} \frac{\partial q}{\partial y}-\frac{\partial \psi}{\partial y} \frac{\partial q}{\partial x}
$$

e $\psi$ é a função de corrente.

Neste trabalho, temos como objetivo fazer o estudo de processo da formação e do crescimento em amplitude dos meandros da CB ao largo do Cabo de Santa Marta. Ao sul da bifurcação de Santos, a CB tem sua espessura aumentada devido ao aporte do ramo sul CSE em nível intermediário. Por essa razão, iremos aproximar o oceano em duas camadas, de forma que, sua estratificação seja minimamente representa por duas camadas homogêneas separadas por uma interface. Consequentemente, essa abordagem é equivalente a filtrar a estrutura modal da corrente aos dois primeiros modos (barotrópico e baroclínico), como veremos adiante.

Para tal, consideremos uma corrente de contorno oeste bordejando uma plataforma continental num oceano quase-geostrófico no plano $f$. Conforme a Equação (5.1), sua dinâmica é governada pela equação de conservação de Vorticidade Potencial (VP) tal que

$$
\frac{D q_{1}}{D t}=\frac{D q_{2}}{D t}=0
$$

onde

$$
\begin{aligned}
& q_{1}=\nabla^{2} \psi_{1}+\frac{f_{0}{ }^{2}}{\epsilon g H_{1}}\left(\psi_{2}-\psi_{1}\right) \\
& q_{2}=\nabla^{2} \psi_{2}+\frac{f_{0}^{2}}{\epsilon g H_{2}}\left(\psi_{1}-\psi_{2}\right)
\end{aligned}
$$


são as chamadas relações de inversibilidade para a camada superior $(i=1)$ e a camada inferior $(i=2)$ que relacionam a VP $\left(q_{i}\right)$ e a função de corrente geostrófica $\left(\psi_{i}\right)$. $\epsilon$ representa o salto de densidade normalizado entre as 2 camadas, dada por

$$
\epsilon=\frac{\rho_{2}-\rho_{1}}{\rho_{0}}
$$

O sistema formado pelas Equações (5.4)-(5.5)-(5.6) será resolvido aproximando a estrutura de VP associada à corrente por funções-degrau de Heaviside $(\mathcal{H})$ e aplicando a técnica de Dinâmica de Contornos (DC). Assumiremos que cada camada será composta por duas regiões de VP uniformes separadas por uma frente de VP localizada em $x=\bar{x}_{i}$ tal que

$$
q_{i}=q_{0 i}+\Delta_{i} \mathcal{H}\left(x-\bar{x}_{1}-\eta_{i}(x, t)\right)
$$

onde $i=1,2, q_{0 i}$ representa o valor costeiro de $q_{i}$ (à direita do jato) e $\Delta_{i}$, o salto de VP devido à presença da frente, e $\eta_{i}(x, t)$, a evolução temporal da frente de VP associada à perturbação.

O sistema (5.4)-(5.5)-(5.6)-(5.8) é, então, adimensionalizado conforme as escalas da Tabela 5.1.

\begin{tabular}{|c|c|}
\hline Definição & Convenção \\
\hline $\begin{array}{l}\text { - Escala de profundidade } \\
\text { (= profundidade total) }\end{array}$ & $H=H_{1}+H_{2}$ \\
\hline $\begin{array}{c}\text { - Escala de comprimento } \\
\text { (= Raio de deformação interno) }\end{array}$ & $R_{d}$ \\
\hline $\begin{array}{l}\text { - Escala de velocidade horizontal } \\
\text { (baseada no transporte na } 1^{\mathrm{a}} \text { camada } \mathcal{V}_{1} \text { ) }\end{array}$ & $\tilde{v}_{1}=\mathcal{V}_{1} / H_{1} R_{d}$ \\
\hline $\begin{array}{l}\text { - Escala de função de corrente } \\
\text { • Escala de tempo }\end{array}$ & $\begin{array}{l}R_{d} \tilde{v}_{1} \\
R_{d} / \tilde{v}_{1}\end{array}$ \\
\hline - Escala de vorticidade potencial & $\tilde{v}_{1} / R_{d}$ \\
\hline - Escala de salto de vorticidade potencial & $\tilde{v} / R_{d}^{2}$ \\
\hline
\end{tabular}

Tabela 5.1: Escalas de Não-dimensionalização. 
Com essas escalas, as relações de inversibilidade tomam a forma de grandezas não-dimensionais tal que

$$
\begin{gathered}
q_{1}=\nabla^{2} \psi_{1}+\mu\left(\psi_{2}-\psi_{1}\right) \\
q_{2}=\nabla^{2} \psi_{2}+\delta \mu\left(\psi_{1}-\psi_{2}\right)
\end{gathered}
$$

onde $\mu$ representa o parâmetro de acoplamento e $\delta$ é a razão de aspecto entre as camadas, definidos por

$$
\begin{gathered}
\mu=\frac{R_{d}^{2}}{R_{d_{1}}^{2}} \\
\delta=\frac{H_{1}}{H_{2}}
\end{gathered}
$$

As relações de inversibilidade (5.9)-(5.10), podem ser re-escritas em forma matricial como

$$
M_{i j} \psi_{j}=\left[\delta_{i j} \nabla^{2}+Z_{i j}\right] \psi_{j}=q_{i}
$$

onde $\delta_{i j}$ é o delta de Kronecker e $Z_{i j}$ é a matriz de estrutura vertical dada por:

$$
Z_{i j}=\left[\begin{array}{cc}
-\mu & \mu \\
\delta \mu & -\delta \mu
\end{array}\right] \text {. }
$$

O campo de VP pode ser separado em uma parte básica $\left(\bar{q}_{i}\right)$ e uma parte perturbada $\left(q_{i}^{\prime}\right)$ através da versão não-dimensional da Equação (5.8) tal que

$$
\begin{gathered}
\bar{q}_{i}=q_{0 i}+\Delta_{i} \mathcal{H}\left(x-\bar{x}_{i}\right) \\
q_{i}^{\prime}=\Delta_{i}\left[\mathcal{H}\left(x-\bar{x}_{i}-\eta_{i}\right)-\mathcal{H}\left(x-\bar{x}_{i}\right)\right] .
\end{gathered}
$$


As Equações (5.15) e (5.16) combinadas com (5.13) permitem que escrevamos:

$$
\begin{aligned}
& M_{i j} \bar{\psi}_{j}=\bar{q}_{i} \\
& M_{i j} \psi_{j}^{\prime}=q_{i}^{\prime} .
\end{aligned}
$$

Em particular, derivando-se (5.17) em relação a $x$, encontramos a relação de inversibilidade para a corrente básica:

$$
M_{i j} \bar{v}_{j}=\Delta_{i} \delta\left(x-\bar{x}_{i}\right)
$$

Já a Equação (5.4) pode ser utilizada na forma das equações cinemáticas dadas por

$$
\frac{D \eta_{i}}{D t}=u_{i}^{\prime} ; \quad \frac{D y_{i}}{D t}=\bar{v}_{i}+v_{i}^{\prime}
$$

Aqui, a Equação (5.4) é re-escrita em termos da evolução temporal da frente de VP na $i$-ésima camada, conforme (5.20), uma vez que se trata de uma linha material (VP é conservada).

A instabilidade da CCO é abordada de duas formas:

- o modelo linear - para obtenção dos valores das taxas de crescimento, velocidade de fase e velocidade de grupo, isto é, obtenção das propriedades de estabilidade linear.

- o modelo não-linear - para obtenção da evolução temporal dos padrões horizontais da frente de VP.

Nos dois modelos, dada a forma simplificada de (5.15) e (5.16), resolvemos analiticamente as relações de inversibilidade pelo Método das Funções de Green. Adicionalmente, usamos condições de não-escorregamento (no-slip) na quebra da plataforma continental $\left(u_{i}=v_{i}=0\right.$ em $\left.x=0\right)$. 


\section{Ortogonalização e Estrutura Modal}

A matriz Z , dada por (5.14), pode ser ortogonalizada para permitir o desacoplamento das Equações (5.13), (5.17) e (5.18). Ou seja,

$$
\mathbf{Z} \mathbf{F}=-\mathbf{F} \Gamma^{2}
$$

onde

$$
\boldsymbol{\Gamma}=\left[\begin{array}{cc}
\gamma_{1}^{2} & 0 \\
0 & \gamma_{2}^{2}
\end{array}\right]=\left[\begin{array}{ll}
0 & 0 \\
0 & 1
\end{array}\right]
$$

é a matriz dos autovalores, e

$$
\mathbf{F}=\left[\begin{array}{cc}
1 & 1 / \sqrt{\delta} \\
1 & -\sqrt{\delta}
\end{array}\right]
$$

é a matriz dos autovetores ou modos ortogonais.

Os autovetores $F_{i m}(i=1,2 ; m=1,2)$ podem ser expressos como a amplitude do $m$-ésimo modo na $i$-ésima camada. Assim, $m=1$ representa o modo barotrópico e $m=2$, o modo baroclínico. As funções de corrente das camadas e as funções de corrente modais se relacionam por:

$$
\left[\begin{array}{l}
\psi_{1} \\
\psi_{2}
\end{array}\right]=\mathbf{F}\left[\begin{array}{l}
\Psi_{1} \\
\Psi_{2}
\end{array}\right] .
$$

Analogamente,

$$
\left[\begin{array}{l}
q_{1} \\
q_{2}
\end{array}\right]=\mathbf{F}\left[\begin{array}{l}
Q_{1} \\
Q_{2}
\end{array}\right] .
$$

Por sua vez, as quantidades modais podem ser invertidas para retornarmos às 
quantidades de camadas, respectivamente, por:

$$
\begin{aligned}
& {\left[\begin{array}{l}
\Psi_{1} \\
\Psi_{2}
\end{array}\right]=\mathbf{F}^{\top}\left[\begin{array}{ll}
h_{1} & 0 \\
0 & h_{2}
\end{array}\right]\left[\begin{array}{l}
\psi_{1} \\
\psi_{2}
\end{array}\right]} \\
& {\left[\begin{array}{l}
Q_{1} \\
Q_{2}
\end{array}\right]=\mathbf{F}^{\top}\left[\begin{array}{ll}
h_{1} & 0 \\
0 & h_{2}
\end{array}\right]\left[\begin{array}{l}
q_{1} \\
q_{2}
\end{array}\right]}
\end{aligned}
$$

onde $h_{i}=H_{i} / H$ são as espessuras de repouso não-dimensionais.

\subsubsection{Modelo Linear}

A solução para o modelo linear é encontrada a partir da suposição de uma forma oscilatória para $\eta_{i}, u_{i}^{\prime}, v_{i}^{\prime}$ e $\psi_{i}^{\prime}$, ou seja,

$$
\left(\begin{array}{c}
\eta_{i} \\
\psi_{i}^{\prime} \\
u_{i}^{\prime} \\
v_{i}^{\prime}
\end{array}\right)=\left(\begin{array}{c}
\hat{\eta}_{i} \\
\hat{\psi}_{i} \\
\hat{u}_{i} \\
\hat{v}_{i}
\end{array}\right) e^{i l(y-c t)}
$$

onde $l$ é o número de onda na direção do jato básico (paralelo à quebra da plataforma) e

$$
c=\frac{\omega}{l}
$$

é a velocidade de fase.

Com (5.28) em (5.18), (5.19) e (5.20), linearizadas em torno de $x=\bar{x}_{i}$, obtemos:

$$
\begin{gathered}
M_{i j}^{(l)} \hat{\psi}_{j}=-\Delta_{i} \hat{\eta}_{i} \delta\left(x-\bar{x}_{i}\right) \\
M_{i j}^{(0)} \bar{u}_{j}=-\Delta_{i} \delta\left(x-\bar{x}_{i}\right) \\
\bar{v}_{i}\left(\bar{x}_{i}\right) \hat{\eta}_{i}-c \hat{\eta}_{i}=\hat{\psi}_{i}\left(\bar{x}_{i}\right) .
\end{gathered}
$$


A matriz $\mathbf{M}^{(l)}$ é definida por:

$$
M_{i j}^{(l)}=\delta_{i j}\left(\frac{\partial^{2}}{\partial x^{2}}-l^{2}\right)+Z_{i j}
$$

Notemos que $\mathbf{M}^{(0)}$ é o caso da aplicação à corrente básica onde consideramos $l, \omega \rightarrow 0$.

As Equações (5.30) e (5.31) podem ser resolvidas analiticamente pelo método das funções de Green, que satisfazem a seguinte relação:

$$
M_{i j}^{(l)} G_{j m}^{(l)}\left(x / x^{\prime}\right)=\delta_{i m} \delta\left(x-\bar{x}_{i}\right)
$$

A função de Green, na presença do contorno oeste, é dada por

$$
G_{i j}^{(l)}=-h_{i} F_{i m} F_{j m} \frac{1}{2 \sqrt{l^{2}+\gamma_{i}^{2}}}\left[e^{\sqrt{l^{2}+\gamma_{i}^{2}}\left|x-x^{\prime}\right|}-e^{\sqrt{l^{2}+\gamma_{i}^{2}}\left|x+x^{\prime}\right|}\right] .
$$

Para o caso especial, onde $l=\gamma_{i}^{2}=0$, a Equação (5.35) se torna:

$$
G_{i j}^{(0)}=-h_{i} F_{i m} F_{j m} \frac{1}{2}\left[\left(\left|x-x^{\prime}\right|-r_{0}\right)-\left(\left|x+x^{\prime}\right|-r_{0}\right)\right] .
$$

Com as Equações (5.35)-(5.36) em (5.30)-(5.31), chegamos respectivamente a

$$
\begin{gathered}
\hat{\psi}_{i}=G_{i j}^{(l)}\left(x-x^{\prime}\right) \Delta_{j} \hat{\eta}_{j} \\
\bar{u}_{i}=G_{i j}^{(0)}\left(x-x^{\prime}\right) \Delta_{j} .
\end{gathered}
$$

Com (5.37)-(5.38), podemos resolver (5.32) e encontrar $c$, formando o tradicional problema de autovalor para os comprimentos de onda $l$ das ondas linearmente estáveis.

A Equação (5.38) pode ser invertida e resolvida para $\Delta_{j}$ mediante a especificação de $\bar{u}_{i}$ sobre as frentes. Esse fato representa grande vantagem, visto que é mais conveniente a especificação das velocidades frontais do que dos saltos de vorticidade. 


\subsubsection{Modelo Não-linear}

O sistema inteiramente não-linear é também solucionado pelo método das funções de Green. Segundo Polvani et al. (1989), a solução de (5.18) passa a ser escrita como:

$$
\psi^{\prime}(x, y, t)=\Delta_{j} \iint_{A_{j}} G_{i j}\left(x, y / x^{\prime}, y^{\prime}\right) \mathrm{d} x^{\prime} \mathrm{d} y^{\prime},
$$

onde $A_{j}$ é a área entre as curvas $\bar{x}_{j}+\eta_{j}$ e $\bar{x}_{j}$. As funções de Green, que respeitam as condições de contorno $\psi^{\prime}(0, y, t)=u^{\prime}(0, y, t)=v^{\prime}(0, y, t)=0$ são dadas por:

$$
G_{i j}=-h_{i} F_{i m} F_{j m} \frac{1}{2 \pi}\left[K_{0}\left(\gamma_{m} r_{+}\right)-K_{0}\left(\gamma_{m} r_{-}\right)\right]
$$

onde $K_{0}$ é a função de Bessel de $2^{\circ}$ tipo e ordem zero, e $r_{+}$e $r_{-}$são dados respectivamente por

$$
\begin{aligned}
& r_{+}=\sqrt{\left(x-x^{\prime}\right)^{2}+\left(y-y^{\prime}\right)^{2}} \\
& r_{-}=\sqrt{\left(x+x^{\prime}\right)^{2}+\left(y-y^{\prime}\right)^{2}} .
\end{aligned}
$$

No caso de $m=1$ (modo barotrópico), que corresponde a $\gamma_{1} \rightarrow 0$, conduz-nos a

$$
K_{0}\left(\gamma_{1} r\right) \rightarrow-\ln (r)
$$

de acordo com Polvani et al. (1989).

As expressões para $u_{i}^{\prime}$ e $v_{i}^{\prime}$ são obtidas diferenciando-se a Equação (5.39), usando as propriedades de simetria das funções de Green (resolvido detalhadamente em da Silveira et al. (1999)) e aplicando o Teorema da divergênia (ou Teorema de Green). Em particular, Polvani et al. (1989) recomenda uma integração por partes adicional para evitar problemas de singularização logarítmica para pequenos argumentos das funções de 
Green. Assim,

$$
\begin{gathered}
u_{i}^{\prime}=\frac{\Delta_{j}}{\pi} h_{i} F_{i m} F_{j m}\left[\oint_{\partial A}\left(x-x^{\prime}\right) K_{1}\left(r_{+}\right) \frac{\mathrm{d} r_{+}^{2}}{2 r_{+}}+\oint_{\partial A}\left(x+x^{\prime}\right) K_{1}\left(r_{-}\right) \frac{\mathrm{d} r_{-}^{2}}{2 r_{-}}\right] \\
v_{i}^{\prime}=\frac{\Delta_{j}}{\pi} h_{i} F_{i m} F_{j m}\left[\oint_{\partial A}\left(y-y^{\prime}\right) K_{1}\left(r_{+}\right) \frac{\mathrm{d} r_{+}^{2}}{2 r_{+}}+\oint_{\partial A}\left(y-y^{\prime}\right) K_{1}\left(r_{-}\right) \frac{\mathrm{d} r_{-}^{2}}{2 r_{-}}\right]
\end{gathered}
$$

onde $K_{1}$ é a função de Bessel de $2^{\circ}$ tipo e primeira ordem.

O esquema numérico empregado segue Pratt \& Stern (1986). O algoritmo essencialmente rastreia o contorno (ou a frente de VP) como um conjunto de parcelas lagrangeanas, avançamos cada uma de acordo com a Equação (5.20). Esta é discretizada usando um esquema Runge-Kutta de segunda ordem, com as velocidades da corrente básica determinadas pela Equação (5.38). O emprego das Equações (5.44)-(5.45) para a determinação das velocidades das ondas segue a aproximação numérica sugerida por Zou et al. (1986).

\subsection{Resultados e Discussão}

\subsubsection{Modelo Linear - Propriedades de Estabilidade}

A escolha dos parâmetros de entrada no modelo foi realizada através das seções verticais de velocidades observadas por L-ADCP apresentadas na Seção 3.3. A partir dessas seções, a Radial 7 do conjunto CARBOM (Figura 3.9) foi escolhida para obtenção dos parâmetros referentes à estrutura vertical do escoamento. A partir dessa seção de velocidade, extraímos o perfil de velocidade integrado para a primeira e segunda camadas $(i=1,2$; superior e inferior, respectivamente) conforme a Figura 5.1 (painel superior). 


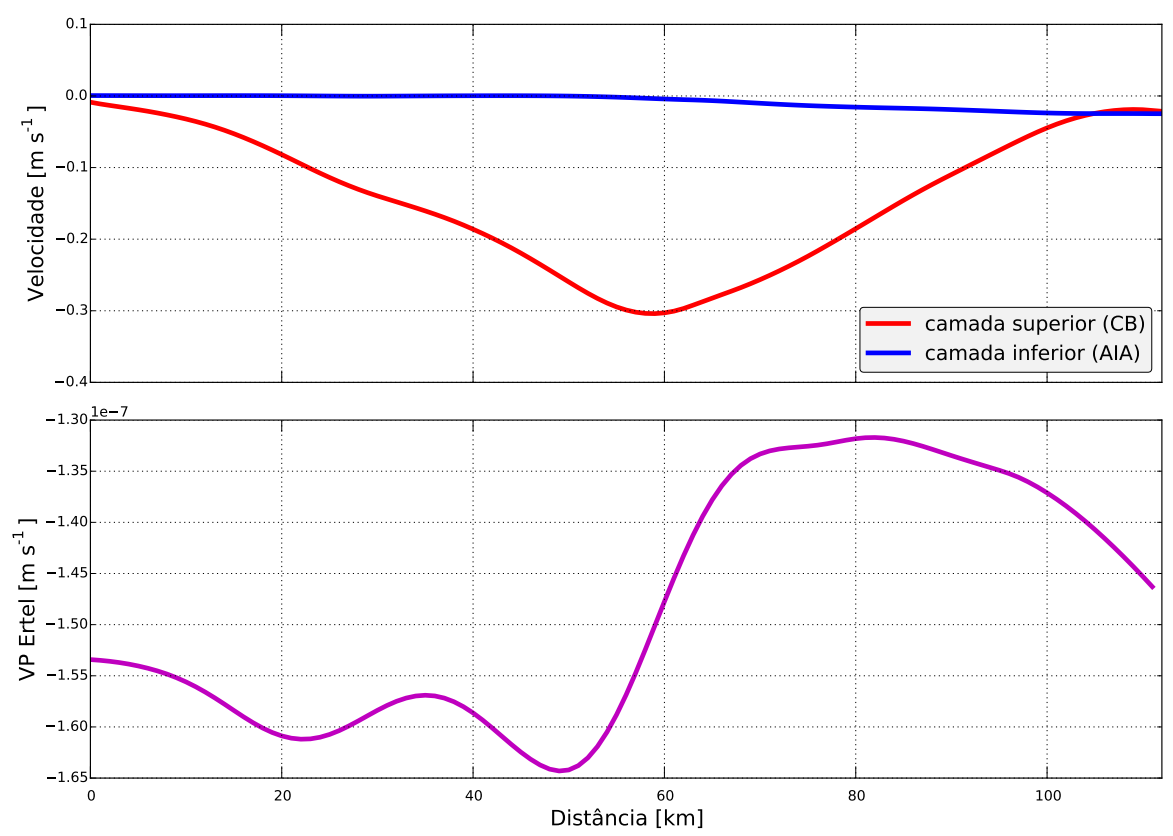

Figura 5.1: Painel superior: Perfis de velocidades das camadas superior e inferior, delimitadas pela isopicnal de $26,9 \mathrm{~kg} \mathrm{~m}^{-3}$ (interface ACAS-AIA) segundo Mémery et al. (2000), obtidos a partir da seção de velocidade de L-ADCP da Radial 7 do conjunto CARBOM. Painel inferior: Perfil de Vorticidade Potencial (VP) obtido respectivamente para a camada superior.

A espessura da primeira camada foi considerada de $H_{1}=500 \mathrm{~m}$ e para a segunda camada, $H_{2}=1300 \mathrm{~m}$. Dessa forma, a velocidade do jato básico de cada camada foi obtida do perfil de velocidade integrado (no respectivo intervalo de profundidade de cada camada) pela escolha do máximo de velocidade de cada perfil, sendo respectivamente para a primeira e segunda camadas: $\bar{v}_{1} \approx 0,30 \mathrm{~m} \mathrm{~s}^{-1} \mathrm{e} \bar{v}_{2} \approx 0,01 \mathrm{~m} \mathrm{~s}^{-1}$.

A posição da frente de VP para cada camada também foi estabelecida através dessa seção de velocidade (Figura 3.9). Segundo ela, a posição do núcleo da CB se encontra em torno de $60 \mathrm{~km}$ e conforme os valores do raio de deformação $(R d)$ estabelecidos por Houry et al. (1987) para o Atlântico Sul ser de aproximadamente $27 \mathrm{~km}$ para a região do CSM, a distância utilizada para a frente de VP nas camadas foi de $\bar{x}_{1}=\bar{x}_{2}=2 R d$.

Utilizando-se os valores acima, obtivemos como resultado do modelo linear (Figura 5.2) que as ondas mais instáveis possuem taxa de crescimento de $\approx 0,034 \mathrm{dia}^{-1}$. Essas ondas possuem comprimento de onda $\lambda \approx 250 \mathrm{~km}$ e se propagam para sul/sudeste com velocidade de fase $c_{p} \approx 0,05 \mathrm{~m} \mathrm{~s}^{-1}$. Esses resultados, em comparação aos valores estimados a partir das imagens satelitárias, apresentam valores menores. Através das imagens de TSM obtivemos os valores médios para o comprimento de onda de $\sim 219 \mathrm{~km}$, velocidade de fase de $\sim 0,068 \mathrm{~m} \mathrm{~s}^{-1}$ e taxa de crescimento de $\sim 0,045 \mathrm{dia}^{-1}$. Essa dife- 
rença decorre da simplicidade do modelo, o qual tenta reproduzir as características básicas do fenômeno reduzindo o processo de instabilidade à frente de VP, a partir da qual é inferida sua variações espaço-temporais. Além disso, nosso modelo foi idealizado considerando fundo plano. Os resultados, no entanto, mostram claramente que os meandros se propagam para sul com velocidades menores que a da CB em superfície.
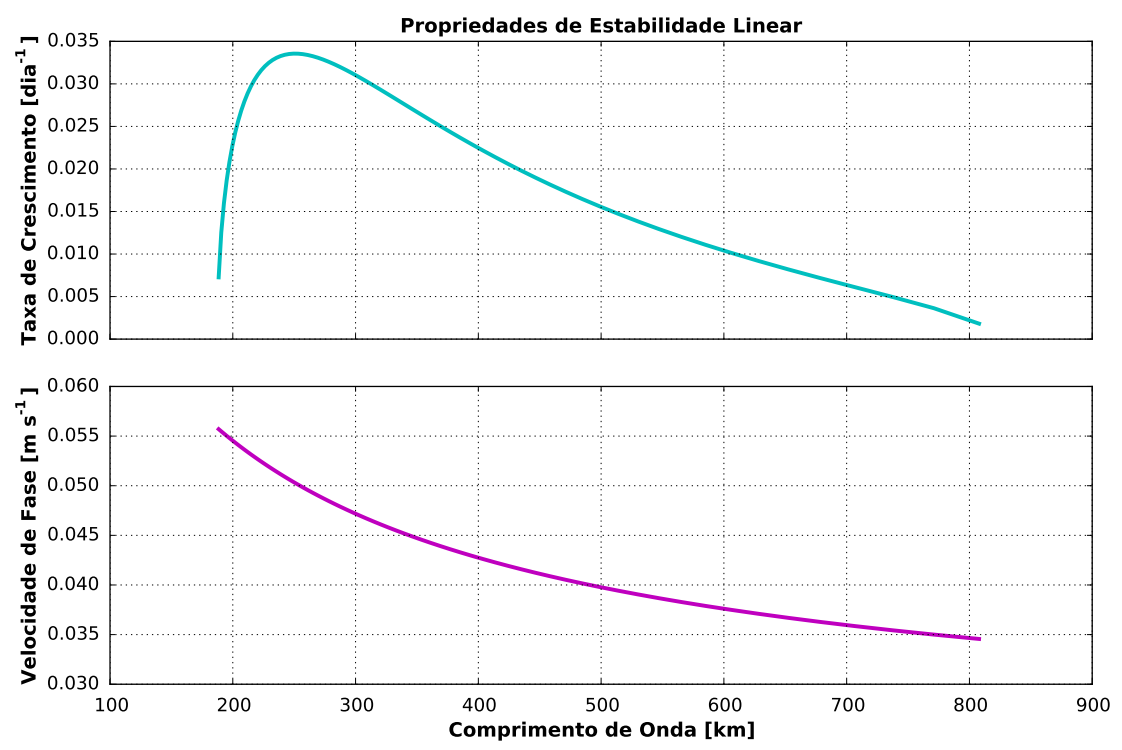

Figura 5.2: Propriedades de estabilidade linear obtidas a partir do modelo linear. As ondas mais instáveis possuem possuem taxa de crescimento $\sigma \approx \mathbf{0 , 0 3 4} \mathbf{d i a}^{-1}$, comprimento de onda $\lambda \approx 250 \mathbf{k m}$ e se propagam para sul/sudeste com velocidade de fase $c_{p} \approx 0,05 \mathrm{~m} \mathrm{~s}^{-1}$. Esses resultados são menores que os observados por meio das imagens satelitárias.

\subsubsection{Modelo Não-linear}

A parte não-linear do sistema, fornece a evolução temporal da frente de VP e é resolvida para as ondas mais instáveis, obtidas a partir do modelo linear. A partir disso, o modelo não-linear foi inicializado com uma pequena perturbação à jusante da corrente básica (Figura 5.3, painel à esquerda). À medida que o sistema evolui, as frentes de VP em cada camada ficam fora de fase (Figura 5.3, painel central) e ocorre o crescimento em amplitude de um meandro cliclônico à montante da perturbação (camada superior), devido ao processo de instabilidade baroclínica, além do desenvolvimento de trem de ondas. Devido à componente barotrópica, podemos observar a propagação do meandro ciclônico (propagação de fase dessas ondas) para sul/sudeste na camada superior. 


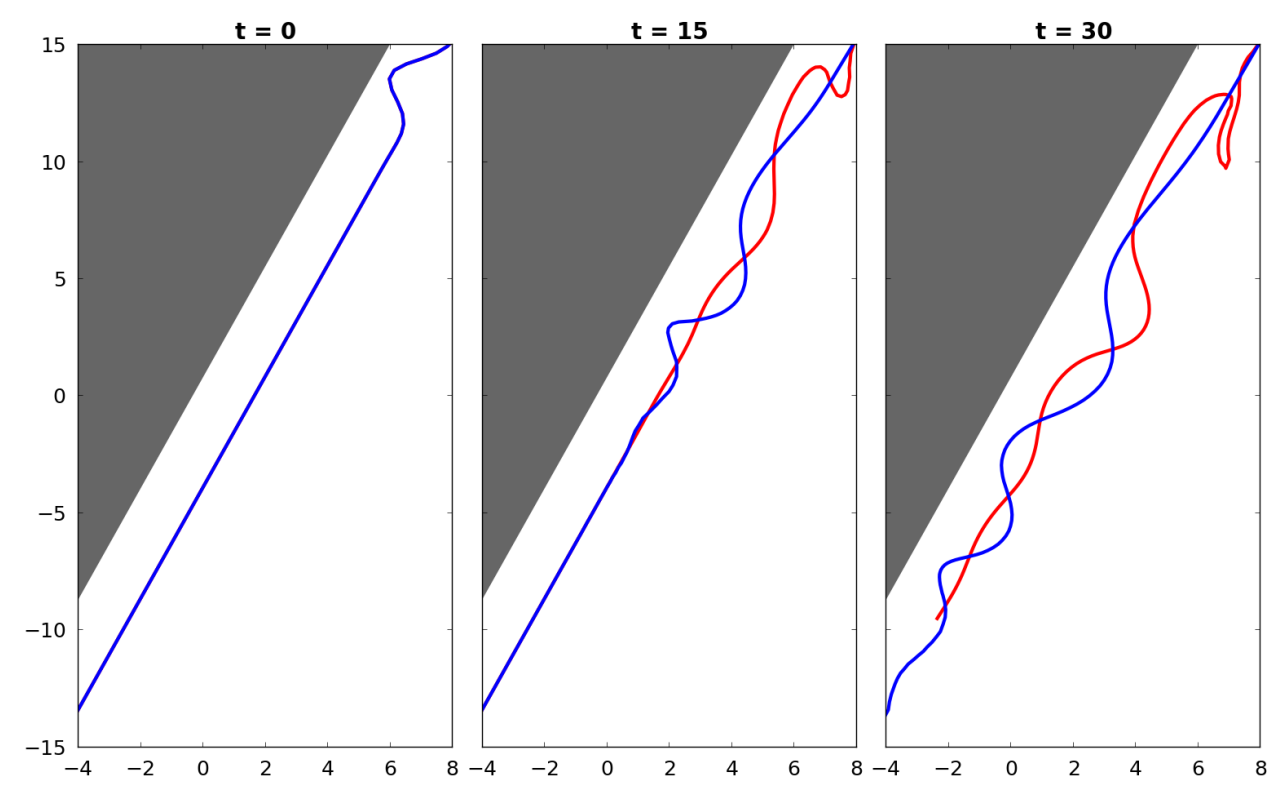

Figura 5.3: Resultados do modelo não-linear para os tempos $t=0,15$ e 30, o qual foi inicializado com uma perturbação de pequena amplitude à montante do domínio. Nota-se a formação e crescimento em amplitude do meandro ciclônico, assim como sua propagação à jusante da corrente básica.

Afirmamos aqui que a propagação é devido à componente barotrópica robusta adquirida pela CB ao sul da BiSan, em nível intermediário, ao comparar com os resultados de simulações de DC realizadas por Meacham (1991). Este autor usou um modelo de 2 camadas muito semelhante ao formulado neste trabalho, no entanto, com o jato básico sem qualquer componente barotrópica, ou seja,, um jato puramente baroclínico. Esse jato, se instabilizado, gerava amplos meandros que não se propagavam (velocidade de fase muito baixas). Interessantemente, esta é a situação que observamos ao norte da BiSan, onde a CB e CCI formam um escoamento médio com componente barotrópica virtualmente nula (Silveira et al., 2004). O resultado é que, em CST e CF, os meandros são quaseestacionários (da Silveira et al., 2008; Rocha et al., 2014).

Portanto, os valores de velocidade de fase de $\sim 0,06 \mathrm{~m} \mathrm{~s}^{-1}$ demonstram uma consequência dinâmica da BiSan, onde ao sul desta, a CB se espessa apresentando ampla componente barotrópica, e as ondas de vorticidade baroclínicas se propagam em direção à Confluência Brasil-Malvinas.

Podemos também comparar o número de Burger $(B u)$ das ondas obtidas no modelo de 2 camadas com aquele inferido através das observações hidrográficas no Capí- 
tulo 3 (Seção 3.3.3). Para o modelo, consideremos $B u$ na forma

$$
B u=\frac{\frac{1}{f_{0}^{2}} \frac{\Delta \rho}{\rho_{0}} g\left(\frac{H_{1}+H_{2}}{H_{1} H_{2}}\right)}{L^{2}}=0,045
$$

valor próximo ao valor inferido $(B u \approx 0,06)$ pelos campos geostróficos da Figura 3.10. 


\section{Capítulo 6}

\section{Considerações Finais}

É sabido que a $\mathrm{CB}$ desenvolve importante atividade de mesoescala ao fluir ao longo da margem continental sul e sudeste. Vários artigos têm reportado a formação de amplos meandros ciclônicos que, ocasionalmente, fecham-se em vórtices. Em particular, vários estudos se dedicaram ao estudo da dinâmica dos meandros quase-estacionários (ou seja, quase sem propagação) entre CST e CF (Garfield, 1990; Silveira et al., 2004; Calado et al., 2006; da Silveira et al., 2008; Calado et al., 2010; Arruda et al., 2013; Rocha et al., 2014). Tais estudos abordam a dinâmica do meandramento da CB ao norte da BiSan, onde o jato médio abaixo dos $500 \mathrm{~m}$ tem sentido oposto ao da corrente em superfície transportando AIA e ACS em direção ao equador.

Entretanto, embora seja comum observar tais feições pelo exame de imagens satelitárias, os vórtices ou meandros ciclônicos na vizinhança do CSM não foram investigados e inexistem artigos que discutam o meandramento da CB entre este cabo até a separação desta da margem continental na Confluência Brasil-Malvinas. Por essa razão, o cerne deste trabalho foi justamente descrever, explorar e entender a dinâmica de mesoescala da $\mathrm{CB}$ ao sul da BiSan, Para tanto, recorremos a:

- Análise de imagens satelitárias (infravermelho) para estimar o número de eventos do meandramento da CB por ano, comprimento das ondas de vorticidade, e a taxa de crescimento e velocidade de fase dos meandros

- Análise de dados quase-sinóticos de cruzeiros históricos e recentes, que envolviam perfilagens de CTD, perfilagens por ADCP de casco e perfilagens por L-ADCP. O intento aqui foi descrever a estrutura vertical de velocidade dos 
meandros, sua composição de massas de água e caracterização em termos dos números de Rossby e Burger.

- Análise de EOFs da radial de fundeios correntográficos do projeto WOCE em torno de $28^{\circ} \mathrm{S}$ para análise dos padrões de variabilidade espaço-temporal da CB.

- Simulações com modelo dinâmico de natureza semi-teórica (no caso, Dinâmica de Contornos para isolar o efeito da instabilidade baroclínica e compreensão do fenômeno de propagação dos meandros da CB para o sul na região de estudo.

\subsection{Síntese da Análise de Imagens Satelitárias}

Para estimar as propriedades cinemáticas e dinâmicas associadas ao meandramento da CB ao largo do CSM, utilizamos o conjunto de imagens satelitárias MUR SST do período entre junho de 2002 à janeiro de 2014. A partir das imgens de TSM, calculamos o gradiente horizontal de temperatura afim de indentificar a FT associada à borda interna (lobo costeiro) da CB e, assim, acompanhar sua evolução espacial e temporal. Em outras palavras, o intento é rastear o meandramento da corrente. As FTs foram digitalizadas visualmente através dos mapas do gradiente de temperatura. A amplitude do meandro foi medida do seu ponto mais distante da FT à quebra da plataforma continental e, a partir disso, estimamos a taxa de crescimento do meandro utilizando um ajuste exponencial recursivo, considerando sequência limitada e disponível de imagens do evento.

A região do CSM apresenta cobertura por nuvens recorrente e persistente, por essa razão, poucos eventos puderam ser observados (recorrência do meandro $\sim 1,2$ eventos por ano). Trata-se então, possivelmente, de uma subestimativa da frequência de ocorrência dos meandros. Encontramos que os meandros ciclônicos têm uma taxa de crescimento de $\sim 0,05 \pm 0,02 \mathrm{dia}^{-1}$, velocidade de fase de $\sim 0,07 \pm 0,03 \mathrm{~m} \mathrm{~s}^{-1}$, com propagação para sul/sudeste. Os comprimentos de onda foram estimados em $\sim 219 \pm 46 \mathrm{~km}$. Portanto, os meandros ciclônicos associados à CB ao largo do CSM se propagam, ainda que com velocidades muito menores que as da corrente de superfície, para sul/sudoeste e diferem 
daqueles observados ao norte da BiSan, que crescem de forma quase-estacionária ao largo dos Cabos de São Tomé $\left(22^{\circ} \mathrm{S}\right)$ e Frio $\left(23^{\circ} \mathrm{S}\right)$.

\subsection{Síntese da Análise de Observações Quase-sinóticas}

Por meio das seções de velocidade observadas e de hidrografia do conjunto de dados MIRAI, CARBOM e EAOS, descrevemos a estrutura vertical da CB e seus meandros. A seção de velocidade do conjunto MIRAI, evidencia claramente a maior barotropicidade da CB ao sul da BiSan, devido ao aporte do ramo sul da bifurcação em nível intermediário. O conjunto de dados CARBOM evidencia a possibilidade de uma rica atividade vortical ao sul da BiSan, no qual fora capturado um meandro ciclônico frontal. A partir das seções de velocidade observadas desses dados, podemos perceber uma estrutura vertical da CB diferenciada daquela observada à jusante na região sudeste. Ao sul da BiSan, a CB apresenta uma estrutura vertical que se estende até aproximadamente $1500 \mathrm{~m}$ transportando AT e ACAS em superfície, e AIA e ACS, em nível intermediário associada ao aporte da bifurcação.

Alem disso, utilizamos os dados do conjunto EAOS no qual fora capturado uma estrutura ciclônica fechada. Mapeamos, a partir destes, a função de corrente geostrófica relativa ao nível de 1200 m, nível máximo de amostragem, utilizando o Método Dinâmico Clássico. A partir do mapa de função de corrente e da estrutura termohalina dessa feição, caracterizamos a estrutura ciclônica em termos de seu número de Rossby $(\sim 0,07)$ e número de Burger $(\sim 0,06)$. Esses valores sugerem que o termo de vorticidade de estiramento tem papel importante na dinâmica dos meandros, consequentemente, instabilidade baroclínica é processo primário reponsável pelo crescimento em amplitude dos meandros. $\mathrm{O}$ valor do número de Burger $(B u \ll 1)$ ainda sugere que a dinâmica do meandro é influenciada pela topografia. 


\subsection{Síntese da Análise EOF da Radial do Fundeios WOCE}

Para a análise da variabilidade espaço-temporal da $\mathrm{CB}$, utilizamos a análise de EOFs bidimensionais aplicadas à radial de fundeios do projeto WOCE. Os dados correntográficos foram inicialmente filtrados com filtro tipo Lanczos de $40 \mathrm{~h}$ para reter apenas os fenômenos subinerciais, que nos são de interesse. A fim de se determinar os modos estatisticamente significativos, realizamos as simulações de Monte Carlo, tendo como resultado que apenas os dois primeiros modos são estatisticamente significativos ao nível de 95\%. Esses modos explicam conjuntamente $84 \%$ da variância total das séries. O primeiro e segundo modos explicam, respectivamente, aproximadamente $54 \%$ e $30 \%$ da variância total. Interpretamos que o primeiro modo EOF está associado ao fenômeno de meandramento de mesoescala associado à CB. O padrão seccional da autofunção estatística mostra que, tipicamente, os ciclones cruzam a radial com cerca de $200 \mathrm{~km}$ de amplitude. A reconstituição das séries temporais usando apenas o primeiro modo sugerem que os anticiclones (cristas) são atrofiados se comparados ao ciclones (cavados) no trem de ondas. Já o segundo modo parece estar relacionado à célula interna de recirculação da CB, com variabilidade mais longa do que aquela relacionada à mesoescala. Para confirmar nossa interpretação, realizamos a análise espectral das séries de amplitudes desses modos e obtivemos que as ondas associadas ao primeiro modo possuem aproximadamente período de 26 dias, enquanto que, para o segundo modo, de 103 dias. Ou seja, a série de amplitudes do primeiro modo EOF tem período dominante típico de fenômenos de mesoescala, e em particular, de ondas baroclínicas longas de vorticidade. Tais ondas são caracterizadas por baixo número de Burger. Assim, os resultados da análise de variabilidade espaço-temporal corroboram os resultados das análises dos cruzeiros hidrográficos quase-sinóticos.

\subsection{Síntese da Simulação com o Modelo Dinâmico}

Para o estudo de processo de instabilidade do meandro ciclônico ao largo do CSM, elaboramos um modelo quase-geostrófico semi-analítico de 2 camadas com o intuito de (i) isolar o efeito de instabilidade baroclínica e (ii) analisar a propagação de fase das 
ondas. De forma original a este tipo de modelo, consideramos o modo barotrópico tanto na corrente básica quanto nas perturbações juntamente com a presença do contorno oeste. O processo de instabilidade é abordado de duas formas: modelo linear e modelo nãolinear.

O modelo linear fornece as propriedades de estabilidade linear, do qual são obtidos os valores das taxas de crescimento, velocidade de fase e comprimento de onda. Obtivemos como resultado do modelo linear que as ondas mais instáveis possuem taxa de crescimento de $\sim 0,034 \mathrm{dia}^{-1}$. Essas ondas possuem comprimento de onda $\sim 250 \mathrm{~km}$ e se propagam para sul/sudeste com velocidade de fase $\sim 0,05 \mathrm{~m} \mathrm{~s}^{-1}$. Dados a simplicidade e o nível de idealização do modelo, consideramos esses resultados satisfatórios e o modelo validado com as análises observacionais conduzidas nesta pesquisa.

O modelo não-linear fornece a evolução do sistema e foi inicializado com uma pequena perturbação. $\mathrm{O}$ crescimento em amplitude da onda de vorticidade ocorre a partir do fechamento de fase, devido ao processo de instabilidade. Portanto, os resultados $(i)$ confirmam que o processo de instabilidade baroclínica é responsável pelo crescimento em amplitude dos meandros ciclônicos e que (ii) a componente barotrópica robusta da CB ao sul da BiSan é responsável pela propagação do meandro na direção do escoamento básico (sul/sudeste).

\subsection{Sugestões para Trabalhos Futuros}

Como sugestões para trabalhos futuros, mencionamos:

1. Estender a análise de imagens satelitárias àqueles de cor do oceano, além das de infravermelho. É possível que mais detalhes das feições sejam revelados pois os meandros ciclônicos entranham águas costeiras, mais ricas em matéria orgânica e fitoplâncton.

2. Estender a análise de dados sinóticos de modo a incluir os cruzeiros realizados pela Marinha do Brasil do Plano Nacional de Coleta de Dados Oceanográficos e disponíveis no Banco Nacional de Dados Oceanográficos. É possível que mais observações sinóticas, envolvendo áreas mais extensas que aquelas 
do conjunto EAOS, permitam uma melhor caracterização em termos de comprimento das ondas de vorticidade a partir de observações in-situ.

3. Utilizar as técnicas de modelo de feição em simulações regionais por modelos oceânicos de equações primitivas que permitam explorar, sem as restrições impostas pela teoria quase-geostrófica de nosso presente modelo, a ocorrência de meandramento a partir de padrões mais realísticos de correntes e de batimetria. 


\section{Referências Bibliográficas}

Arruda, W. Z., E. J. D. Campos, V. Zharkov, R. G. Soutelino, \& I. C. A. Silveira, 2013: Events of equatorward translation of the Vitoria Eddy. Cont. Shelf Res., 70, 61-73.

Boebel, O., E. R. Davis, M. Ollitraut, R. G. Peterson, P. L. Richard, C. Schmid, \& W. Zenk, 1999: The intermediate depth circulation of western South Atlantic. Geophys. Res. Letters, 26(21), 3329-3332.

Bonatti, J. P. \& V. B. Rao, 1999: Meso-scale perturbations and thermohaline fronts in the south atlantic ocean. Dynam. Atmos. Oceans, 30, 1-24.

Bretherton, F. P., R. E. Davis, \& C. B. Fandry, 1976: A technique for objective analysis and design of oceanographic experiments applied to MODE-73. Deep-Sea Res., 23, $559-582$.

Calado, L., 2001: Dinâmica da formação dos meandros e vórtices da Corrente do Brasil ao largo do sudeste brasileiro. Dissertação de Mestrado. Universidade de São Paulo, $95 \mathrm{pp}$.

Calado, L., I. C. A. da Silveira, A. Gangopadhyay, \& B. M. de Castro, 2010: Eddyinduced upwelling off Cape São Tomé (22 S, Brazil). Cont. Shelf Res., 30, 1181-1188.

Calado, L., A. Gangopadhyay, \& I. C. A. Silveira, 2006: A parametric model for the Brazil Current meanders and eddies off southeastern Brazil. Geophys. Res. Lett., 33, LI2602.

Campos, E., 2006: Equatorward translation of the Vitoria Eddy in a numerical simulation. Geophys. Res. Lett., 33(L22607).

Campos, E. J. D., J. E. Gonçalves, \& Y. Ikeda, 1995: Water mass characteristics and 
geostrophic circulation in the South Brazil Bight: Summer of 1991. J. Geophys. Res., 100(C9), 18.537-18.550.

Campos, E. J. D., Y. Ikeda, B. M. Castro, S. A. Gaeta, J. Lorenzzetti, \& M. Stevenson, 1996: Experiment Studies Circulation in the Western South Atlantic Western South Atlantic. EOS Transaction, 77(27), 253-259.

Campos, E. J. D. \& D. B. Olson, 1991: Stationary Rossby Waves in Western Boundary Current Extensions. J. Phys. Oceanogr., 21, 1202-1225.

Campos, E. J. D., D. Velhote, \& I. C. A. Silveira, 2000: Shelf break upwelling driven by Brazil Current cyclonic. Geophys. Res. Lett., 27(6), 751-754.

Campos, P. C., O. O. MollerJr., A. R. Piola, \& E. D. Palma, 2013: Seasonal variability and coastal upwelling near Cape Santa Marta (Brazil). J. Geophys. Res., 118, 1-14.

Carter, E. F. \& A. R. Robinson, 1987: Analysis Models for the estimation of oceanc features. J. Atms. Ocean. Techn., 4, 49-74.

Castelão, R. M., E. J. D. Campos, \& J. L. Miller, 2004: A modelling study of coastal upwelling driven by wind and meanders of the Brazil Current. J. Coastal Res., 20(3), $662-667$.

Cushman-Roisin, B. \& J.-M. Beckers, 2011: Introduction to Geophysical Fluid Dynamics, volume 1. Elsevier, 2a edição, 828 pp.

da Silveira, I. C. A. \& G. R. Flierl, 2002: Eddy formation in 2- $\frac{1}{2}$ layer quasigeostrophic jets. J. Phys. Oceanogr., 62, 729-745.

da Silveira, I. C. A., G. R. Flierl, \& W. S. Brown, 1999: Dynamics of separating western boundary currents. J. Phys. Oceanogr., 29(2), 119-144.

da Silveira, I. C. A., J. A. M. Lima, A. C. K. Schimidt, W. Ceccopieri, A. Sartori, C. P. F. Francisco, \& R. F. C. Fontes, 2008: Is the meander growth in the Brazil Current system off Southeast Brazil due to baroclinic instability? Dynam. Atmos. Oceans, 45 (3-4), 187-207. 
de Miranda, J. A., 2013: Dynamics of Brazil Current dipoles: barotropic instabilities and flow-western boundary interactions. Tese de Doutorado, Instituto Oceanográfico da Universidade de São Paulo, São Paulo, 138 pp.

Emery, W. J. \& R. E. Thomson, 2001: Data analysis methods in Phisical Oceanography, volume 1. Elsevier, 2a edição, 638 pp.

Fernandes, A. M., I. C. A. da Silveira, L. Calado, E. J. D. Campos, \& A. M. Paiva, 2009: A two-layer approximation to the Brazil Current-Intermediate Western Boundary Current System between $20^{\circ} \mathrm{S}$ and $28^{\circ} \mathrm{S}$. Ocean Modelling, 29, 154-158.

Firing, E., 1991: Acoustic doppler current profiling measurements and navigation. In WHP Hydrographic Operations and Methods. University of Hawaii, Honolulu, 1-24.

Garcia, C. A. E., Y. V. B. Sarma, M. M. Mata, \& V. M. T. Garcia, 2004: Chlorophyll variability and eddies in the Brazil-Malvinas Confluence region. Deep-Sea Res., 51(II), $159-172$.

Garfield, N., 1990: The Brazil Current at subtropical latitudes. Tese de Doutorado, University of Rhode Island, Rhode Island, $121 \mathrm{pp}$.

Garzoli, S. L., 1993: Geostrophic velocity and transport variability in the Brazil-Malvinas Confluence. Deep-Sea Res., 40(7), 1379-1403.

Gordon, A. L. \& C. L. Greengrove, 1986: Geostrophic circulation on the Brazil-Falkland Confluence. Deep-Sea Res., 33(5), 573-585.

Hogg, N. G., G. Siedler, \& W. Zenk, 1999: Circulation and Variability at the Southern Boundary of the Brazil Basin. J. Phys. Oceanogr., 29, 145-157.

Houry, S., E. Dombrows, P. D. Mey, \& J.-F. Minster, 1987: Brunt-Väisälä Frequency and Rossby Radii in the South Atlantic. J. Phys. Oceanogr., 17, 1619-1626.

Legeais, J. F., M. Ollitraut, \& M. Arhan, 2013: Lagrangian observations in the Intermediate Western Boundary Current of South Atlantic. Deep-Sea Res., 85, 109-126.

Lentini, C. A. D., G. J. Goni, \& D. B. Olson, 2006: Investigation of Brazil Current rings in the confluence region. J. Geophys. Res., 111(C06013). 
Lentini, C. A. D., D. B. Olson, \& G. P. Podestá, 2002: Statistics of Brazil Current rings observed from AVHRR: 1993 to 1998. Geophys. Res. Lett., 29(16), 1811.

Lorenzzetti, J. A., J. L. Stech, W. L. M. Filho, \& A. T. Assireu, 2009: Satellite observation of Brazil Current inshore thermal front in the SW South Atlantic: Space/time variability and sea surface temperatures. Cont. Shelf Res., 29, 2061-2068.

Mascarenhas, A. S., L. B. Miranda, \& N. J. Rock, 1971: A study of oceanographic conditions in the region of Cabo Frio, Brazil. Costlow J. D., 1, 285-308.

Meacham, S. P., 1991: Meander Evolution on piecewise-uniform, quasi-geostrophic jets. J. Phys. Oceanogr., 21(8), 1139-1170.

Mémery, L., M. Arhan, X. A. Alvarez-Salgado, M.-J. Messia, H. Mercier, C. G. Castro, \& A. F. Rios, 2000: The water masses along the western boundary of the south and equatorial Atlantic. Prog. Oceanogr., 47(1), 69-98.

Müller, J. M., Y. Ikeda, N. Zangenberg, \& L. V. Nonato, 1998: Direct measurements of western boundary currents off Brazil between $20^{\circ} \mathrm{S}$ and $28^{\circ} \mathrm{S}$. J. Geophys. Res., 103(C3), 5429-5437.

Oliveira, L. R., 2003: Estudo da variabilidade da Corrente do Brasil a $28^{\circ}$ Sul. Dissertação de Mestrado. Fundação da Universidade Federal do Rio Grande, 78 pp.

Olson, D. B., G. P. Podesta, R. H. Evans, \& O. B. Brown, 1988: Temporal variations in the separation of Brazil and Malvinas currents. Deep-Sea Res., 35(12), 1971-1990.

Osgood, K. E., J. M. Bane, \& W. K. Dewar, 1987: Vertical velocities and dynamical balances in Gulf Stream meanders. J. Geophys. Res., 92, 13.029-13.040.

Pereira, D. P. C., 2009: Processos de Instabilidade Barotrópica da Corrente do Brasil na Bacia de Santos. Dissertação de Mestrado. Universidade de São Paulo, 85 pp.

Polvani, L. M., N. J. Zabusky, \& G. R. Flierl, 1989: Two-layer geostrophic vortex dynamics. Part.1 Upper layer V-states and merger. J. Fluid. Mech., 24, 89-115.

Pratt, L. J. \& M. E. Stern, 1986: Dynamics of potencial vorticity fronts and eddy detachment. J. Phys. Oceanogr., 16(6), 1101-1120. 
Preisendorfer, R. W., 1988: Principal component analysis in Meteorology and Oceanography. Elsevier, Amsterdam, 126 pp.

Reid, J. L. \& A. W. Mantyla, 1978: On the mid-depth circulation of the North Pacific Ocean. J. Phys. Oceanogr., 6(8), 946-951.

Rocha, C. B., I. C. A. da Silveira, B. M. Castro, \& J. A. M. Lima, 2014: Vertical structure, energetics, and dynamics of the Brazil Current. J. Geophys. Res., 119, 52-69.

Saraceno, M., C. Provost, A. R. Piola, J. Bava, \& A. Gagliardini, 2004: Brazil Malvinas Frontal System as seen from 9 years of advanced very high resolution radiometer data. J. Geophys. Res., 109(C05027), 1-14.

Schmid, C., H. Schäfer, G. Podestá, \& W. Zenk, 1995: The Vitória Eddy and its relation to the Brazil Current. J. Phys. Oceanogr., 25(2532).

Schmitz, W. J., 1995: On the interbasin-scale thermohaline circulation. Rev. Geophys., $33(2), 151-173$.

Schott, F. A., M. Dengler, R. Zantopp, L. Stramma, J. Fisher, \& P. Brandt, 2005: The Shallow and Deep Western Boundary Circulation of the South Atlantic at $5^{\circ}-11^{\circ} \mathrm{S} . J$. Phys. Oceanogr., 35, 2031-2053.

Signorini, S. R., 1978: On the circulation and volume transport of the Brazil Current between the Cape of São Tomé and Guanabara Bay. Deep-Sea Res., 25(5), 481-490.

Silveira, I. C. A., W. S. Brown, \& G. R. Flierl, 2000b: Dynamics of the North Brazil Current retroflection from the Western Tropical Atlantic Experiment observations. $J$. Geophys. Res., 105(C12), 28.559-28.583.

Silveira, I. C. A., L. Calado, B. M. Castro, M. Cirano, J. A. M. Lima, \& A. D. S. Mascarenhas, 2004: On the baroclinic structure of the Brazil current-intermediate western boundary current system at $22^{\circ}-23^{\circ} \mathrm{S}$. Geophys. Res. Let., 31(L14308).

Silveira, I. C. A., L. B. Miranda, \& W. S. Brown, 1994: On the origins of the North Brazil Current. J. Geophys. Res., 99(C11), 22.501-22.512. 
Silveira, I. C. A., A. C. K. Schmidt, E. J. D. Campos, S. S. Godoi, \& Y. Ikeda, 2000a: A Corrente do Brasil ao largo da Costa Leste Brasileria. Rev. Bras. Oceanogr., 48(2), $171-183$.

Soutelino, R. G., A. Gangogaphyay, \& I. C. A. Silveira, 2013: The roles of vertical shear and topography on eddy formation near the site of origin of the Brazil Current. Cont. Shelf Res., 70, 46-60.

Soutelino, R. G., I. C. A. Silveira, A. Gangogaphyay, \& J. Miranda, 2011: Is the Brazil Current eddy dominated to the north of $20^{\circ}$ S? Geophys. Res. Lett., 38(L03607).

Stramma, L. \& M. England, 1999: On the water masses and mean circulation of the South Atlantic Ocean. J. Geophys. Res., 104(C9), 20.863-20.883.

Stramma, L., J. Fischer, \& J. Reppin, 1995: The North Brazil Undercurrent. Deep-Sea Res., 42(5), 773-795.

Talley, L. D., G. L. Pickard, W. J. Emery, \& J. H. Swift, 2011: Descriptive Phisical Oceanography. Elsevier, 6a edição, 555 pp.

Tarbell, S., R. Meyer, N. Hogg, \& W. Zenk, 1994: A moored array along the southern of the brazil basin for the deep basin experiment - report of a joint experiment 1991-1992. Número 94-07. Mass. (Also Ber. Inst. Meereskd. Univ. Kiel, 243, 77 pp., 1994).

Tsuchiya, M., 1985: Evidence of a double-cell subtropical gyre in the South Atlantic Ocean. J. Mar. Res., 43(1), 57-65.

Vazquez-Cuervo, J., B. Dewitte, T. M. Chin, E. M. Armstrong, S. Puca, \& E. Albuquerque, 2013: An analysis of SST gradients off the Peruvian Coast: The impact of going to higher resolution. Remote Sensing of Environment, 131, 76-84.

Vianna, M. L. \& V. V. Menezes, 2005: Circulação oceânica: monitoramento por meio de altimetria multi-satélite. In Oceanografia por satélites, R. B. Souza (editor). Oficina de Textos, São Paulo, 50-60.

Visbeck, M., 2002: Deep velocity using Acoustic Doppler Current Profiles: Bottom Track and Inverse Methods. J. Atmos. Oc. Tech., 19, 794-807. 
Zemba, J. C., 1991: The structure and transport of the Brazil Current between $27^{\circ}$ and $36^{\circ}$ South. Tese de Doutorado, Massachusetts Institute of Technology and Woods Hole Oceanographic Institution, Massachusetts, $160 \mathrm{pp}$.

Zembruscki, S. G., 1979: Geomorfologia da margem continental sul brasileira e das bacias oceânicas adjacentes. In PROJETO REMAC, número 7 in Série REMAC. PETROBRAS. CENPES. DINTEP, Rio de Janeiro, 129-177.

Zou, Q., H. M. Wu, \& N. J. Zabusky, 1986: Contour Dynamics for the Euler equations: Curvature controlled initial node displacement and accuracy. J. Comp. Phys., 78, 350372. 